\title{
Condensation of a nuclear mRNA export factor regulates mRNA transport during stress
}

Stephanie Heinrich ${ }^{1, \#}$, Maria Hondele ${ }^{1,2}$, Désirée Marchand ${ }^{1}$, Carina Patrizia Derrer ${ }^{1}$, Mostafa Zedan $^{1}$, Alexandra Oswald ${ }^{1}$, Federico Uliana ${ }^{1}$, Roberta Mancini ${ }^{1}$, David Grunwald ${ }^{3}$, Karsten Weis ${ }^{1, \#}$

${ }^{1}$ Institute of Biochemistry, ETH Zurich, Otto-Stern-Weg 3, 8093 Zurich, Switzerland

2 Biozentrum, University of Basel, Klingelbergstrasse 50/70, 4056 Basel, Switzerland

${ }^{3}$ University of Massachusetts Medical School, RNA Therapeutics Institute, 368 Plantation Street, Worcester MA 01605, USA

\# Corresponding author, lead contact: karsten.weis@bc.biol.ethz.ch

\section{Highlights}

- The nuclear Poly(A)-binding protein Nab2 forms condensates upon acute cellular depletion of the DEAD-box ATPase Dbp5

- Nab2 dimerization but not its intrinsically disordered regions (IDRs) are essential for condensation in vitro and in vivo

- Glucose stress leads to global mRNA retention in the nucleus and depends on Nab2 condensation

- Nab2 condensation confers selectivity of RNA retention during glucose stress

- Proper Nab2 condensation is essential for survival after prolonged stress

\section{Summary}

Unidirectional transport of mRNA from the nucleus to the cytoplasm via nuclear pore complexes is an essential step in the gene expression of all eukaryotes. Although factors involved in mRNA transport have been characterized, a comprehensive mechanistic understanding of this critical process and its regulation is lacking. Here, we use real-time single RNA imaging to demonstrate that acute depletion of the budding yeast DEAD-box ATPase Dbp5 causes rapid nuclear accumulation of mRNAs in vivo and dramatic changes in nuclear dynamics of RNA export factors. In particular, the essential export factor $\mathrm{Nab} 2$ ceases to shuttle between the nucleus and cytoplasm and forms an RNA-dependent condensate throughout the nucleus. Phase-separation can be recapitulated in vitro, with Nab2 forming RNAdependent liquid droplets, which depend on the presence of Dbp5. Intriguingly, in glucose stress, condensation of Nab2 blocks bulk mRNA export while selectively allowing the passage of stress-induced mRNAs from the nucleus to the cytoplasm to elicit a timely cellular stress response. This is accompanied by a lowered abundance of the DEAD-box ATPase Dbp5 at the cytoplasmic sites of nuclear pore complexes, which leads to the formation of the Nab2 condensates. Our results suggest that cells use selective mRNA retention in nuclear Nab2 condensates to re-wire mRNA export and to regulate gene expression during stress.

\section{Keywords}

RNA, mRNA export, phase separation, Nab2, DEAD-box ATPase Dbp5, glucose stress 


\section{Introduction}

Gene expression in eukaryotic cells is intricately regulated and aided by subcellular compartmentalization. The nuclear envelope serves as a physical barrier and separates nuclear transcription from cytoplasmic translation processes. Embedded in the nuclear membrane are nuclear pore complexes (NPC) that regulate the passage of macromolecules to and from the nucleus, including the export of messenger RNAs (mRNA) that relay the genetic information to the protein translation machinery in the cytoplasm (reviewed in (Ashkenazy-Titelman et al., 2020; De Magistris, 2021)). mRNAs are extensively processed in the nucleus and undergo a coordinated series of modifications before export, which includes the addition of a $5^{\prime} \mathrm{m} 7 \mathrm{G}$ cap structure, removal of introns through splicing, and 3' end processing for poly(A) tail synthesis (reviewed in (Herzel et al., 2017; Rambout and Maquat, 2020; Shi and Manley, 2015)). To facilitate these processes, a range of RNA-binding proteins (RBPs) form a dynamic mRNA coat on the nascent mRNA, either co-transcriptionally or post-transcriptionally in the nucleoplasm. The orderly assembly of this coat is essential for forming an export-competent mRNA-protein (mRNP) particle (reviewed in (Ashkenazy-Titelman et al., 2020; Singh et al., 2015)). Early binding proteins include the cap-binding complex (CBC; comprising Cbc1 (CBP80 in vertebrates) and Cbc2 (CBP20)), which binds co-transcriptionally to the 5'-cap of nascent mRNAs (Izaurralde et al., 1994). Another early binding complex, the transcription and export (TREX) complex (consisting of the multi-subunit THO subcomplex, the DExD/H-box ATPase Sub2 (UAP56), and the RNA binding protein Yra1 (ALYREF)) connects 3' end processing with mRNA export (Katahira, 2012; Pühringer et al., 2020; Sträßer et al., 2002; Sträßer and Hurt, 2001). Similar to TREX, the abundant class of serine-arginine-rich (SR) proteins (e.g., yeast Npl3) has been implicated in a multitude of mRNA processing steps, such as co-transcriptional splicing, $3^{\prime}$ end processing and nuclear export (reviewed in (Wegener and Müller-McNicoll, 2019)). The export factor $\mathrm{Nab} 2$ (ZC3H14) is recruited to the poly(A) tail of the pre-mRNA and is involved in nuclear mRNA surveillance protecting mRNAs against degradation by the nuclear exosome (Anderson et al., 1993; Hector et al., 2002; Schmid et al., 2012, 2015). Nab2 has been shown to dimerize on RNA and to play a role in proper 3 ' end processing of nascent transcripts to terminate polyadenylation and facilitate compaction of the mRNP (Aibara et al., 2017; Alpert et al., 2020; Fasken et al., 2019). In addition, it directly interacts with the NPC component Mlp1 (Green et al., 2003). The translocation of mature transcripts through NPCs is mediated by the export factor Mex67:Mtr2 (NXF1:NXT1), which functions akin to a mobile nuclear pore protein facilitating transport by binding to both mRNPs as well as phenylalanineglycine (FG)-containing NPC components (nucleoporins)(Ashkenazy-Titelman et al., 2020; Derrer et al., 2019). On the cytoplasmic face of the NPC, the essential DEAD-box ATPase Dbp5 (DDX19B), aided by its interaction partners Nup159 (NUP214), Gle1 and inositol hexakisphosphate (IP), has been suggested to remodel emerging mRNPs by removing export factors such as Nab2 from the mRNA, thereby facilitating their release into the cytoplasm (Alcázar-Román et al., 2006; Tran et al., 2007; Weirich et al., 2006). However, these models are mainly based on in vitro studies (Montpetit et al., 2011; Noble et al., 2011; Tran et al., 2007), and the in vivo function of Dbp5 in directional transport remains unclear.

In addition to membrane-based compartmentalization, cells also organize their content in membraneless organelles through liquid-liquid phase separation (LLPS)(reviewed in (Banani et al., 2017; Shin and Brangwynne, 2017). Formation of these biomolecular condensates depends on weak, multivalent interactions and proteins undergoing LLPS often contain low-complexity domains with intrinsically disordered regions (IDRs). IDRs are frequently found in RNA-binding proteins and RNA can enhance their LLPS (reviewed in (Roden and Gladfelter, 2021)). LLPS is an evolutionarily ancient and conserved selforganizing principle (Hondele et al., 2019; Riback et al., 2017). Within a cell, many structures can be 
defined as membraneless organelles and they have been implicated in various aspects of gene expression regulation (reviewed in (Banani et al., 2017)). For example, stress conditions such as nutrient depletion or acute temperature shifts have been shown to induce the formation of cytoplasmic condensates such as P-bodies (PB) or stress granules (SG) (Kroschwald et al., 2015; Sheth and Parker, 2003). If LLPS contributes to or controls directional mRNA export is unknown.

Here, we report that nuclear condensation of the mRNA export factor Nab2 selectively regulates mRNA transport in glucose stress, which is modulated by the activity of the DEAD-box ATPase Dbp5. Nab2 condensation leads to the retention of bulk mRNAs in the nucleus but allows selective export of stressinduced transcripts, which is impaired in Nab2 mutants that affect the state of the condensate. Our results establish condensation as a regulator of mRNA transport during cellular stress and provide mechanistic insights into mRNA export regulation.

\section{Results}

\section{Acute Dbp5 depletion causes nuclear mRNA accumulation and Nab2 mobility reduction}

To characterize the function of Dbp5 in directional mRNA export in vivo, we employed the auxininducible acute protein depletion system in the budding yeast Saccharomyces cerevisiae (Nishimura 2009, Fig. $1 \mathrm{~A}$, 'degron'). Addition of auxin led to the efficient and specific depletion of Dbp5 with a half-time of approx. 12 min (Fig. S1A,B), without affecting the overall NPC composition based on the quantification of selected nucleoporins using a previously established method (NuRIM (Rajoo et al., 2018); Fig. S1C). Dbp5 depletion did not affect protein export as an NLS-NES-2xGFP reporter did not enrich in the nucleus after auxin addition. In contrast, blocking Xpo1-dependent export using Leptomycin B (LMB) in an LMB-sensitive Xpo1 mutant (Stade et al., 1997) strongly impaired nuclear export of the GFP reporter (Fig. S1D-G). Furthermore, addition of LMB to cells that were already Dbp5-depleted shifted the GFP reporter distribution towards the nucleus. This shows that nuclear protein import and export remain functional when Dbp5 is depleted (Fig. S1D-G).

Upon Dbp5 depletion, we observed a global nuclear retention of poly(A) RNA using fluorescence in situ hybridization (FISH) with an oligo(dT)30 probe, similar to previous reports using temperature-sensitive dbp5 alleles (Fig. S1H)(Hodge et al., 1999; Snay-Hodge et al., 1998). To investigate whether this oligo(dT)30 staining corresponds to the nuclear retention of mRNA, we examined the export of individual mRNAs. To this end, we marked transcripts of an essential gene, glutamine-fructose-6phosphate amidotransferase (GFA1), with the PP7-PCP stem loop labeling system ((Larson et al., 2011), Fig. 1A) in the Dbp5 degron background. In the presence of Dbp5, the GFA1-PP7 transcripts were mostly localized in the cytoplasm (Fig. 1B). Upon Dbp5 depletion, transcripts accumulated in the nucleus close to the nuclear periphery. Interestingly, the mobility of nuclear mRNAs was reduced in the absence of Dbp5 based on single particle tracking results obtained from a custom-built microscope ((Smith et al., 2015), Fig. 1C, Video S1, Video S2). To test whether the dynamics of nuclear export factors was also affected, we performed fluorescence recovery after photobleaching (FRAP) measurements after Dbp5 depletion. The nuclear dynamics of the export factors Yra1 and Npl3 as well as an NLS-GFP(3x) control did not change when Dbp5 was depleted (Fig. S2A-F). However, the nuclear mobility of the poly(A)binding protein Nab2 was dramatically reduced (Fig. 1D-F), with a $>5$-fold reduction of recovery halftime in the absence of Dbp5. Intriguingly, FRAP of approximately half of the nucleus showed very slow recovery of Nab2 in the entire bleached region (Fig. 1F). The reduction in Nab2 mobility is RNAdependent as additional depletion of a polymerase II subunit (Rpb2-AID) reverted the phenotype (Fig. 
$1 \mathrm{G}, \mathrm{H}$ ) by reducing the amount of poly(A) RNA in the nucleus (Fig. S2G). The mRNA-dependent mobility of Nab2 in the nucleus controlled by the DEAD-box ATPase Dbp5 is reminiscent of PBs or SGs which are mRNA-dependent cytoplasmic condensates regulated by the DEAD box ATPases, Dhh1 and Ded1, respectively (Hilliker et al., 2011; Hondele et al., 2019; Mugler et al., 2016; Teixeira and Parker, 2007). Therefore, our results suggest that Nab2 forms an mRNA-dependent condensate in the nucleus in vivo, whose dynamics depend on the presence of Dbp5.

\section{Nab2 phase-separates in vitro, which is reverted by active Dbp5}

The sequence of Nab2 shows many hallmarks of RNA-binding proteins that can undergo LLPS. In addition to an N-terminal domain required for Mlp1 binding and mRNA export, Nab2 contains a Q-rich domain of unknown function (QQQP), an RGG domain with an internal nuclear localization signal (NLS), and 7 zinc fingers ( $\mathrm{ZnF}$ ), of which ZnF5-7 are essential for RNA binding (Fig. S2H)(Anderson et al., 1993; Marfatia et al., 2003; Soniat et al., 2013). Furthermore, according to PONDR, a predictor of naturally disordered regions ( $\mathrm{Li}$ et al., 1999; Romero et al., 1997), the Q-rich domain and the RGG domain are intrinsically disordered (Fig. S2H). We therefore wanted to examine whether Nab2 can undergo phase separation in vitro. Intriguingly, in the presence of poly(A) RNA recombinant Nab2 forms liquid droplets at close to endogenous concentrations (Fig. 2A, Fig. S2I,J). These droplets are dynamic as they had the ability to fuse and grow over time (Video S3), and were mildly sensitive to the aliphatic alcohol 1,6-hexanediol, consistent with them being formed via liquid-liquid phase separation (Fig. $\mathrm{S} 2 \mathrm{~K}, \mathrm{~L})$.

$\mathrm{Nab} 2$ condensates form at physiological salt concentrations and are $\mathrm{pH}$-dependent (Fig. 2B). In addition, $\mathrm{Nab} 2$ can form condensates with other single-nucleoside polymers (poly $(\mathrm{U}) / \operatorname{poly}(\mathrm{G}) / \operatorname{poly}(\mathrm{C})$, Fig. 2C), suggesting that $\mathrm{Nab} 2$ does not exclusively bind to the poly(A) tail. Indeed, previous reports have shown that Nab2 can bind also non-poly(A) RNA in vitro (Anderson et al., 1993) and associates with mRNA regions upstream of the poly(A) tail in vivo (Tuck and Tollervey, 2013).

We next wanted to understand the interplay between Nab2 and Dbp5. In vitro work by Tran et al. demonstrated that Dbp5 is able to replace Nab2 from poly(A) RNA (Tran et al., 2007). Strikingly, coincubation of Nab2 with wild type Dbp5 and its ATPase-activators Gle1 and IP 6 (Alcázar-Román et al., 2006; Weirich et al., 2006) prevented condensate formation (Fig. S2M). This was dependent on Dbp5 as Gle1 and $\mathrm{IP}_{6}$ alone did not block droplet formation (Fig. S2M). Furthermore, a dominant-active Dbp5 mutant, Dbp5 $5^{\Delta \mathrm{N} 90}$, which functions independently of Gle1 and IP 6 (Montpetit et al., 2011), also inhibits Nab2 condensation (Fig. 2D). Conversely, the ATP-locked form of Dbp5, Dbp5 $5^{\triangle \mathrm{N} 90-\mathrm{DQAD}}$, is unable to affect Nab2 condensation (Fig. 2D), suggesting that the ATP hydrolysis cycle is required to inhibit Nab2 condensation.

Together our results indicate that RNA-dependent Nab2 condensation can be regulated by the ATPase activity of Dbp5 and that loss of Dbp5 activity triggers Nab2 condensation.

\section{Glucose stress causes reduction of nuclear Nab2 dynamics and bulk nuclear mRNA retention}

Having established that $\mathrm{Nab} 2$ forms a condensate in vitro, we next asked if Nab2 condensation can also be observed in physiologically relevant conditions in cells. It has been previously observed that Dbp5 relocalizes from the NPC to the nucleoplasm in specific stress conditions, such as acute ethanol stress (Izawa et al., 2005; Takemura et al., 2004). We therefore tested Dbp5 localization upon nutrients stress. Interestingly, NPC localization of Dbp5, but not its cytoplasmic NPC-interaction partners Nup159 and Gle1, is reduced both upon acute (30 min -DEX) and prolonged (24 hrs -DEX) glucose starvation. (Fig. $3 \mathrm{~A}, \mathrm{~B}$ and S3A,B). Furthermore, in these starvation conditions, export of bulk mRNA is blocked (Fig. 3C,D). Intriguingly, glucose starvation resulted in the formation of predominantly nuclear Nab2 foci, 
while other export factors such as Yra1 and Npl3 were unaffected (Fig. 3C,D and S3C,D). Discrete Nab2 foci form during short-term glucose withdrawal and focus formation is enhanced upon long-term glucose starvation (Fig. 3C,D). Nab2 foci are mostly resistant to 1,6-hexanediol treatment, which dissolves cytoplasmic membraneless organelles such as P-bodies, but not stress granules (Fig. S4A-C) (Kroschwald et al., 2015). Nab2 focus formation is accompanied by nuclear accumulation of poly(A) RNA in a punctate pattern overlapping with Nab2 foci (Fig. 3C, D). The poly(A) RNA that is retained in these foci seem to correspond to intact transcripts as they also show co-localization with the cap-binding complex proteins Cbc1 and Cbc2 ((Izaurralde et al., 1994), Fig. S4G). Nab2-mRNA foci are reversible, as release from starvation conditions into medium containing glucose led to the full dispersal of Nab2 in the nucleus within an hour (Fig. S4D). These results suggest that Nab2 condensation confers nuclear enrichment of bulk mRNA in long-term starvation.

We then tested Nab2 mobility in short-term and long-term starvation. Similar to acute Dbp5 depletion, we observed a reduction in nuclear dynamics after $30 \mathrm{~min}$ of acute glucose starvation (Fig. 3E,F). This phenotype was even more prominent upon long-term glucose starvation (24 hrs) (Fig. 3G,H). The reduction in dynamics was specific for $\mathrm{Nab} 2$ as the mobility of other export factors such as Npl3 and Yra1 was not affected (Fig. S3E-H). Nab2 mobility reduction was dependent on the presence of mRNA and treatment with the transcription inhibitor thiolutin (Tipper, 1973) restored Nab2 mobility to the levels of non-stressed cells (Fig. S4E,F). We next wanted to examine whether Nab2 focus formation is triggered by the loss of Dbp5 from the NPC during long-term stress. Intriguingly, when Dbp5 is prevented to leave the NPC, by using a strain in which Dbp5 is permanently fused to its interaction partner Nup159 ('Dbp5 tether', Dbp5- ${ }^{\Delta \mathrm{N}} \mathrm{Nup} 159$, (Adams and Wente, 2020)), Nab2 focus formation is strongly reduced and the mobility of Nab2 is only mildly affected in long-term glucose withdrawal (Fig. $3 \mathrm{I}-\mathrm{K}$ and S3I). This suggests that reduction of Dbp5 abundance at the NPC in response to glucose starvation is required for Nab2 focus formation.

We conclude that upon glucose starvation, RNA-dependent Nab2 focus formation correlates with reduction of Dbp5 abundance at the NPC to facilitate bulk mRNA retention in the nucleus.

\section{Protein-protein dimerization, but not predicted IDRs, drives Nab2 condensation}

$\mathrm{Nab} 2$ is predicted to contain several IDRs including an RGG and a polyQ domain (Fig. S2H). To identify the domains in Nab2 that are responsible for the alterations in nuclear dynamics in glucose stress, we tested if removal of the IDR domains would affect condensation behavior in vitro. Deleting the Q-rich domain did not abolish condensate formation, but slightly shifted the $\mathrm{pH}$-dependency to higher $\mathrm{pH}$ values (Fig. S5A). Deleting the RGG domain and replacing it with an exogenous nuclear import signal $\left(\triangle \mathrm{RGG}^{\mathrm{SV} 40 \mathrm{NLS}}\right.$, with the SV40NLS replacing the endogenous NLS found in the RGG domain) also affected the $\mathrm{pH}$ sensitivity of $\mathrm{Nab} 2$, which was even more pronounced than for Nab2 ${ }^{\Delta \mathrm{Q}}$-GFP (Fig. S5A). Surprisingly, when both domains were deleted (Nab2 $2^{\Delta \mathrm{Q}-\triangle \mathrm{RGGSV} 40 \mathrm{NLS}}-\mathrm{GFP}$, 'IDR mutant'), condensates could still form, even though the major regions expected to be critical for condensation were removed. In addition, droplets with this Nab2 variant even formed in the absence of RNA (Fig. 4A) and were less dynamic and more solid-like compared to their wild type counterparts, as shown by a reduction in recovery by FRAP (Fig. 4B). We then tested a Nab2 variant that has been previously described to affect mRNA compaction by impairing Nab2 dimerization on RNA (Nab2 ${ }^{\mathrm{F} 450 \mathrm{~A}}$, (Aibara et al., 2017)). Intriguingly, this Nab2 dimerization mutant displayed a strong reduction in condensate formation (Fig. 4A). Thus, our results suggest that Nab2 condensate formation does not depend on the IDRs but instead requires the protein's ability to dimerize on RNA, Furthermore, the major disordered regions within the protein, in particular the RGG domain, help to keep Nab2 condensates dynamic. 


\section{The type of $\mathrm{Nab} 2$ condensate determines the degree of nuclear mRNA retention}

How does the ability of Nab2 to undergo phase separation affect nuclear focus formation and RNA retention in vivo? Whereas the expression of a Nab2 variant that lacks the Q-rich domain $(\Delta \mathrm{Q})$ does not result in any growth disadvantages, deletion of the RGG domain $\left(\Delta \mathrm{RGG}^{\mathrm{SV} 40 \mathrm{NLS}}\right)$ leads to a severe growth impairment (Fig, S5B). Intriguingly, the combined deletion of both the Q and the RGG domain $(\Delta \mathrm{Q}$ $\Delta \mathrm{RGG}^{\mathrm{SV} 40 \mathrm{NLS}}$, 'IDR mutant') rescues the growth defect of the $\Delta \mathrm{RGG}^{\mathrm{SV} 40 \mathrm{NLS}}$ mutant (Fig. S5B), and we therefore continued our experiments with this mutant (Fig. S5C). Consistent with our in vitro results, both $\mathrm{Nab}^{\triangle \mathrm{Q}}$-GFP and Nab2 ${ }^{\Delta \mathrm{Q}-\Delta \mathrm{RGG}-S V 40 N L S_{-}}$GFP still formed foci in the nucleus upon long-term glucose starvation (Fig. 4C and Fig. S5E) coinciding with a reduction in nuclear mobility compared to WT in FRAP (Fig. 4D,E and Fig. S5F,G). In contrast, the dimerization mutant Nab2 ${ }^{\mathrm{F} 450 \mathrm{~A}}$ formed almost no nuclear foci (Fig. 4C) and also did not show a reduction in nuclear mobility (Fig. 4F). This suggests that the degree to which $\mathrm{Nab} 2$ mutants form condensates in vitro reflects focus formation and nuclear mobility in vivo.

Intriguingly, the capability of Nab2 to form foci in stress is also linked to the ability to retain RNA in the nucleus: while the IDR mutant shows an increased nuclear poly(A) RNA signal, the dimerization mutant displays decreased nuclear poly(A) RNA retention during stress (Fig. 5A,B). This implies that the level of $\mathrm{Nab} 2$ condensate formation determines the degree of nuclear RNA retention in long-term glucose starvation. Of note, the Nab2 IDR mutant also shows a slight nuclear mRNA retention phenotype already in $\log$ growing cells (Fig. 5A, S5H), suggesting that the RGG domain is important for efficient mRNA export both in unstressed and stressed cells.

\section{Nab2 condensation confers selective RNA retention in stress}

In order to identify which mRNAs are retained in nuclear Nab2 foci in stress, and examine if this altered in the Nab2 mutant background (Nab2 $2^{\triangle \mathrm{Q}-\Delta \mathrm{RGGSV} 40 \mathrm{NLS}}-\mathrm{GFP}$ and Nab2 ${ }^{\mathrm{F} 450 \mathrm{~A}}$-GFP) we next purified poly(A)RNA from whole cells cultured in +glucose and $24 \mathrm{hrs}$-glucose conditions, as well as from nuclear fractions of cells starved for $24 \mathrm{hrs}$ in -glucose (Fig. S5J,K and Supplementary Table 4). As expected, we detected a global rearrangement of the transcriptional landscape between the +glucose and 24 hrs glucose conditions on a whole cell level, (Fig. S6A), in agreement with RNA FISH quantifications showing a 5-fold reduction of total poly(A) RNA abundance in 24 hrs -glucose compared to +glucose (Fig. S5I). However, for a given condition, the RNA sequencing reads of the wild type and the mutants did not differ (Fig. S6A) and a stress response was initiated to a similar extent in all strains at the total RNA level (Fig. S6B). By contrast, differences in the nuclear RNA fractions could be observed between the wild type and the Nab2 mutants in the 24 hrs -glucose revealing an increase in sequencing reads (CPM, counts per million) for the IDR mutant Nab2 $2^{\Delta \mathrm{Q}-\Delta \mathrm{RGGSV} 40 \mathrm{NLS}}$ compared to wild type, whereas the dimerization mutant $\mathrm{Nab}^{\mathrm{F} 450 \mathrm{~A}}$ did not significantly differ from the wild type (Fig. 5C and S6D). Intriguingly, the IDR mutant displayed selective nuclear enrichment of certain transcripts whereas others did not show any selective enrichment (Fig. 5C). Gene ontology (GO) term analysis of the most abundant enriched transcripts (CPM >500 (318 genes) representing 42\% of the total reads; Fig. 5C (blue dots), Fig. 5D (purple) and Fig. S6E,F) revealed the highest GO scores in stress response (oxidation-reduction processes, cellular response to heat), carbohydrate metabolic processes and glucose import. Transcripts that were not differentially enriched fraction (Fig. 5D, grey) showed highest GO scores in translation, rRNA processing, glycolytic process/gluconeogenesis and proton transport (i.e. 'pro-proliferation' mRNAs). To confirm our RNA sequencing results, we also performed RNA FISH experiments using probes against individual $\mathrm{mRNAs}$ that either belong to the class of differentially enriched mRNAs (BTN2, HSP42, HXT6, Fig. 6A-F) or to the not differentially enriched mRNAs (DED1, Fig. 6G,H). 
Indeed, these experiments confirmed nuclear RNA retention and condensate selectivity for the tested transcripts.

Our results reveal that wild-type Nab2 retains pro-proliferation mRNAs in the nucleus that are not induced in stress allowing the selective export of stress-induced mRNAs (Fig. 6). The altered condensate state seen in the IDR mutant Nab2 $2^{\triangle \mathrm{Q}-\Delta \mathrm{RGGSV} 40 \mathrm{NLS}}$ prevents the selective transport of stress-induced mRNAs, which results in their nuclear accumulation.

\section{Correct Nab2 condensation is essential for survival after prolonged stress}

Finally, we also asked whether there is a physiological consequence of the altered mRNA retention in long-term stress. We therefore washed cells acutely into medium without glucose and incubated them for 5 days before allowing them to recover on rich medium plates containing dextrose. Compared to wild type, the IDR mutant $\mathrm{Nab2} 2^{\triangle \mathrm{Q}-\triangle \mathrm{RGGSV} 40 \mathrm{NLS}}$ displays a slight growth disadvantage on rich medium plates in log growing cells, which gets exacerbated after prolonged glucose withdrawal (Fig. 7A) and when stress is maintained after dextrose recovery by incubating cells at different temperatures (Fig. 7A and S7A). Furthermore, gradual glucose depletion also affects the recovery of the IDR mutant as cells recovered from early stationary phase ( $24 \mathrm{hrs}$ after mid-log phase) show a similar growth impairment as after acute glucose withdrawal (Fig. S7B).

In summary, our results suggests that aberrant mRNA localization caused by altered Nab2 condensation affects survival in and recovery from glucose stress conditions.

\section{Discussion}

Here we show that the mRNA export factor Nab2 can form biomolecular condensates in vitro and in vivo, which are counteracted by the activity of the DEAD-box ATPase Dbp5. Our results provide evidence that the nuclear RNA-dependent Nab2 condensates globally retain bulk mRNAs in the nucleus in physiologically relevant stress conditions. Furthermore, our results suggest that a group of stress-induced mRNAs do not accumulate in the nucleus and predominantly localize in the cytoplasm. Therefore, we propose a model in which stress-related transcripts can escape nuclear retention to elicit a timely cellular stress response, suggesting that cells use selective confinement in or release from nuclear condensates to re-wire mRNA export during stress (Fig. 7B). Nuclear retained mRNAs are intact as both the cap-binding complex as well as the poly(A)-binding protein Nab2 enrich in stress-induced nuclear RNA foci, and largely represent pro-proliferation transcripts (Fig. 5C,D and Fig. S4G). Storing them in the nucleus during glucose starvation might be a cellular strategy required for re-initiation of cell growth after stress release, which could allow cells to quickly re-start protein production in a transcription-independent fashion, minimizing energy consumption at early stages of re-growth. Nuclear retained mRNAs tend to be longer (Fig. S6G) and more likely stem from intron-containing genes (Fig. S6H) than the RNAs that evade nuclear retention (e.g., those induced in glucose stress, Fig. 5D), although it is unclear if those mRNAs still contain introns once they are present in nuclear Nab2 condensates. Nab2 has been implicated in splicing regulation and artificial depletion of Nab2 from the nucleus leads to transcriptional read-through which produces chimeric transcripts with retained introns (Alpert et al., 2020; Soucek et al., 2016). RNA length has been reported to correlate with enrichment in cytoplasmic stress granules and poor translation efficiency (Khong et al., 2017), suggesting that short transcripts, such as mRNAs responsible for the cellular stress response, could evade both nuclear and cytoplasmic condensates to allow for their preferential translation in stress conditions. Furthermore, nuclear mRNA retention has previously been reported in mammalian systems, where it serves to rapidly modify the neuronal 
transcriptome upon stimulation (Mauger et al., 2016), or to buffer gene expression noise (Bahar Halpern et al., 2015). Buffering mechanisms could also be at play in yeast, which needs to be investigated in the future.

We show that Nab2 condensate formation is regulated by the activity of Dbp5 (Fig. 2D and Fig. S2M), and that forcing Dbp5 to nuclear pore complexes (NPCs) via fusion to ${ }^{\Delta \mathrm{N}} \mathrm{Nup} 159$ prevents stress-induced Nab2 mobility reduction and nuclear focus formation (Fig. 3I-K). Previous reports have demonstrated a transient Nab2 and Dbp5 interaction at the NPC using a splitVenus system (Adams and Wente, 2020). We speculate that Dbp5 could generally act to dissolve RNA-containing condensates. Consistent with this, overexpression of the mammalian ortholog of Dbp5, DDX19, prevents stress granule formation in an RNA-binding dependent manner (Hochberg-Laufer et al., 2019; Tauber et al., 2020). However, the local ATPase activation through its interaction partner Gle1, which exclusively resides at the NPC, could target Dbp5's activity largely towards specific RNPs such as Nab2-bound mRNAs that pass the NPC during export. In line with this, Dbp5 $-{ }^{\Delta \mathrm{N}} \mathrm{Nup} 159$ localization has been shown to be sufficient for viability (Adams and Wente, 2020), suggesting that the essential role of Dbp5 is restricted to the NPC.

Nuclear Nab2 condensation depends on several domains that modulate the degree of condensation and the material properties of the condensates controlling the degree of nuclear RNA retention (Fig. 5A,B). Surprisingly, when we deleted the major regions predicted to be causal for condensation (Fig. S2H), the Q-rich domain and the RGG domain, we observed a stronger Nab2 condensation phenotype, indicating that these domains act together to function as 'liquefiers' of condensates or to block condensation altogether. Similar observations have been made for the stress granule component Ded1, where deletion of evolutionarily preserved residues in its $\mathrm{N}$-terminal intrinsically disordered region (IDR) lead to constitutive SG formation (Iserman et al., 2020).

Conversely, Nab2 condensation (and nuclear focus formation/RNA retention) depends on its ability to dimerize on RNA (Nab2 ${ }^{\mathrm{F} 450 \mathrm{~A}}$, Fig. $4 \mathrm{~A}, \mathrm{C}$ and $5 \mathrm{~A}$ ). The dimerization mutation lies within the zinc fingers $(\mathrm{ZnF})$ essential for RNA binding, highlighting the multivalent binding mode of Nab2 as well as the importance of non-IDR regions for condensate formation. Indeed, Yang et al. have previously shown that increasing the number of $\mathrm{ZnFs}$ promotes cytoplasmic condensation of the SG component G3BP1, highlighting how altering RNA binding strength and potentially the valency of interaction affects condensate formation (Yang et al., 2020).

Glucose starvation is accompanied by an intracellular $\mathrm{pH}$ drop from $\mathrm{pH} 7.5$ to $\mathrm{pH}$ 6-6.5 (Dechant et al., 2014; Joyner et al., 2016; Orij et al., 2009). Intriguingly, altered condensation of the IDR mutant Nab2 $2^{\Delta Q-}$ ${ }_{\triangle \mathrm{RGGSV} 40 \mathrm{NLS}}$ resulted in $\mathrm{pH}$ insensitivity in vitro (Fig. 4A) and a slight nuclear enrichment of poly(A) RNA already in +DEX conditions (Fig. 5A and Fig. S5H), suggesting that Nab2 condensation could also play a role in mRNA export in exponentially growing cultures. Future research needs to determine to which extent mRNP (micro)condensation is also involved in mRNA export in unstressed cells, and if the essential function Dbp5 in mRNA export is to locally prevent or modulate mRNP condensation. 


\section{Materials and Methods}

\section{Supplementary Table 1 (Strain list)}

\begin{tabular}{|c|c|c|c|}
\hline Strain name & Genotype & Figure & Reference \\
\hline KWY6116 & $\begin{array}{l}\text { MAT A bis3 } 11 \text { leu2 } \triangle 0 \text { ura3 } 40 \text { NDC1::NCD1-yomKate2-URA3 } \\
\text { GFA1::GFA1-24xPP7stemloops::loxP-kanR-loxP } \\
\text { yEGFP::LEU2 }\end{array}$ & $1 \mathrm{~B}, \mathrm{C}$ & This study \\
\hline KWY6353 & $\begin{array}{l}\text { MAT A bis3 } 41 \text { leu2 } \Delta 0 \text { ura3 } 10 \text { NDC1::NCD1-yomKate2-URA3 } \\
\text { GFA1::GFA1-24xPP7stemloops pMET25-PP7CP-yEGFP::LEU2 }\end{array}$ & $1 \mathrm{~B}, \mathrm{C}$ & This study \\
\hline KWY8262 & $\begin{array}{l}\text { MAT A leu2 bis3 NAB2::NAB2-yEGFP-URA3 DBP5::DBP5-3V5- } \\
\text { LAA7-KANMX trp1-1:: dsRed-HDEL }\end{array}$ & 1D-H & This study \\
\hline KWY8263 & $\begin{array}{l}\text { MAT alpha leu2 NAB2::NAB2-yEGFP-URA3 DBP5::DBP5-3V5- } \\
\text { LAA7-KANMX trp1-1:: dsRed-HDEL HIS::pGPD1-osTIR-HIS }\end{array}$ & 1D-H & This study \\
\hline KWY8258 & $\begin{array}{l}\text { MAT A leu2 bis3 NAB2::NAB2-yEGFP-URA3 DBP5::DBP5-3V5- } \\
\text { IAA7-KANMX RPB2::RPB2-3V5-IAA7-KANMX trp1-1:: dsRed- } \\
\text { HDEL }\end{array}$ & $1 G, H$ & This study \\
\hline KWY8395 & $\begin{array}{l}\text { MAT A leu2 bis3 NAB2::NAB2-yEGFP-URA3 DBP5::DBP5-3V5- } \\
\text { LAA7-KANMX RPB2::RPB2-3V5-LAA7-KANMX trp1-1:: dsRed- } \\
\text { HDEL pNH603-pGPD1-osTIR::HIS }\end{array}$ & $1 \mathrm{G}, \mathrm{H}$ & This study \\
\hline KWY6567 & $\begin{array}{l}\text { MAT alpha bis3-11,15 trp1-1 ura3-1 ade2-1 DBP5::DBP5-link- } \\
\text { yEGFP::CaURA3 TRP1:: dsRed-HDEL }\end{array}$ & $\begin{array}{l}3 \mathrm{~A}, \mathrm{~B} \\
\text { S3A,B } \\
\text { S3I }\end{array}$ & $\begin{array}{l}\text { Rajoo et al. } \\
\text { PNAS } 2018\end{array}$ \\
\hline KWY9296 & MAT alpha bis3 $\Delta 1$ leu2 $\Delta 0$ lys $2 \Delta 0$ ura3 $\Delta 0 N A B 2:: N A B 2-y E G F P-H I S M X$ & $\begin{array}{l}\text { 3C-H, } \\
\text { 4C,D,G } \\
\text { 5A-C } \\
6 \mathrm{~A}-\mathrm{H} \\
7 \mathrm{~A} \\
\text { S4A-F } \\
\text { S5C,D,H } \\
-\mathrm{K} \\
\text { S6A-H } \\
\text { S7A,B }\end{array}$ & This study \\
\hline KWY9399 & 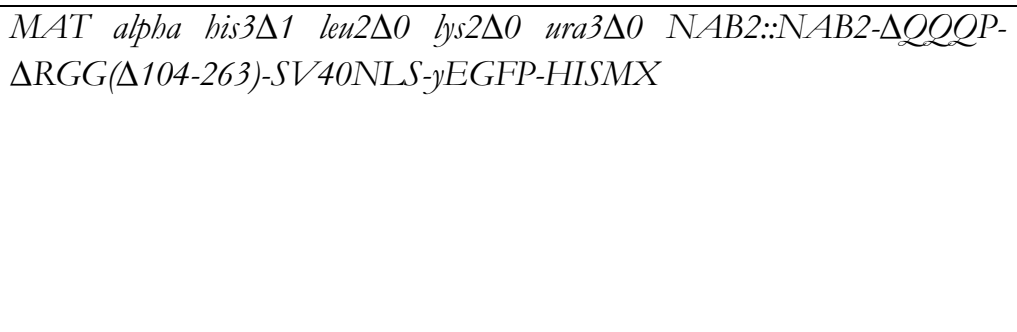 & $\begin{array}{l}\text { 4C,E,G } \\
5 \mathrm{~A}-\mathrm{C} \\
6 \mathrm{~A}-\mathrm{H} \\
7 \mathrm{~A} \\
\text { S5C,H-K } \\
\text { S6A-H } \\
\text { S7A,B }\end{array}$ & This study \\
\hline KWY9823 & 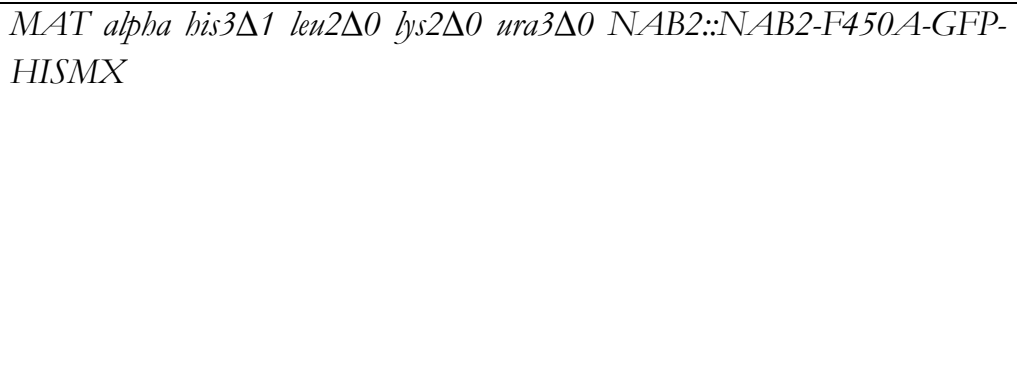 & $\begin{array}{l}\text { 4C,F,G } \\
5 \mathrm{~A}-\mathrm{C} \\
6 \mathrm{~A}-\mathrm{H} \\
7 \mathrm{~A} \\
\text { S5D,H- } \\
\text { K } \\
\text { S6A-H } \\
\text { S7A,B }\end{array}$ & This study \\
\hline KWY10392 & MAT A bis3-11,15 ura3-1 leu2-3 trp1-1Nab2-GFP::HIS & $3 \mathrm{I}-\mathrm{K}$ & This study \\
\hline KWY10394 & 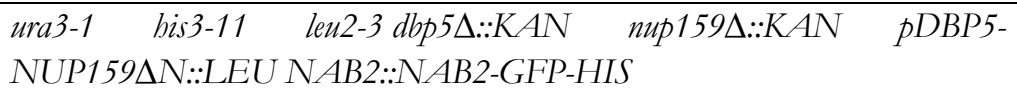 & $3 \mathrm{I}-\mathrm{K}$ & This study \\
\hline
\end{tabular}


bioRxiv preprint doi: https://doi.org/10.1101/2022.01.30.478372; this version posted January 30,2022 . The copyright holder for this

preprint (which was not certified by peer review) is the author/funder. All rights reserved. No reuse allowed without permission.

\begin{tabular}{|c|c|c|c|}
\hline KWY7462 & $\begin{array}{l}\text { MAT alpha TRP1::dsRed-HDEL DBP5::DBP5-GFP-IAA7-KANMX } \\
\text { pNH603-pGPD1-osTIR::HIS }\end{array}$ & S1A & This study \\
\hline KWY6037 & $\begin{array}{l}\text { MATalpha his3-11,15 trp1-1 ura3-1 ade2-1 NUP84::NUP84-link- } \\
\text { yEGFP::CaURA3 TRP1::dsRed-HDEL }\end{array}$ & $\mathrm{S} 1 \mathrm{C}$ & $\begin{array}{l}\text { Rajoo et al. } \\
\text { PNAS } 2018\end{array}$ \\
\hline KWY6041 & $\begin{array}{l}\text { MATalpha his3-11,15 trp1-1 ura3-1 ade2-1 NUP133::NUP133-link- } \\
\text { yEGFP::CaURA3 TRP1::dsRed-HDEL }\end{array}$ & S1C & $\begin{array}{l}\text { Rajoo et al. } \\
\text { PNAS } 2018\end{array}$ \\
\hline KWY6048 & $\begin{array}{l}\text { MATalpha his3-11,15 trp1-1 ura3-1 ade2-1 NUP82::NUP82-link- } \\
\text { yEGFP::CaURA3 TRP1::dsRed-HDEL }\end{array}$ & $\mathrm{S} 1 \mathrm{C}$ & $\begin{array}{l}\text { Rajoo et al. } \\
\text { PNAS } 2018\end{array}$ \\
\hline KWY6053 & $\begin{array}{l}\text { MATalpha his3-11,15 trp1-1 ura3-1 ade2-1 NUP60::NUP60-link- } \\
\text { yEGFP::CaURA3 TRP1::dsRed-HDEL }\end{array}$ & S1C & $\begin{array}{l}\text { Rajoo et al. } \\
\text { PNAS } 2018\end{array}$ \\
\hline KWY6054 & $\begin{array}{l}\text { MATalpha bis3-11,15 trp1-1 ura3-1 ade2-1 NUP159::NUP159-link- } \\
\text { yEGFP::CaURA3 TRP1::dsRed-HDEL }\end{array}$ & $\begin{array}{l}\text { S1C } \\
\text { S3A,B }\end{array}$ & $\begin{array}{l}\text { Rajoo et al. } \\
\text { PNAS } 2018\end{array}$ \\
\hline KWY6921 & $\begin{array}{l}\text { MATalpha bis3-11,15 trp1-1 ura3-1 ade2-1 NUP159::NUP159-link- } \\
\text { yEGFP::CaURA3 TRP1::dsRed-HDEL DBP5::DBP5-GFP-IAA7- } \\
\text { KANMX }\end{array}$ & S1C & This study \\
\hline KWY7056 & $\begin{array}{l}\text { MATalpha his3-11,15 trp1-1 ura3-1 ade2-1 NUP159::NUP159-link- } \\
\text { yEGFP::CaURA3 TRP1::dsRed-HDEL DBP5::DBP5-GFP-IAA7- } \\
\text { KANMX pNH603-pGPD1-osTIR::HIS }\end{array}$ & $\mathrm{S} 1 \mathrm{C}$ & This study \\
\hline KWY7407 & $\begin{array}{l}\text { MATalpha bis3-11,15 trp1-1 ura3-1 ade2-1 NUP133::NUP133-link- } \\
\text { yEGFP::CaURA3 TRP1::dsRed-HDEL DBP5::DBP5-GFP-IAA7- } \\
\text { KANMX }\end{array}$ & S1C & This study \\
\hline KWY7408 & $\begin{array}{l}\text { MATalpha bis3-11,15 trp1-1 ura3-1 ade2-1 NUP82::NUP82-link- } \\
\text { yEGFP::CaURA3 TRP1::dsRed-HDEL DBP5::DBP5-GFP-IAA7- } \\
\text { KANMX }\end{array}$ & S1C & This study \\
\hline KWY7412 & $\begin{array}{l}\text { MATalpha bis3-11,15 trp1-1 ura3-1 ade2-1 NUP60::NUP60-link- } \\
\text { yEGFP::CaURA3 TRP1::dsRed-HDEL DBP5::DBP5-GFP-IAA7- } \\
\text { KANMX }\end{array}$ & $\mathrm{S} 1 \mathrm{C}$ & This study \\
\hline KWY7444 & $\begin{array}{l}\text { MATalpha bis3-11,15 trp1-1 ura3-1 ade2-1 NUP133::NUP133-link- } \\
\text { yEGFP::CaURA3 TRP1::dsRed-HDEL DBP5::DBP5-GFP-IAA7- } \\
\text { KANMX pNH603-pGPD1-osTIR::HIS }\end{array}$ & $\mathrm{S} 1 \mathrm{C}$ & This study \\
\hline KWY7446 & $\begin{array}{l}\text { MATalpha bis3-11,15 trp1-1 ura3-1 ade2-1 NUP82::NUP82-link- } \\
\text { yEGFP::CaURA3 TRP1::dsRed-HDEL DBP5::DBP5-GFP-LAA7- } \\
\text { KANMX pNH603-pGPD1-osTIR::HIS }\end{array}$ & S1C & This study \\
\hline KWY7458 & $\begin{array}{l}\text { MATalpha bis3-11,15 trp1-1 ura3-1 ade2-1 NUP60::NUP60-link- } \\
\text { yEGFP::CaURA3 TRP1::dsRed-HDEL DBP5::DBP5-GFP-IAA7- } \\
\text { KANMX pNH603-pGPD1-osTIR::HIS }\end{array}$ & S1C & This study \\
\hline KWY8118 & 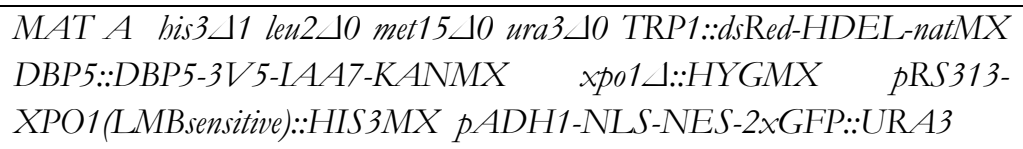 & S1B,D-G & This study \\
\hline KWY10381 & 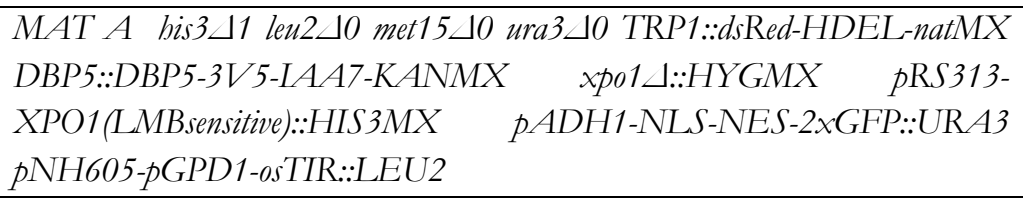 & S1D-G & This study \\
\hline KWY9559 & 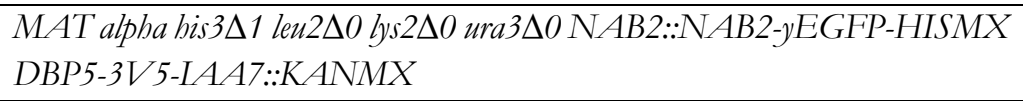 & S1H & This study \\
\hline KWY9579 & 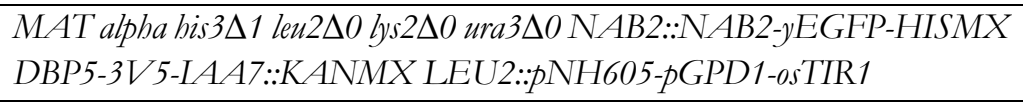 & $\begin{array}{l}\text { S1H, } \\
\text { S2G }\end{array}$ & This study \\
\hline KWY7642 & $\begin{array}{l}\text { MAT A bis3A1 leu2 } 40 \text { met15 } \triangle 0 \text { DBP5::DBP5-3V5-LAA7-KANMX } \\
\text { YRA1::yEGFP-YRA1-NATMX }\end{array}$ & S2A,B & This study \\
\hline KWY7652 & $\begin{array}{l}M A T A \text { bis3 } \triangle 1 \text { leu2 } \triangle 0 \text { met15 } \triangle 0 \text { DBP5::DBP5-3V5-IAA7-KANMX } \\
\text { YRA1::yEGFP-YRA1-NATMX TRP1::pGPD1-osTIR-hphNT1 }\end{array}$ & S2A,B & This study \\
\hline KWY8009 & MAT A bis3 $\Delta 1$ leu2 $\Delta 0$ met15 $\Delta 0 \quad$ TRP1::dsRed-HDEL-NATMX & S2C,D & This study \\
\hline
\end{tabular}


bioRxiv preprint doi: https://doi.org/10.1101/2022.01.30.478372; this version posted January 30,2022 . The copyright holder for this

preprint (which was not certified by peer review) is the author/funder. All rights reserved. No reuse allowed without permission.

\begin{tabular}{|c|c|c|c|}
\hline & DBP5::DBP5-3V5-LAA7-KANMX NPL3::NPL3-yEGFP-URA3 & & \\
\hline KWY8010 & $\begin{array}{ll}M A T A \text { bis3 } \Delta 1 \text { leu2 } \triangle 0 \text { met15 } & \text { TRP1::dsRed-HDEL-NATMX } \\
\text { DBP5::DBP5-3V5-LAA7-KANMX } & \text { NPL3::NPL3-yEGFP-URA3 } \\
\text { pNH603-pGPD1-osTIR::HIS } & \end{array}$ & S2C,D & This study \\
\hline KWY7855 & $\begin{array}{l}\text { MAT A bis3A1 leu2 } \triangle 0 \text { met15 } 10 \text { ura3 } \triangle 0 \text { TRP1::dsRed-HDEL-natMX } \\
D B P 5:: D B P 5-3 V 5-L A A 7-K A N M X p(P H O 4-N L S \text {-GFP3 ::URA3) }\end{array}$ & S2E,F & This study \\
\hline KWY7949 & 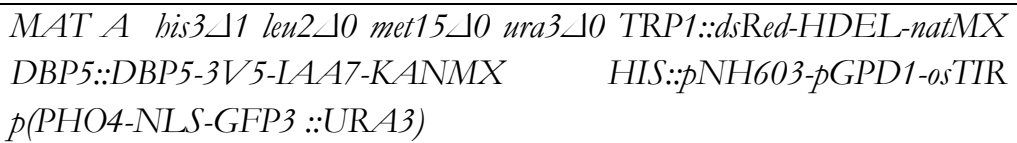 & S2E,F & This study \\
\hline KWY8259 & $\begin{array}{l}\text { MAT alpha leu2 NAB2::NAB2-yEGFP::URA3 DBP5::DBP5-3V5- } \\
\text { LAA7::KANMX RPB2::RPB2-3V5-LAA7-KANMX trp1-1::dsRed- } \\
\text { HDEL-TRP1 HIS::pGPD1-osTIR-HIS }\end{array}$ & S2G & This study \\
\hline KWY8050 & $\begin{array}{l}\text { MATalpha bis3-11,15 trp1-1 ura3-1 ade2-1 DHH1::DHH1-yEGFP- } \\
\text { URA3 }\end{array}$ & S2I,J & This study \\
\hline KWY8650 & $\begin{array}{l}\text { MAT A bis3A1 leu2 } \triangle 0 \text { met15 } 10 \text { ura3 } \triangle 0 \text { TRP1::dsRed-HDEL-URA3 } \\
\text { NAB2::NAB2-yEGFP-HIS3 }\end{array}$ & $\begin{array}{l}\text { S2I,J } \\
\text { S5B }\end{array}$ & This study \\
\hline KWY6051 & $\begin{array}{l}\text { MATalpha his3-11,15 trp1-1 ura3-1 ade2-1 GLE1::GLE1-link- } \\
\text { yEGFP::CaURA3 TRP1::dsRed-HDEL }\end{array}$ & S3A,B & $\begin{array}{l}\text { Rajoo et al. } \\
\text { PNAS } 2018\end{array}$ \\
\hline KWY6268 & $M A T A$ bis3 $\Delta 1$ leu2 $\Delta 0$ met15 10 YRA1:: NATMX-yEGFP-YRA1 & S3C,E,F & This study \\
\hline KWY8008 & $\begin{array}{l}\text { MAT A bis3A1 leu2A0 met15 } 0 \text { TRP1::dsRed-HDEL-NATMX } \\
\text { DBP5::DBP5-3V5-LAA7-KANMX NPL3::NPL3-yEGFP-URA3 }\end{array}$ & S3D,G,H & This study \\
\hline $\begin{array}{l}\text { KWY10277 } \\
\text { (SWY6285) }\end{array}$ & 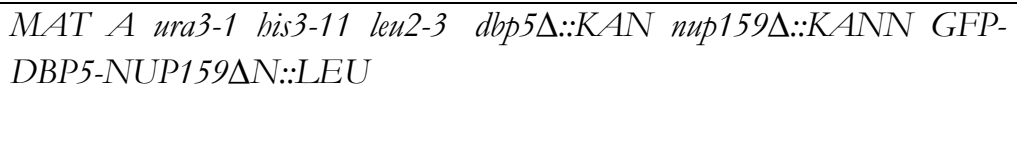 & S3I & $\begin{array}{lr}\text { Adams } & \& \\
\text { Wente, } & \text { PLoS } \\
\text { Genetics } & 2020\end{array}$ \\
\hline KWY7690 & $M A T A$ bis3 $\Delta 1$ leu2 $\triangle 0$ met15 $\triangle 0$ CBC2::CBC2-GFP(S65T)-HIS3MX & S4G & $\begin{array}{l}\text { Huh et al. } \\
\text { Nature } 2003\end{array}$ \\
\hline KWY7696 & MAT A bis3 $\Delta 1$ leu2 $\Delta 0$ met15 $\triangle 0$ CBC1::CBC2-GFP(S65T)-HIS3MX & S4G & $\begin{array}{l}\text { Huh et al. } \\
\text { Nature } 2003\end{array}$ \\
\hline KWY8215 & $\begin{array}{l}\text { MAT alpha bis3 } \triangle 1 \text { leu2 } \triangle 0 \text { ura3 } \triangle 0 \text { TRP1::dsRed-HDEL-natMX } \\
\text { NAB2::NAB2-GFP-Y66L-LAA7-KANMX } \\
\text { osTIR::HIS }\end{array}$ & S5B & This study \\
\hline KWY9288 & $\begin{array}{l}\text { MAT alpha bis3A1 leu2 } 40 \text { ura3 } 40 \text { TRP1::dsRed-HDEL-natMX } \\
\text { NAB2::NAB2-GFP-Y66L-LAA7-KANMX } \\
\text { osTIR::HIS p(Nab2-yEGFP-LEU2 (CEN)) }\end{array}$ & S5B & This study \\
\hline KWY9289 & $\begin{array}{l}\text { MAT alpha bis3 } \Delta 1 \text { leu2 } \triangle 0 \text { ura3 } \triangle 0 \text { TRP1::dsRed-HDEL-natMX } \\
\text { NAB2::NAB2-GFP-Y66L-LAA7-KANMX } \\
\text { osTIR::HIS pNH603-pGPD1- } \\
\text { (CEN)) }\end{array}$ & S5B & This study \\
\hline KWY9290 & $\begin{array}{l}\text { MAT alpha bis3 } \triangle 1 \text { leu2 } \triangle 0 \text { ura3 } \triangle 0 \text { TRP1::dsRed-HDEL-natMX } \\
\text { NAB2::NAB2-GFP-Y66L-LAA7-KANMX } \quad \text { pNH603-pGPD1- } \\
\text { osTIR::HIS p(Nab2- } \triangle Q Q Q P-\triangle R G G(\Delta 104-263)-S V 40 N L S_{-y E G F P-} \\
\text { LEU2 (CEN)) }\end{array}$ & S5B & This study \\
\hline KWY8666 & 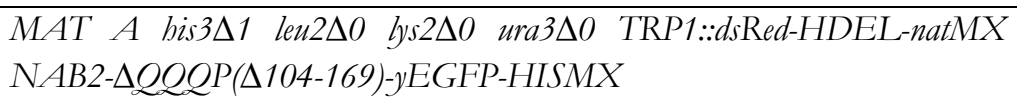 & S5C & This study \\
\hline KWY10234 & 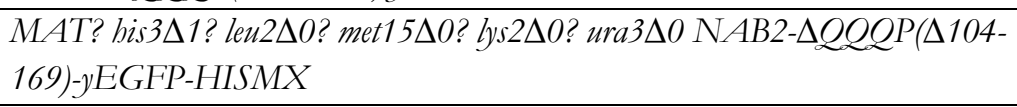 & S5E-G & This study \\
\hline
\end{tabular}

\section{Supplementary Table 2 (Plasmid List)}

\begin{tabular}{|l|l|l|l|}
\hline $\begin{array}{l}\text { Plasmid } \\
\text { name }\end{array}$ & description & Figure & Published \\
\hline
\end{tabular}


bioRxiv preprint doi: https://doi.org/10.1101/2022.01.30.478372; this version posted January 30,2022 . The copyright holder for this preprint (which was not certified by peer review) is the author/funder. All rights reserved. No reuse allowed without permission.

\begin{tabular}{|c|c|c|c|}
\hline pKW2499 & 6xHIS-TEV- $\Delta$ N90-Dbp5 (KAN) & $2 \mathrm{C}$ & $\begin{array}{l}\text { Montpetit et al. } \\
\text { Nature } 2011\end{array}$ \\
\hline pKW2501 & 6xHIS-TEV- $\triangle$ N90-Dbp5-DQAD (KAN) & $2 \mathrm{C}$ & This study \\
\hline pKW3714 & 6xHis-V5-Dbp5-mCherry (AMP) & S5B & This study \\
\hline pKW4404 & 6xHis-V5-Gle1 s.c. [244-538] (AMP) & S5B & This study \\
\hline pKW4814 & 6xHis-TwinStrep-PreScission-Nab2-yEGFP (AMP) & $\begin{array}{l}2 \mathrm{~A}-\mathrm{C} \\
4 \mathrm{~A} \\
\text { S5B-D }\end{array}$ & This study \\
\hline pKW4817 & 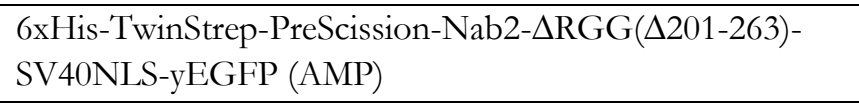 & S8G & This study \\
\hline pKW4818 & $\begin{array}{l}\text { 6xHis-TwinStrep-PreScission-Nab2- } \Delta \text { QQQP- } \\
\Delta \text { RGG(A104-263)-SV40NLS-yEGFP (AMP) }\end{array}$ & $4 \mathrm{~A}$ & This study \\
\hline pKW4954 & 6xHis-TwinStrep-PreScission-Nab2-F450A-yEGFP (AMP) & $4 \mathrm{~A}$ & This study \\
\hline pKW4957 & $\begin{array}{l}\text { 6xHis-TwinStrep-PreScission-Nab2- } \Delta \text { QQQP }(\Delta 104-169)- \\
\text { yEGFP (AMP) }\end{array}$ & S8G & This study \\
\hline
\end{tabular}

\section{Supplementary Table 3 (Oligo list (smFISH))}

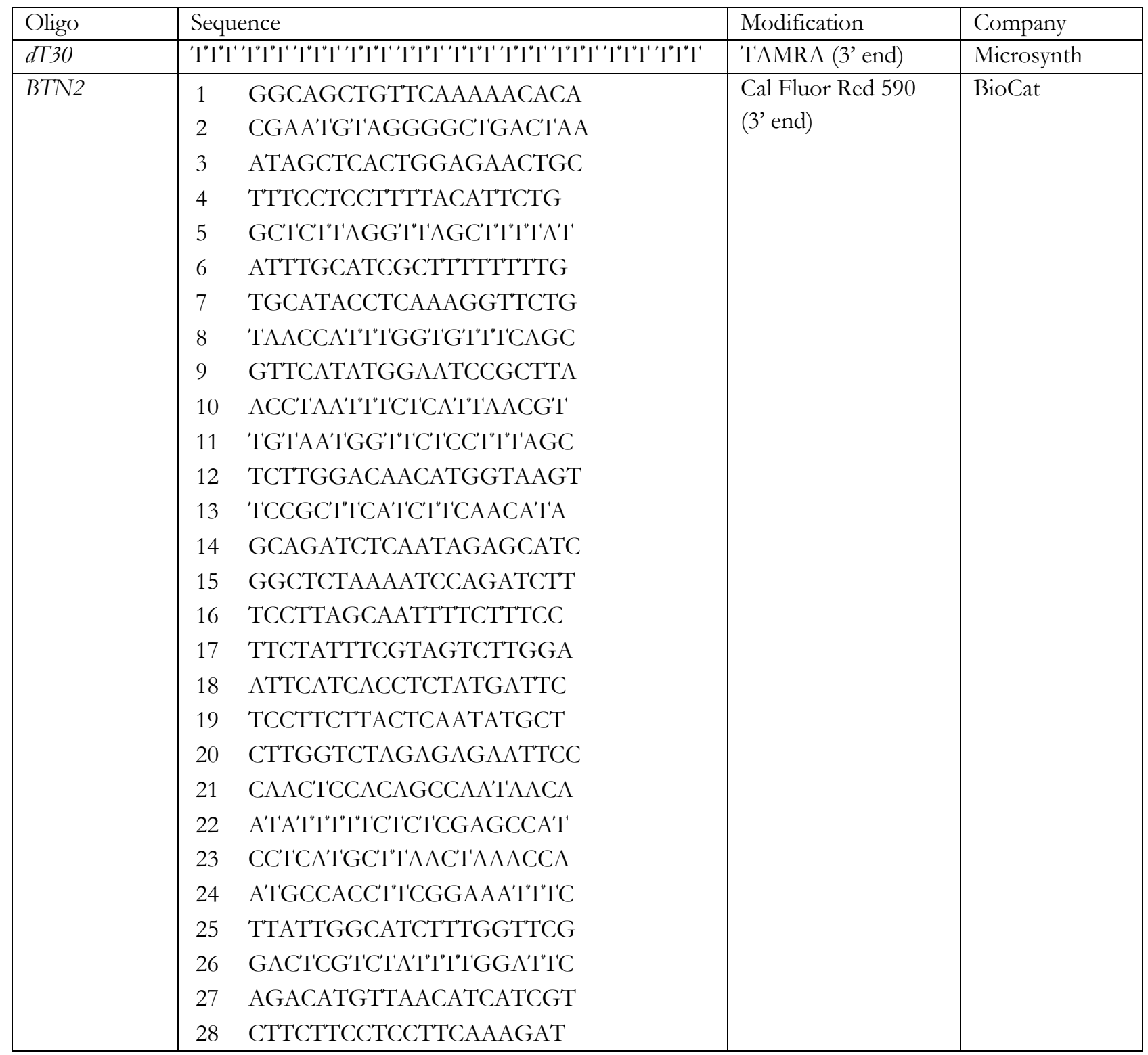




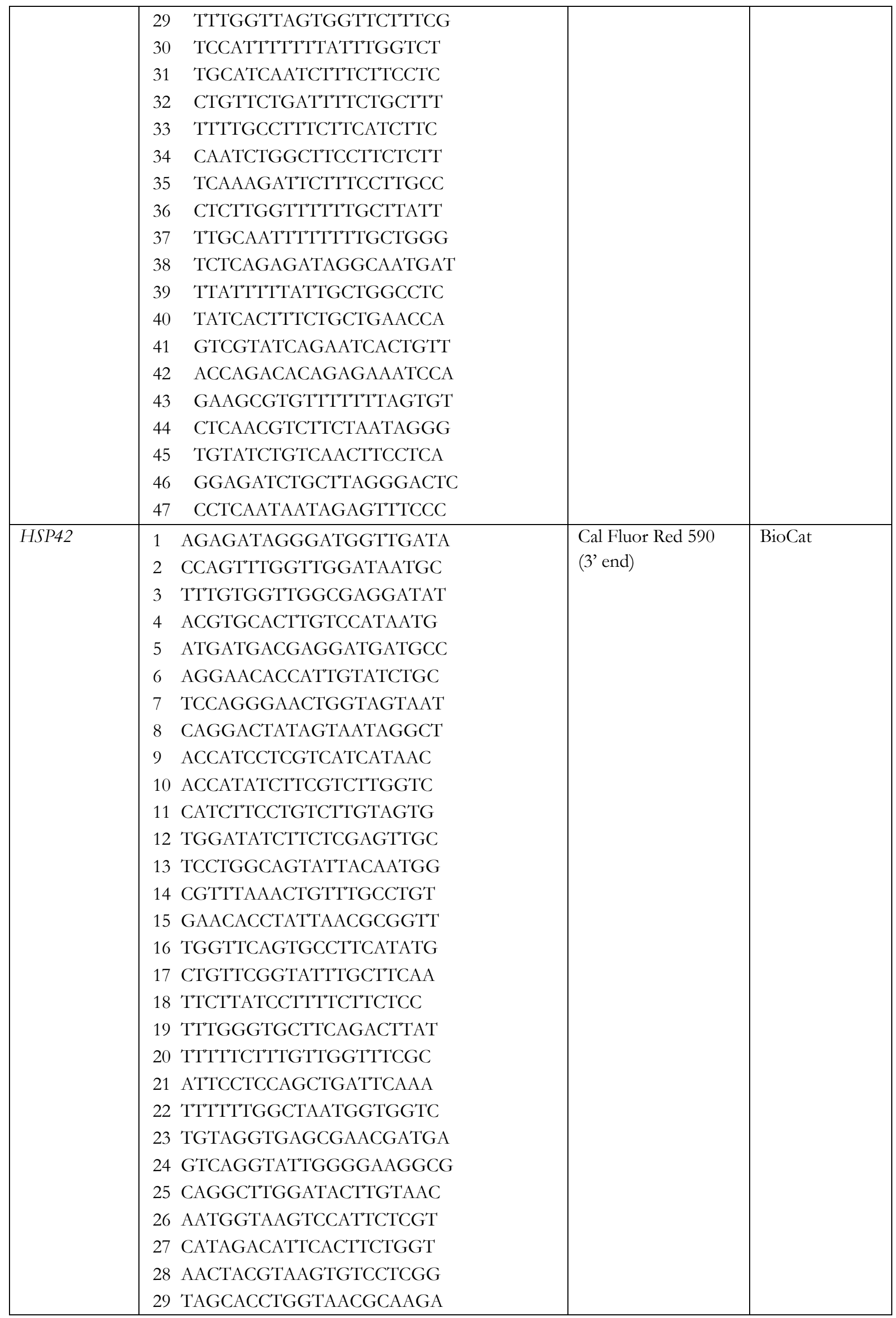




\begin{tabular}{|c|c|c|c|}
\hline & $\begin{array}{l}30 \text { TCAATGTGGAAAGCCCTAGA } \\
31 \text { CTCATGAGAAGATGGATGGT } \\
32 \text { TCGATCTTACCCTTGATGAG } \\
33 \text { TTTCATCAATGCCCACTCTG } \\
34 \text { AGTTCCGTGATCTTCAAGAA } \\
35 \text { TCTCTCAAACGCACCATATT } \\
36 \text { GCAGCACGGGGAATTTAACG } \\
37 \text { ATTTCTTCGTCCTTAATGCG } \\
38 \text { ACCGTTGTTGTAAGTAGCTT } \\
39 \text { TAGGCACCTTAATTTGTAGT } \\
40 \text { GCTTTTCAGTGTCATTGACA } \\
41 \text { AATGGCGATCCTCTT'TT'TTG } \\
42 \text { CAATTCTTCGTCGGGTATTT } \\
43 \text { CAATTT'TCTACCGTAGGGTTT }\end{array}$ & & \\
\hline HXT6 & $\begin{array}{ll}1 & \text { AGGAGTTTGCTCTGCAATAG } \\
2 & \text { TCAACAGCAGAGAGATGCTC } \\
3 & \text { GATAAAACCGAGTGGGAGGC } \\
4 & \text { TCTTTCAGCCTTGTTTGATG } \\
5 & \text { ACCTTCACCATAAGCTTTTA } \\
6 & \text { CTGGTCTCTTTGGAATTTCA } \\
7 & \text { GAGACAGTGACATAGGCAGA } \\
8 & \text { ACGAAACCACCAAAGGCGAT } \\
9 & \text { AAATGGTACCAGTATCCCAA } \\
10 & \text { AGTACCATCTTTATGCTTCA } \\
11 & \text { ACCAGTTCTAACCTTAGACA } \\
12 & \text { CACCAATGGCACAACCAATG } \\
13 & \text { CCGTACATATCACCCAATTT } \\
14 & \text { CGACAATCAAACCCACCTTA } \\
15 & \text { AACGGCAATACCACCAACAC } \\
16 & \text { GCTTTGGGGATACTTCAGAA } \\
17 & \text { CAAGAGACTAAAGTACCCCT } \\
18 & \text { ACCGGCAGTAATCATCAATT } \\
19 & \text { GTTGGTACAGTAACCCAAGA } \\
20 & \text { TGGAGTAGTTCTTAGTACCG } \\
21 & \text { ACCTAATGGAACTCTCCATT } \\
22 & \text { TCATAAACAAAGCCCAGGCA } \\
23 & \text { ACGTGGAGACTCTGGAACAA } \\
24 & \text { TTCGATCTTACCGACTTCAG } \\
25 & \text { ACGGCAATAGAACGTTTGGC } \\
26 & \text { TGGATCATCAACAGCAACCT } \\
27 & \text { AGCTTCGACTTCAGCCAAAA } \\
28 & \text { TTACCAGCTAATTTCTCTGC } \\
29 & \text { ACTAAACAATTCACCCCAGG } \\
30 & \text { AAACGCTGAAGGACCTTTGT } \\
31 & \text { TTGAATCATAGCACCCATGA } \\
32 & \text { CACCTGTCAATTGTTGTAGA } \\
33 & \text { ACTCAAACCAACAGCCTTGA } \\
34 & \text { ACCCCATAGCAAACAAGTAC }\end{array}$ & $\begin{array}{l}\text { Cal Fluor Red } 590 \\
\left(3^{\prime} \text { end }\right)\end{array}$ & BioCat \\
\hline
\end{tabular}




\begin{tabular}{|c|c|c|c|}
\hline & $\begin{array}{l}35 \text { TACAAGCAGTCATGGATGCA } \\
36 \text { ATTTGGCCATAATCTGGTGA } \\
37 \text { CTTGGAAGATGGTTGGTCTT } \\
38 \text { AGCCCATGTAGTAGCAAAAC } \\
39 \text { AGACTTGACTCTCAATGGGA } \\
40 \text { GCAGCTGTAGCAATAGACAT } \\
41 \text { TCAAGAAACCCCACAACCAA } \\
42 \text { CAGCCCATGAAAACGTAACC } \\
43 \text { CCCTTAGTTTCTGGAACAAC } \\
44 \text { TGGTGTTGACT'TCTTCCAAA } \\
45 \text { CATGGTAGAACACCTTCTTC } \\
46 \text { TAGATGGTGGAACCCATGAG } \\
47 \text { TTATCATCGTGAGCCATTTC } \\
48 \text { T'TTGGTGCTGAACATTCTCT }\end{array}$ & & \\
\hline DED1 & $\begin{array}{ll}1 & \text { AATTTTGCACTTGTTCGCTC } \\
2 & \text { TAACCATTCTCGTTGTTGTC } \\
3 & \text { GTTTTCCTCTTAAGTGAGGA } \\
4 & \text { ACTGTTATTTCTGGCACTTC } \\
5 & \text { CCGTTGTTGTTATTGTAGTT } \\
6 & \text { TTGTTGCTAAAGAAGCTGCC } \\
7 & \text { TTGTTTCCACCGAAGAAACC } \\
8 & \text { CACCAAATATGGCGATCTCG } \\
9 & \text { TGGAAATTTGGATCCTCGGG } \\
10 & \text { CGTCCACTGGAATATCATCG } \\
11 & \text { TGGTTCAGGAACATCCTTAC } \\
12 & \text { TTCCAATAACAATCCGTCCA } \\
13 & \text { TGGTGAAACGGGCCAATTTG } \\
14 & \text { GGAGTATTTTTGCACAGGTG } \\
15 & \text { TGATTCGGACAACACTGGGA } \\
16 & \text { GAGACTCTGGTTGAGGAGAT } \\
17 & \text { GGCCTTTCTTTGGTAAAAGG } \\
18 & \text { TCTCTAGTTGGAGCCATAAT } \\
19 & \text { ATCGAAAATTTGGGTGGCCA } \\
20 & \text { TTGACCCAGGATCTATAAGT } \\
21 & \text { TTACCAATTGGAGAACCACC } \\
22 & \text { AGATCGCAACCACGTTCAAT } \\
23 & \text { TTCAAACGACCTGGAGTAGC } \\
24 & \text { TTTACCACGTTCCAACAAGT } \\
25 & \text { TACTTGACGTTGGCCAAAGA } \\
26 & \text { ATCAGCTTCATCTAGAACCA } \\
27 & \text { GTTCGAAACCCATATCCAAC } \\
28 & \text { CAGGAGTCATATCACAGTCT } \\
29 & \text { ATCAGAGTTTGTCTTTCACC } \\
30 & \text { TCAGCGGGAAAAGTAGCTGA } \\
31 & \text { AATCACGGGCCAAATGTTGG } \\
32 & \text { AACCGACTCTACCAACAGAC } \\
33 & \text { AGGCTGACTTCTTATCTTGA } \\
34 & \text { AGTCAAACCGTCAGTGGATG }\end{array}$ & $\begin{array}{l}\text { Cal Fluor Red } 590 \\
\text { (3' end) }\end{array}$ & BioCat \\
\hline
\end{tabular}




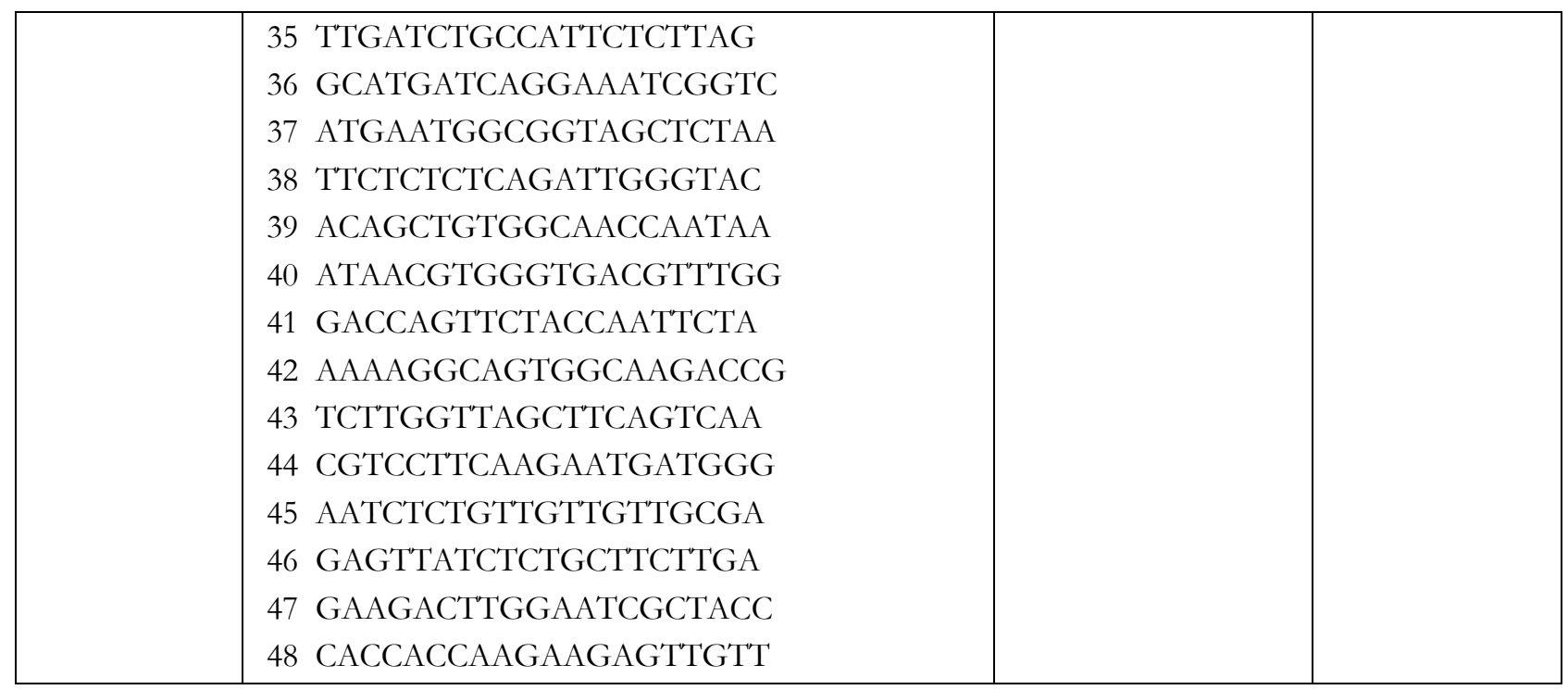

\section{Yeast strain construction}

Saccharomyces cerevisiae strains were constructed using standard yeast genetic techniques either by transformation of a CEN plasmid, a linearized plasmid, or of a PCR amplification product with homology to the target site (Longtine et al., 1998). All yeast strains expressing a GFP-tagged protein were tagged with a yeast-optimized monomeric EGFP version (A206K).

Nab2- $\Delta \mathrm{Q}$ and Nab2- $\Delta \mathrm{Q}-\Delta \mathrm{RGG} \mathrm{SV}^{\mathrm{SV} 4 \mathrm{NLS}}$ mutant strains were constructed using a CRISPR/Cas9 strategy (Laughery et al., 2015). In brief, gRNA sites were determined using Benchling (settings: single guide of $20 \mathrm{nt}$ length and an NGG PAM site (SpCas9, 3' side)). For both Nab2- $\Delta \mathrm{Q}$ and Nab2- $\Delta \mathrm{Q}-\Delta \mathrm{RGG}^{\text {SV40NLS }}$ the cut site lies within the Q-rich region (gRNA regions amplified off pML104 (Laughery et al., 2015): (A) 'upstream' gRNA: GTCCCTAGTTGTGGCTGAAGgttttagagctagaaatagcaagttaaaataaggctagtccg + cggaaacgctatacctccacc; (B) 'downstream' gRNA: gcgaggaagcggaagagcg + ctagctctaaaacCTTCAGCCACAACTAGGGACgatcatttatctttcactgcggagaag; KWY9296 was transformed with stitched gRNA regions, SwaI-digested pML104 and PCR amplification products with homology to the target site $(\Delta \mathrm{Q}$ : amplified homology product from genomic DNA excluding DNA region coding for aa104-169; $-\Delta \mathrm{Q}-\Delta \mathrm{RGG}^{\mathrm{SV} 40 \mathrm{NLS}}$ amplified homology product from plasmid $\mathrm{pKW} 4774$ where DNA region coding for aa104-263 was replaced by SV40NLS sequence (AAAGGCCTAAGAAGAAGAGGAAAGTATTA)).

\section{Yeast Cell Culturing}

Cells were cultured in synthetic complete media containing 2\% glucose (Formedium, CSC0205) (for microscopy, RNA FISH and nuclear extraction assay). Cells were inoculated from saturated overnight cultures into fresh medium and grown at $25^{\circ} \mathrm{C}$ to $\mathrm{OD}_{600} 0.6-0.8$. For acute glucose withdrawal, cells were then washed 3 times in synthetic complete media without glucose, resuspended in the same medium and cultured for the indicated time (30 min or 24 hours).

Acute degron depletion was performed by addition of auxin ( $500 \mu \mathrm{M}$ indole-3-acetic acid (IAA); $500 \mathrm{mM}$ stock in ethanol) for the indicated time points (typically 1 or 2 hours). As a solvent control, cells were treated with ethanol.

\section{Single-molecule fluorescence in situ hybridization (smFISH)}

Probe design: DNA probes coupled to CAL Fluor Red 590 (Stellaris Biosearch Technologies, synthesized by BioCat) were used for smFISH, targeting gene-specific moieties for single molecule visualization. $d T 30$ 
DNA probes coupled to TAMRA (synthesized by Microsynth AG) targeting poly(A) stretches were used for $\operatorname{poly}(\mathrm{A}) \mathrm{RNA}$ visualization.

Methodology: Samples were processed as described in (Derrer et al., 2019). Briefly, cultures were fixed for 30 min with 4\% paraformaldehyde (Electron Microscopy Sciences, 15714). Cells were washed once with buffer $\mathrm{B}\left(1.2 \mathrm{M}\right.$ sorbitol and $100 \mathrm{mM} \mathrm{KHPO4,} \mathrm{pH} 7.5$, at $\left.4^{\circ} \mathrm{C}\right)$, then spheroplasted for 20 min using $1 \% 20 \mathrm{~T}$ zymolyase in $1.2 \mathrm{M}$ sorbitol, $100 \mathrm{mM}$ KHPO4, $\mathrm{pH}$ 7.5, $20 \mathrm{mM}$ vanadyl ribonuclease complex (New England Biolabs, S1402S), and $20 \mu \mathrm{M} \beta$-mercaptoethanol. To stop the spheroplasting reaction, cells were washed once with buffer $B$, and then transferred into pre-hybridization buffer $(10 \%$ formamide (Merck Millipore, S4117), 2x SSC (saline-sodium citrate buffer; Life Technologies, AM9624). Separately, $0.5 \mu \mathrm{L}$ of probe mix (stock $25 \mu \mathrm{M}$ ) was mixed with $2 \mu \mathrm{L}$ of salmon-sperm DNA $(10 \mathrm{mg} / \mathrm{ml}$; Life Technologies, 15632-011) and $2 \mu \mathrm{L}$ yeast transfer RNA (10mg/ml; Life Technologies, AM7119). The probe mix was denatured in $50 \mu \mathrm{L}$ of hybridization buffer $\mathrm{F}(20 \%$ formamide and $10 \mathrm{mMNaHPO} 4$, $\mathrm{pH} 7.0$ ) for $3 \mathrm{~min}$ at $95^{\circ} \mathrm{C}$, and then mixed with $50 \mu \mathrm{L}$ hybridization buffer $\mathrm{H}$ (4x SSC, $4 \mathrm{mg} / \mathrm{ml}$ acetylated BSA (Sigma Fluka Aldrich, B8894-1.5mL), $20 \mathrm{mM}$ vanadyl ribonuclease complex). This final hybridization mixture was added to the pre-hybridized cell pellet (which corresponds to approx. 3 OD $_{600}$ ) and incubated overnight at $37^{\circ} \mathrm{C}$. The next day, cells were washed in 1x PBS/DAPI and incubated for 3 min, washed again in $1 \mathrm{x}$ PBS and then stored at $4{ }^{\circ} \mathrm{C}$.

\section{Microscopy for live cell imaging and smFISH}

For live cell imaging and NuRIM fluorescence intensity quantification experiments, cells were transferred to a 384 well plate (Brooks, Matrical MGB101-1-2-LG-L) treated with Concanavalin A (stock solution of $1 \mathrm{mg} / \mathrm{ml}$, air-dried), and spun down for $1 \mathrm{~min}$ at $100 \mathrm{rcf}$.

For smFISH, approx. $1 \mathrm{OD}_{600}$ of fixed cells were spread onto a glass slide using a $12 \mathrm{~mm}$ cover slip (Huber, 10.0360.52) to obtain a single layer of cells prior to imaging. Alternatively, fixed cells were transferred to a 384 well plate (Brooks, Matrical MGB101-1-2-LG-L) treated with Concanavalin A (stock solution of $1 \mathrm{mg} / \mathrm{ml}$, air-dried), and spun down for $1 \mathrm{~min}$ at $100 \mathrm{rcf}$, and washed twice with 1x PBS to obtain a single layer of cells.

All imaging experiments were performed at $25^{\circ} \mathrm{C}$. Microscopy was performed using an inverted epifluoresence microscope (Nikon Ti) equipped with a Spectra X LED light source and a Hamamatsu Flash 4.0 sCMOS camera using a 100X Plan-Apo objective NA 1.4 and NIS Elements software. For live cell imaging and smFISH image analysis, images were processed using FIJI software and plots were generated in GraphPad Prism 8 (GraphPad). For NuRIM quantification, images were processed using NuRIM code (Rajoo et al., 2018; Vallotton et al., 2019) in MATLAB. Briefly, this method uses the HDEL-DsRed signal to generate a mask that segments the nuclear envelope. This mask is then transferred to the GFP channel to extract average intensity information from this mask.

\section{Fluorescence recovery after photobleaching (FRAP)}

A) Yeast cells:

$200 \mu \mathrm{L}$ of a culture with OD 0.6-0.8 was added to a Concanavalin A treated imaging well (IBIDI, $\mu$ Slide 8-well, 80827), and spun down for $1 \mathrm{~min}$ at $100 \mathrm{rcf}$. Microscopy was performed on a Leica TCS SP8 STED/FLIM/FCS or a Leica TCS SP8-AOBS microscope using a 63x 1.4NA Oil HC PL APO CS2 objective. A bidirectional scanner at a speed of 8,000 Hz, NF488/561/633, an Airy unit of 1.5, and a FRAP booster for bleaching were applied for every FRAP experiment using a PMT detector (500-551 nm). An image size of 504 x 50 pixel and a zoom of 4 were used together with line accumulation of three, yielding a frame rate of 74.07 frames/s with a pixel dwell time of 73 ns. 50 prebleach and 300 postbleach frames were acquired. A 488-nm argon laser line was used at 30\% 
power. An elliptical region covering approximately one half of the cell nucleus was bleached. The bleaching was performed using $80 \%$ argon laser power for $195 \mathrm{~ms}$. Imaging was conducted with $1.5 \%$ laser intensity (with a gain of 570 for Nab2-GFP and GFP-Yra1, and 560 for Npl3-GFP) to illuminate the GFP during prebleach and postbleach acquisition.

B) In vitro droplets:

Protein droplets were set up according to (Hondele et al., 2019). In brief, reactions were pipetted in 384-well microscopy plates (Brooks, Matrical MGB101-1-2-LG-L). $3 \mu \mathrm{L}$ recombinant GFP-tagged protein (stock $150 \mu \mathrm{M}$ to a final concentration of $20 \mu \mathrm{M}$ ) was mixed at room temperature with 20 $\mu \mathrm{L}$ of a master mix (14.5 $\mu \mathrm{L}$ LSB-100 (100 mM KCl, 30 mM HEPES-KOH pH 7.4, 2 mM MgCl 2$)$, $0.9 \mu \mathrm{L}$ CRM reconstitution mix $(40 \mathrm{mM} \mathrm{ATP}, 40 \mathrm{mM} \mathrm{MgCl}$, $200 \mathrm{mM}$ creatine phosphate, $70 \mathrm{U}$ ml-1 creatine kinase), $1.8 \mu \mathrm{L} \mathrm{ATP} / \mathrm{MgCl} 2(100 \mathrm{mM}), 0.9 \mu \mathrm{L}$ BSA $(10 \mathrm{mg} \mathrm{mL}-1), 0.9 \mu \mathrm{L}$ poly(A) RNA (1 mg mL-1), $0.9 \mu \mathrm{L}$ 1M HEPES pH 6.8, $0.1 \mu \mathrm{L}$ RNasin Plus (Promega). Microscopy was performed on a Leica TCS SP8 STED/FLIM/FCS or a Leica TCS SP8-AOBS microscope using a 63x 1.4NA Oil HC PL APO CS2 objective. A bidirectional scanner at a speed of 8,000 $\mathrm{Hz}$, NF488/561/633, an Airy unit of 1.5, and a FRAP booster for bleaching were applied for every FRAP experiment using a PMT detector (500-551 nm). An image size of 504 x 50 pixel and a zoom of 4 were used together with line accumulation of three, yielding a frame rate of 74.07 frames $/ \mathrm{s}$ with a pixel dwell time of 73 ns. 50 prebleach and 800 postbleach frames were acquired. A 488-nm argon laser line was used at 30\% power. Imaging was conducted with $1.5 \%$ laser intensity (with a gain of 570) to illuminate the GFP during prebleach and postbleach acquisition. The bleach was performed using 80\% argon laser power for $195 \mathrm{~ms}$. The bleaching was performed by defining an elliptical region covering approximately one half of the droplet.

C) Image analysis: 1) yeast cells: Fluorescence recovery in the bleached region was evaluated by subtracting the extracellular background from the intensity of the bleached region, and the values were then bleach-corrected by normalizing for total cell intensity (Bancaud et al., 2010). 2) droplets: Fluorescence recovery in the bleached region was evaluated by subtracting the background signal outside the droplet from the intensity of the bleached region, and the values were then bleachcorrected by normalizing for total droplet intensity. All curves were fitted with an exponential function in a custom-written MATLAB script. Plots were generated in GraphPad Prism 8 (GraphPad).

\section{Nucleus extraction}

The protocol was adapted from (Aris and Blobel, 1991) and (Niepel et al., 2017). Cells were inoculated in a $10 \mathrm{~mL}$ pre-culture of synthetic complete media containing $2 \%$ glucose (SCD, Formedium, CSC0205), and cultured for 8-10 hrs at $25^{\circ} \mathrm{C}$. Cells were then back-diluted in $500 \mathrm{~mL} \mathrm{SCD}$ to $\mathrm{OD}_{600} 0.006$, grown for 16-18 hrs at $25{ }^{\circ} \mathrm{C}$ to $\mathrm{OD}_{600} 0.8$ and harvested onto a cellulose ester membrane filter (Whatman 10400921) using a vacuum filtration pump. Cells were then washed from the membrane with $40 \mathrm{~mL}$ $\mathrm{ddH}_{2} \mathrm{O}$ into a $50 \mathrm{~mL}$ Falcon tube, spun down for $2 \mathrm{~min}$ at $845 \mathrm{rcf}$, resuspended in $25 \mathrm{~mL}$ buffer $1(0.1 \mathrm{M}$ Tris- $\mathrm{HCl} \mathrm{pH} 7.4,10 \mathrm{mM} \mathrm{DTT})$ and incubated shaking at $30{ }^{\circ} \mathrm{C}$ for $20 \mathrm{~min}$ in a horizontal shaker at 150 rpm. Cells were then spun down for $2 \mathrm{~min}$ at $845 \mathrm{rcf}$, washed in $10 \mathrm{~mL}$ buffer 2 (20mM KPi pH 7.4, 1.2M Sorbitol), and spun down again for $2 \mathrm{~min}$ at $845 \mathrm{rcf}$. For cell wall digestion (spheroplasting), cells were resuspended in $50 \mathrm{~mL}$ buffer $3(20 \mathrm{mM} \mathrm{KPi} \mathrm{pH} \mathrm{7.4,1.2M} \mathrm{Sorbitol,} 10 \mathrm{mM}$ ribonucleoside vanadyl complex (NEB S1402S, pre-warmed at $65{ }^{\circ} \mathrm{C}$ ), $0.08 \mathrm{mg} / \mathrm{ml}$ Zymolyase-20T (Amsbio 326921)) and incubated for $60 \mathrm{~min}$ at $30^{\circ} \mathrm{C}$ in a rotation wheel. Spheroplasts were spun at $3000 \mathrm{rcf}$ for $2 \mathrm{~min}$, washed in $10 \mathrm{~mL}$ buffer 4 (20mM KPi pH 6.4, 1.2M Sorbitol), and spun again at $3000 \mathrm{rcf}$ for $2 \mathrm{~min}$. To release nuclei, spheroplasts were carefully resuspended in $20 \mathrm{~mL}$ buffer F (20\% Ficoll, 20mM KPi pH 6.4, $5 \mathrm{mM}$ 
RVC, $0.005 \mathrm{mg} / \mathrm{ml}$ Pepstatin A, 1x protease inhibitor cocktail (PIC, Sigma P8215-5mL), $250 \mu \mathrm{g} / \mathrm{mL}$ DAPI) and put on ice. To mechanically assist nuclei release, the lysate was then processed with 5 slow strokes in a dounce homogenizer on ice (this step is not essential as most of the nuclei are already released upon resuspension in buffer F). To separate nuclei from remaining cells/spheroplasts, the lysate was spun for $5 \mathrm{~min}$ at $3460 \mathrm{rcf}$ at $4{ }^{\circ} \mathrm{C}$. Afterwards, the supernatant was carefully removed with a $25 \mathrm{~mL}$ pipet until ca. $2 \mathrm{~mL}$ was left (to avoid pipetting the cell/spheroplast pellet) and transferred to a fresh $15 \mathrm{~mL}$ Falcon tube on ice. For nucleus enrichment and removal of other organelles, a sucrose gradient was prepared as follows: ice-cold $5 \mathrm{~mL} 2.5 \mathrm{M}$ sucrose was added to the bottom of an open-top plastic tube (Beckman-Coulter 344058), carefully topped up with ice-cold $5 \mathrm{~mL} 1.875 \mathrm{M}$ sucrose, which in turn was carefully topped up with ice-cold $5 \mathrm{~mL} 1.7 \mathrm{M}$ sucrose. Lastly, the lysate supernatant was carefully added on top of the $1.7 \mathrm{M}$ sucrose layer, and the full tube was transferred to a pre-cooled metal holder of a SW32Ti ultracentrifuge rotor (Beckman-Coulter). Tubes were spun for $30 \mathrm{~min}$ at $103.000 \mathrm{rcf}$ at $4{ }^{\circ} \mathrm{C}$, which resulted in 'cloudy' layer formation between the $1.7 \mathrm{M}$ and $1.875 \mathrm{M}$ sucrose interface (containing mostly cytoplasmic organelles, fraction 1) and between the $1.875 \mathrm{M}$ and $2.5 \mathrm{M}$ sucrose layer (containing nuclei, fraction 2). The enriched nucleus fraction 2 (typically around $4 \mathrm{~mL}$ ) was then harvested by carefully pipetting away the top layers. To reduce the sucrose molarity, $4 \mathrm{~mL}$ of ice-cold buffer 5 (20mM KHPO4 $\mathrm{pH}$ 6.45) was added to the nucleus fraction 2, mixed and spun for $4 \mathrm{~min}$ at $3460 \mathrm{rcf}$ at $4{ }^{\circ} \mathrm{C}$. The supernatant was carefully removed with a $10 \mathrm{~mL}$ pipet until ca. $2 \mathrm{~mL}$ was left to separate any remaining cell debris from the nuclear fraction. $2 \times 500 \mu \mathrm{L}$ aliquots were taken for DNA content determination as a proxy for the amount of harvested nuclei. Enriched nuclei were then immediately processed for RNA extraction (see below).

\section{RNA extraction from nuclear sucrose gradient fraction}

The enriched nucleus fraction was transferred to a fresh open-top plastic tube (Beckman-Coulter 344058) and spun for $30 \mathrm{~min}$ at $20.000 \mathrm{rcf}$ for $30 \mathrm{~min}$ in SW32Ti rotor. The pellet was resuspended in $500 \mu \mathrm{L}$ RNase-free TES buffer (10 mM TrisHCl pH 7.5, $10 \mathrm{mM}$ EDTA, 0.5\% SDS) and transferred to screwcap tubes. $500 \mu \mathrm{L}$ acid-saturated phenol was added, the mixture was vortexed and incubated for $30 \mathrm{~min}$ in a thermo block at $65^{\circ} \mathrm{C}$ (shaking at $150 \mathrm{rpm}$ ). Afterwards, the tube was put on ice for 5 min and then spun for $10 \mathrm{~min}$ at $13.000 \mathrm{rcf}$ at $4{ }^{\circ} \mathrm{C}$. The upper aqueous phase was transferred to a fresh RNase-free tube, mixed with $500 \mu \mathrm{L}$ acid-saturated phenol, vortexed and spun for $5 \mathrm{~min}$ at $13.000 \mathrm{rcf}$ at $4{ }^{\circ} \mathrm{C}$. The upper aqueous phase was transferred to a chloroform-resistant screw-cap tube, mixed with $500 \mu \mathrm{L}$ chloroform, vortexed and spun for $5 \mathrm{~min}$ at $13.000 \mathrm{rcf}$ at $4{ }^{\circ} \mathrm{C}$. The upper aqueous phase was transferred to a fresh RNase-free tube, mixed with $60 \mu \mathrm{L} 3 \mathrm{M} \mathrm{NaOAc}$ pH 5.2 and $700 \mu \mathrm{L}$ isopropanol, and incubated overnight at $-20{ }^{\circ} \mathrm{C}$. The next morning, the mixture was spun for $40 \mathrm{~min}$ at $13.000 \mathrm{rcf}$ at $4{ }^{\circ} \mathrm{C}$, the supernatant was decanted and $300 \mu \mathrm{L} 75 \% \mathrm{EtOH}$ was added, followed by centrifugation for 5 min at $13.000 \mathrm{rcf}$ at $4{ }^{\circ} \mathrm{C}$. The supernatant was removed and the pellet was air-dried for $10 \mathrm{~min}$ on ice, resuspended in nuclease-free $\mathrm{H} 2 \mathrm{O}$ and stored at $-80^{\circ} \mathrm{C}$.

\section{RNA extraction from whole cell lysates}

Cells were inoculated in a $10 \mathrm{~mL}$ pre-culture of synthetic complete media containing $2 \%$ glucose (SCD, Formedium, CSC0205), and cultured for 8-10 hrs at $25^{\circ} \mathrm{C}$. Cells were then back-diluted in $400 \mathrm{~mL}$ SCD to $\mathrm{OD}_{600} 0.006$, grown for $16-18 \mathrm{hrs}$ at $25^{\circ} \mathrm{C}$ to $\mathrm{OD}_{600} 0.8$ and harvested onto a cellulose ester membrane filter (Whatman 10400921) using a vacuum filtration pump. Cells were scraped off the membrane with a metal rod and snap-frozen in a $50 \mathrm{~mL}$ Falcon tube containing liquid nitrogen. To lyse the cells, the cell pellet was resuspended in $400 \mathrm{uL}$ TES buffer (10mM TrisHCl $\mathrm{pH} 7.5,10 \mathrm{mM}$ EDTA, 0.5\% SDS), followed by addition of $400 \mathrm{uL}$ acid-saturated phenol. The samples were incubated at $65^{\circ} \mathrm{C}$ for 1 hour 
with constant vortexing. Afterwards, the tube was put on ice for $5 \mathrm{~min}$ and then spun for $10 \mathrm{~min}$ at $13.000 \mathrm{rcf}$ at $4{ }^{\circ} \mathrm{C}$. The upper aqueous phase was transferred to a fresh RNase-free tube, mixed with 500 $\mu \mathrm{L}$ acid-saturated phenol, vortexed and spun for $5 \mathrm{~min}$ at $13.000 \mathrm{rcf}$ at $4{ }^{\circ} \mathrm{C}$. The upper aqueous phase was transferred to a chloroform-resistant screw-cap tube, mixed with $500 \mu \mathrm{L}$ chloroform, vortexed and spun for $5 \mathrm{~min}$ at $13.000 \mathrm{rcf}$ at $4{ }^{\circ} \mathrm{C}$. The upper aqueous phase was transferred to a fresh RNase-free tube, and the RNA was precipitated by adding 50uL 3M NaOAc pH5.2 and $500 \mathrm{uL}$ isopropanol to 500 uL sample, and incubated at $-20^{\circ} \mathrm{C}$ for at least 2 hours. The next morning, the mixture was spun for 30 min at $13.000 \mathrm{rcf}$ at $4{ }^{\circ} \mathrm{C}$, the supernatant was decanted and washed with $300 \mu \mathrm{L} 75 \% \mathrm{EtOH}$, followed by centrifugation for $5 \mathrm{~min}$ at $13.000 \mathrm{rcf}$ at $4^{\circ} \mathrm{C}$. The RNA pellet was eventually resuspended in nucleasefree water.

\section{RNA seq library preparation and sequencing}

For polyA selection, $150 \mathrm{ug}$ of total RNA in $200 \mathrm{uL}$ binding buffer $(10 \mathrm{mM}$ Tris- $\mathrm{HCl} \mathrm{pH}$ 7.5, 0.5 M LiCl, $6.7 \mathrm{mM}$ EDTA) was first denatured at $80^{\circ} \mathrm{C}$ for $2 \mathrm{~min}$, and immediately incubated on ice. $150 \mu \mathrm{L}$ of resuspended oligo-dT beads were first washed twice with binding buffer, then mixed with the total RNA samples, and incubated for $5 \mathrm{~min}$ at room temperature. The beads were then washed twice with washing buffer (10 mM Tris-HCl pH 7.5, $0.15 \mathrm{M} \mathrm{LiCl}, 1 \mathrm{mM}$ EDTA), then resuspended in $40 \mu \mathrm{L} 10 \mathrm{mM}$ Tris $\mathrm{pH} 7$ followed by incubation at $80^{\circ} \mathrm{C}$ for 2 min to elute the RNA. The polyA+ RNA was used to generate strand-specific sequencing libraries using the NEXTflex Rapid Directional Illumina RNA-Seq Library Prep Kit [BioO] according to the manufacturer's instructions. The libraries were sequenced on an Nextseq2000 sequencer. Reads were adaptor trimmed using cutadapt, reads were mapped using tophat2 after rRNA reads subtraction using botwtie2, and quantified using featurecount.

For nuclear extracts, spike-in reads were summed per sample, and sample normalization within a replicate was performed by calculating the spike-in ratios between Nab2-GFP (set to '1'), Nab2-GFP:Nab2 ${ }^{\Delta \mathrm{Q}-\Delta \mathrm{RGG}-}$ SV40NLS_GFP and Nab2-GFP:Nab2 ${ }^{\mathrm{F} 450 \mathrm{~A}}$-GFP. Spike-in correction of the CPM values was then performed by multiplying the spike-in ratio value of each sample with the CPM value of each gene.

\section{Protein expression and purification}

All recombinantly expressed Nab2 proteins were amplified from yeast genomic DNA of the yeast strains used in this study and cloned into pETMCN-based expression vector with a cleavable $\mathrm{N}$-terminal $6 \times$ HisTwinStrep tag plus a C-terminal mGFPA206K tags. Plasmids are listed in Supplementary Table 3. The plasmids were transformed into chemically competent E. coli BL21* under the selection of $0.1 \mathrm{mg} / \mathrm{mL}$ ampicillin. Pre-cultures were grown in $\mathrm{LB}$ at $37^{\circ} \mathrm{C}$ overnight, and diluted 1:100 into rich medium the next morning. Cells were grown at $37^{\circ} \mathrm{C}$ to an $\mathrm{OD}_{600}$ of 0.6 and induced with final $200 \mathrm{mM}$ IPTG. Cells were then grown overnight at $18{ }^{\circ} \mathrm{C}$, collected and resuspended in $30 \mathrm{ml}$ lysis buffer $(500 \mathrm{mM} \mathrm{NaCl}, 25$ $\mathrm{mM}$ Tris- $\mathrm{HCl} \mathrm{pH} 7.5,10 \mathrm{mM}$ imidazole, $10 \%$ glycerol, protease inhibitors) per cell pellet from 2L of culture. After cell lysis by EmulsiFlex (Avestin), the $6 \times$ His-tagged proteins were affinity extracted with $\mathrm{Ni2}+$ sepharose in small columns, supplemented with prescission (3C) protease for cleavage of the 6xHis-TwinStrep tag, and dialysed into storage buffer $(200 \mathrm{mM} \mathrm{NaCl}, 25 \mathrm{mM}$ Tris- $\mathrm{HCl} \mathrm{pH}$ 7.5, $10 \mathrm{mM}$ imidazole, $5 \%$ glycerol). The next day, protein solutions were further concentrated and purified by size exclusion with a Superdex 200 column on an AEKTA purifier (GE Life Sciences) in the final storage buffer (200 mM NaCl, $25 \mathrm{mM}$ Tris- $\mathrm{HCl}$ pH 7.5, $10 \mathrm{mM}$ imidazole, 5\% glycerol). Protein expression levels, His eluates and gel filtration fractions were analysed by SDS-PAGE. Clean Superdex elution fractions were pooled, concentrated to approximately $500 \mu \mathrm{M}$ using Millipore Amicon Centrifugation units, snap frozen as $20 \mu \mathrm{L}$ aliquots in siliconized tubes in liquid nitrogen and stored at $-80^{\circ} \mathrm{C}$. Dbp $5 \Delta \mathrm{N}$ constructs were purified according to the same protocol. 


\section{In vitro droplet formation assay}

A) Nab2-GFP wild-type and mutant experimental setup:

Protein droplets were set up according to (Hondele et al., 2019). In brief, reactions were pipetted in 384-well microscopy plates (Brooks, Matrical MGB101-1-2-LG-L). $2 \mu \mathrm{L}$ recombinant GFP-tagged protein (stock $195 \mu \mathrm{M}$ to a final concentration of $23 \mu \mathrm{M}$ ) was mixed at room temperature with $15 \mu \mathrm{L}$ of a master mix $(10.875 \mu \mathrm{L}$ low-salt buffer (LSB; variable: LSB-100 $(100 \mathrm{mM} \mathrm{KCl,} 30 \mathrm{mM}$ HEPES$\mathrm{KOH}$ pH 7.4, $2 \mathrm{mM} \mathrm{MgCl}$ ) or LSB-150 (150 mM KCl, $30 \mathrm{mM}$ HEPES-KOH pH 7.4, $2 \mathrm{mM} \mathrm{MgCl}$ )), $0.675 \mu \mathrm{L} \mathrm{CKM} \mathrm{reconstitution} \mathrm{mix} \mathrm{(40} \mathrm{mM} \mathrm{ATP,} 40 \mathrm{mM} \mathrm{MgCl}_{2}, 200 \mathrm{mM}$ creatine phosphate, $70 \mathrm{U}$ ml-1 creatine kinase), $1.35 \mu \mathrm{L} \mathrm{ATP} / \mathrm{MgCl} 2(100 \mathrm{mM}), 0.675 \mu \mathrm{L}$ BSA $(10 \mathrm{mg} \mathrm{mL}-1), 0.675 \mu \mathrm{L}$ poly(A) RNA (1 mg mL-1), 0.675 $\mu \mathrm{L}$ 1M HEPES (variable: pH 6.6/6.8/7.0/7.2/7.4), 0.075 $\mu \mathrm{L}$ RNasin Plus (Promega). For final concentration of $11.5 \mu \mathrm{L}, 1 \mu \mathrm{L}$ Nab2-GFP (from $195 \mu \mathrm{M}$ stock) was mixed with $16 \mu \mathrm{L}$ of the aforementioned master mix. For final concentration of $34.5 \mu \mathrm{L}, 3 \mu \mathrm{L}$ Nab2-GFP (from $195 \mu \mathrm{M}$ stock) was mixed with $14 \mu \mathrm{L}$ of the aforementioned master mix.

Droplets were imaged 20-30 min after setup at $25^{\circ} \mathrm{C}$. Microscopy was performed using an inverted epi-fluorescence microscope (Nikon Ti) equipped with a Spectra X LED light source and a Hamamatsu Flash 4.0 sCMOS camera using a 100X Plan-Apo objective NA 1.4 and NIS Elements software. Images were processed using FIJI software.

B) Nab2+Dbp5 experimental setup:

$2 \mu \mathrm{l}$ of a $100 \mu \mathrm{M}$ Nab2 solution was mixed with a total of $3 \mu \mathrm{l} \operatorname{Dbp} 5 \Delta \mathrm{N}$ protein (WT or mutant) mixed with Dbp5 storage buffer $(200 \mathrm{mM} \mathrm{NaCl}, 25 \mathrm{mM}$ Tris $\mathrm{pH} 7.5,5 \%$ glycerol) to achieve the final concentration as indicated. The final volume of $5 \mu \mathrm{l}$ protein solution was mixed with $20 \mu \mathrm{L}$ master mix (16 $\mu \mathrm{L}$ LSB100 buffer $(100 \mathrm{mM} \mathrm{KCl,} 30 \mathrm{mM}$ HEPES-KOH pH 7.4, $2 \mathrm{mM} \mathrm{MgCl}$ ), $1 \mu \mathrm{L}$ $10 \mathrm{mg} / \mathrm{ml} \mathrm{BSA}, 1 \mu \mathrm{L} 100 \mathrm{mM}$ ATP / 100 mM MgCl, $1 \mu \mathrm{l}$ HEPES-KOH pH 6.2, $1 \mu \mathrm{L}$ poly(A) 1 $\mathrm{mg} / \mathrm{mL}$ ). Reactions were incubated for 10 minutes at room temperature and images recorded as described above.

\section{Acknowledgements}

We thank S. Wente and A. Corbett for providing yeast strains and plasmids, ScopeM and J. Kusch for microscopy support, L. Malinovska for experimental assistance and discussions, and the Weis lab for critical comments on the manuscript. This work was supported by an EMBO long-term fellowship to S.H. and M.H. (ALTF 290-2014, EMBOCOFUND2012, GA-2012-600394 to S.H.; ALTF 870-2014 to M.H.). M.H. was supported by a Human Frontier Science Program (HFSP) postdoctoral fellowship (LT000914/2015) and an ETH postdoctoral fellowship (FEL-37-14-2). This work was supported by the Swiss National Science Foundation (SNF 31003A_179275 and CRSII5_193740 to K.W.).

\section{Competing Interest Statement}

The authors have declared no competing interest.

\section{Author contributions}

Conceptualization, S.H., M.H. and K.W.; Methodology, S.H., M.H., D.G. and K.W.; Investigation, S.H., M.H., C.P.D., D.M., M.Z., R.M.; Formal analysis, S.H., M.Z., A.O., F.U.; Writing - Original Draft, S.H.; Writing - Review \& Editing, S.H., M.H., D.M., M.Z., R.M., A.O., F.U. and K.W.; Funding Acquisition, S.H., M.H. and K.W.; Resources, K.W.; Supervision, S.H. and K.W. 


\section{References}

Adams, R.L., and Wente, S.R. (2020). Dbp5 associates with RNA-bound Mex67 and Nab2 and its localization at the nuclear pore complex is sufficient for mRNP export and cell viability. PLOS Genet. 16, e1009033.

Aibara, S., Gordon, J.M.B., Riesterer, A.S., McLaughlin, S.H., and Stewart, M. (2017). Structural basis for the dimerization of Nab2 generated by RNA binding provides insight into its contribution to both poly(A) tail length determination and transcript compaction in Saccharomyces cerevisiae. Nucleic Acids Res. 45, 1529-1538.

Alcázar-Román, A.R., Tran, E.J., Guo, S., and Wente, S.R. (2006). Inositol hexakisphosphate and Gle1 activate the DEAD-box protein Dbp5 for nuclear mRNA export. Nat. Cell Biol. 8, 711-716.

Alpert, T., Straube, K., Oesterreich, F.C., and Neugebauer, K.M. (2020). Widespread Transcriptional Readthrough Caused by Nab2 Depletion Leads to Chimeric Transcripts with Retained Introns. Cell Rep. 33.

Anderson, J.T., Wilson, S.M., Datar, K.V., and Swanson, M.S. (1993). NAB2: a yeast nuclear polyadenylated RNA-binding protein essential for cell viability. Mol. Cell. Biol. 13, 2730-2741.

Aris, J.P., and Blobel, G. (1991). Isolation of yeast nuclei. In Methods in Enzymology. 194, 735-749.

Ashkenazy-Titelman, A., Shav-Tal, Y., and Kehlenbach, R.H. (2020). Into the basket and beyond: the journey of mRNA through the nuclear pore complex. Biochem. J. 477, 23-44.

Bahar Halpern, K., Caspi, I., Lemze, D., Levy, M., Landen, S., Elinav, E., Ulitsky, I., and Itzkovitz, S. (2015). Nuclear Retention of mRNA in Mammalian Tissues. Cell Rep. 13, 2653-2662

Banani, S.F., Lee, H.O., Hyman, A.A., and Rosen, M.K. (2017). Biomolecular condensates: organizers of cellular biochemistry. Nat. Rev. Mol. Cell Biol. 18, 285-298.

Bancaud, A., Huet, S., Rabut, G., and Ellenberg, J. (2010). Fluorescence Perturbation Techniques to Study Mobility and Molecular Dynamics of Proteins in Live Cells: FRAP, Photoactivation, Photoconversion, and FLIP. Cold Spring Harb. Protoc. 2010, pdb.top90.

De Magistris, P. (2021). The Great Escape: mRNA Export through the Nuclear Pore Complex. Int. J. Mol. Sci. 22, 11767.

Dechant, R., Saad, S., Ibáñez, A.J., and Peter, M. (2014). Cytosolic pH Regulates Cell Growth through Distinct GTPases, Arf1 and Gtr1, to Promote Ras/PKA and TORC1 Activity. Mol. Cell 55, 409-421.

Derrer, C.P., Mancini, R., Vallotton, P., Huet, S., Weis, K., and Dultz, E. (2019). The RNA export factor Mex67 functions as a mobile nucleoporin. J. Cell Biol. 218 (12), 3967-3976

Fasken, M.B., Corbett, A.H., and Stewart, M. (2019). Structure-function relationships in the Nab2 polyadenosine-RNA binding Zn finger protein family. Protein Sci. 28, 513-523.

Green, D.M., Johnson, C.P., Hagan, H., and Corbett, A.H. (2003). The C-terminal domain of myosinlike protein $1(\mathrm{Mlp} 1 \mathrm{p})$ is a docking site for heterogeneous nuclear ribonucleoproteins that are required for mRNA export. Proc. Natl. Acad. Sci. 100, 1010-1015.

Hector, R.E., Nykamp, K.R., Dheur, S., Anderson, J.T., Non, P.J., Urbinati, C.R., Wilson, S.M., Minvielle-Sebastia, L., and Swanson, M.S. (2002). Dual requirement for yeast hnRNP Nab2p in mRNA poly(A) tail length control and nuclear export. EMBO J. 21, 1800-1810. 
Herzel, L., Ottoz, D.S.M., Alpert, T., and Neugebauer, K.M. (2017). Splicing and transcription touch base: co-transcriptional spliceosome assembly and function. Nat. Rev. Mol. Cell Biol. 18, 637-650.

Hilliker, A., Gao, Z., Jankowsky, E., and Parker, R. (2011). The DEAD-Box Protein Ded1 Modulates Translation by the Formation and Resolution of an eIF4F-mRNA Complex. Mol. Cell 43, 962-972.

Hochberg-Laufer, H., Schwed-Gross, A., Neugebauer, K.M., and Shav-Tal, Y. (2019). Uncoupling of nucleo-cytoplasmic RNA export and localization during stress. Nucleic Acids Res. 47, 4778-4797.

Hodge, C.A., Colot, H.V., Stafford, P., and Cole, C.N. (1999). Rat8p/Dbp5p is a shuttling transport factor that interacts with Rat7p/Nup159p and Gle1p and suppresses the mRNA export defect of xpo11 cells. EMBO J. 18, 5778-5788.

Hondele, M., Sachdev, R., Heinrich, S., Wang, J., Vallotton, P., Fontoura, B.M.A., and Weis, K. (2019). DEAD-box ATPases are global regulators of phase-separated organelles. Nature. 573 (7772), 144-148

Huang, D.W., Sherman, B.T., Tan, Q., Collins, J.R., Alvord, W.G., Roayaei, J., Stephens, R., Baseler, M.W., Lane, H.C., and Lempicki, R.A. (2007). The DAVID Gene Functional Classification Tool: a novel biological module-centric algorithm to functionally analyze large gene lists. Genome Biol. 8 , R183.

Iserman, C., Desroches Altamirano, C., Jegers, C., Friedrich, U., Zarin, T., Fritsch, A.W., Mittasch, M., Domingues, A., Hersemann, L., Jahnel, M., et al. (2020). Condensation of Ded1p Promotes a Translational Switch from Housekeeping to Stress Protein Production. Cell 181, 818-831.e19.

Izaurralde, E., Lewis, J., McGuigan, C., Jankowska, M., Darzynkiewicz, E., and Mattaj, I.W. (1994). A nuclear cap binding protein complex involved in pre-mRNA splicing. Cell 78, 657-668.

Izawa, S., Takemura, R., Ikeda, K., Fukuda, K., Wakai, Y., and Inoue, Y. (2005). Characterization of Rat8 localization and mRNA export in Saccharomyces cerevisiae during the brewing of Japanese sake. Appl. Microbiol. Biotechnol. 69, 86-91.

Joyner, R.P., Tang, J.H., Helenius, J., Dultz, E., Brune, C., Holt, L.J., Huet, S., Müller, D.J., and Weis, K. (2016). A glucose-starvation response regulates the diffusion of macromolecules. ELife 5, e09376.

Katahira, J. (2012). mRNA export and the TREX complex. Biochim. Biophys. Acta BBA - Gene Regul. Mech. 1819, 507-513.

Khong, A., Matheny, T., Jain, S., Mitchell, S.F., Wheeler, J.R., and Parker, R. (2017). The Stress Granule Transcriptome Reveals Principles of mRNA Accumulation in Stress Granules. Mol. Cell 68, 808-820

Kroschwald, S., Maharana, S., Mateju, D., Malinovska, L., Nüske, E., Poser, I., Richter, D., and Alberti, S. (2015). Promiscuous interactions and protein disaggregases determine the material state of stress-inducible RNP granules. ELife 4, e06807.

Larson, D.R., Zenklusen, D., Wu, B., Chao, J.A., and Singer, R.H. (2011). Real-Time Observation of Transcription Initiation and Elongation on an Endogenous Yeast Gene. Science 332, 475-478.

Laughery, M.F., Hunter, T., Brown, A., Hoopes, J., Ostbye, T., Shumaker, T., and Wyrick, J.J. (2015). New vectors for simple and streamlined CRISPR-Cas9 genome editing in Saccharomyces cerevisiae. Yeast Chichester Engl. 32, 711-720.

Li, X., Romero, P., Rani, M., Dunker, A.K., and Obradovic, Z. (1999). Predicting Protein Disorder for N-, C-, and Internal Regions. Genome Inform. Workshop Genome Inform. 10, 30-40. 
Longtine, M.S., Mckenzie III, A., Demarini, D.J., Shah, N.G., Wach, A., Brachat, A., Philippsen, P., and Pringle, J.R. (1998). Additional modules for versatile and economical PCR-based gene deletion and modification in Saccharomyces cerevisiae. Yeast 14, 953-961.

Marfatia, K.A., Crafton, E.B., Green, D.M., and Corbett, A.H. (2003). Domain Analysis of the Saccharomyces cerevisiae Heterogeneous Nuclear Ribonucleoprotein, Nab2p dissecting the requirements for Nab2p-facilitated Poly(A) RNA export. J. Biol. Chem. 278, 6731-6740.

Mauger, O., Lemoine, F., and Scheiffele, P. (2016). Targeted Intron Retention and Excision for Rapid Gene Regulation in Response to Neuronal Activity. Neuron 92, 1266-1278.

Montpetit, B., Thomsen, N.D., Helmke, K.J., Seeliger, M.A., Berger, J.M., and Weis, K. (2011). A conserved mechanism of DEAD-box ATPase activation by nucleoporins and InsP6 in mRNA export. Nature 472, 238-242.

Mugler, C.F., Hondele, M., Heinrich, S., Sachdev, R., Vallotton, P., Koek, A.Y., Chan, L.Y., and Weis, K. (2016). ATPase activity of the DEAD-box protein Dhh1 controls processing body formation. ELife $5, \mathrm{e} 18746$.

Niepel, M., Farr, J.C., Rout, M.P., and Strambio-De-Castillia, C. (2017). Rapid isolation of functionally intact nuclei from the yeast Saccharomyces. BioRxiv 162388.

Nishimura, K., Fukagawa, T., Takisawa, H., Kakimoto, T., and Kanemaki, M. (2009). An auxin-based degron system for the rapid depletion of proteins in nonplant cells. Nat. Methods 6, 917-922.

Noble, K.N., Tran, E.J., Alcázar-Román, A.R., Hodge, C.A., Cole, C.N., and Wente, S.R. (2011). The Dbp5 cycle at the nuclear pore complex during mRNA export II: nucleotide cycling and mRNP remodeling by Dbp5 are controlled by Nup159 and Gle1. Genes Dev. 25, 1065-1077.

Orij, R., Postmus, J., Beek, A.T., Brul, S., and Smits, G.J. (2009). In vivo measurement of cytosolic and mitochondrial $\mathrm{pH}$ using a $\mathrm{pH}$-sensitive GFP derivative in Saccharomyces cerevisiae reveals a relation between intracellular $\mathrm{pH}$ and growth. Microbiology 155, 268-278.

Pühringer, T., Hohmann, U., Fin, L., Pacheco-Fiallos, B., Schellhaas, U., Brennecke, J., and Plaschka, C. (2020). Structure of the human core transcription-export complex reveals a hub for multivalent interactions. ELife 9, e61503.

Rajoo, S., Vallotton, P., Onischenko, E., and Weis, K. (2018). Stoichiometry and compositional plasticity of the yeast nuclear pore complex revealed by quantitative fluorescence microscopy. Proc. Natl. Acad. Sci. 201719398.

Rambout, X., and Maquat, L.E. (2020). The nuclear cap-binding complex as choreographer of gene transcription and pre-mRNA processing. Genes Dev. 34, 1113-1127.

Riback, J.A., Katanski, C.D., Kear-Scott, J.L., Pilipenko, E.V., Rojek, A.E., Sosnick, T.R., and Drummond, D.A. (2017). Stress-Triggered Phase Separation Is an Adaptive, Evolutionarily Tuned Response. Cell 168, 1028-1040.e19.

Roden, C., and Gladfelter, A.S. (2021). RNA contributions to the form and function of biomolecular condensates. Nat. Rev. Mol. Cell Biol. 22, 183-195.

Romero, P., Obradovic, Z., and Dunker, A.K. (1997). Sequence Data Analysis for Long Disordered Regions Prediction in the Calcineurin Family. Genome Inform. Workshop Genome Inform. 8, 110-124. 
Schmid, M., Poulsen, M.B., Olszewski, P., Pelechano, V., Saguez, C., Gupta, I., Steinmetz, L.M., Moore, C., and Jensen, T.H. (2012). Rrp6p Controls mRNA Poly(A) Tail Length and Its Decoration with Poly(A) Binding Proteins. Mol. Cell 47, 267-280.

Schmid, M., Olszewski, P., Pelechano, V., Gupta, I., Steinmetz, L.M., and Jensen, T.H. (2015). The Nuclear PolyA-Binding Protein Nab2p Is Essential for mRNA Production. Cell Rep. 12(1), 128-139.

Sheth, U., and Parker, R. (2003). Decapping and Decay of Messenger RNA Occur in Cytoplasmic Processing Bodies. Science 300, 805-808.

Shi, Y., and Manley, J.L. (2015). The end of the message: multiple protein-RNA interactions define the mRNA polyadenylation site. Genes Dev. 29, 889-897.

Shin, Y., and Brangwynne, C.P. (2017). Liquid phase condensation in cell physiology and disease. Science 357(6357), eaaf4382.

Singh, G., Pratt, G., Yeo, G.W., and Moore, M.J. (2015). The Clothes Make the mRNA: Past and Present Trends in mRNP Fashion. Annu. Rev. Biochem. 84, 325-354.

Smith, C., Lari, A., Derrer, C.P., Ouwehand, A., Rossouw, A., Huisman, M., Dange, T., Hopman, M., Joseph, A., Zenklusen, D., et al. (2015). In vivo single-particle imaging of nuclear mRNA export in budding yeast demonstrates an essential role for Mex67p. J. Cell Biol. 211, 1121-1130.

Snay-Hodge, C.A., Colot, H.V., Goldstein, A.L., and Cole, C.N. (1998). Dbp5p/Rat8p is a yeast nuclear pore-associated DEAD-box protein essential for RNA export. EMBO J. 17, 2663-2676.

Soniat, M., Sampathkumar, P., Collett, G., Gizzi, A.S., Banu, R.N., Bhosle, R.C., Chamala, S., Chowdhury, S., Fiser, A., Glenn, A.S., et al. (2013). Crystal structure of human Karyopherin $\beta 2$ bound to the PY-NLS of Saccharomyces cerevisiae Nab2. J. Struct. Funct. Genomics 14, 31-35.

Soucek, S., Zeng, Y., Bellur, D.L., Bergkessel, M., Morris, K.J., Deng, Q., Duong, D., Seyfried, N.T., Guthrie, C., Staley, J.P., et al. (2016). Evolutionarily Conserved Polyadenosine RNA Binding Protein Nab2 Cooperates with Splicing Machinery To Regulate the Fate of Pre-mRNA. Mol. Cell. Biol. 36, 2697-2714.

Stade, K., Ford, C.S., Guthrie, C., and Weis, K. (1997). Exportin 1 (Crm1p) Is an Essential Nuclear Export Factor. Cell 90, 1041-1050.

Sträßer, K., and Hurt, E. (2001). Splicing factor Sub2p is required for nuclear mRNA export through its interaction with Yra1p. Nature 413, 648-652.

Strässer, K., Masuda, S., Mason, P., Pfannstiel, J., Oppizzi, M., Rodriguez-Navarro, S., Rondón, A.G., Aguilera, A., Struhl, K., Reed, R., et al. (2002). TREX is a conserved complex coupling transcription with messenger RNA export. Nature 417, 304-308.

Takemura, R., Inoue, Y., and Izawa, S. (2004). Stress response in yeast mRNA export factor: reversible changes in Rat8p localization are caused by ethanol stress but not heat shock. J. Cell Sci. 117, 41894197.

Tauber, D., Tauber, G., Khong, A., Treeck, B.V., Pelletier, J., and Parker, R. (2020). Modulation of RNA Condensation by the DEAD-Box Protein eIF4A. Cell 180(3), 411-426.

Teixeira, D., and Parker, R. (2007). Analysis of P-Body Assembly in Saccharomyces cerevisiae. Mol. Biol. Cell 18, 2274-2287. 
Tipper, D.J. (1973). Inhibition of Yeast Ribonucleic Acid Polymerases by Thiolutin. J. Bacteriol. 116(1), 245-56

Tran, E.J., Zhou, Y., Corbett, A.H., and Wente, S.R. (2007). The DEAD-Box Protein Dbp5 Controls mRNA Export by Triggering Specific RNA:Protein Remodeling Events. Mol. Cell 28, 850-859.

Tuck, A.C., and Tollervey, D. (2013). A Transcriptome-wide Atlas of RNP Composition Reveals Diverse Classes of mRNAs and lncRNAs. Cell 154, 996-1009.

Vallotton, P., Rajoo, S., Wojtynek, M., Onischenko, E., Kralt, A., Derrer, C.P., and Weis, K. (2019). Mapping the native organization of the yeast nuclear pore complex using nuclear radial intensity measurements. Proc. Natl. Acad. Sci. 116, 14606-14613.

Wegener, M., and Müller-McNicoll, M. (2019). View from an mRNP: The Roles of SR Proteins in Assembly, Maturation and Turnover. In: Oeffinger M., Zenklusen D. (eds) The Biology of mRNA: Structure and Function. Advances in Experimental Medicine and Biology, vol 1203. Springer, Cham. https://doi.org/10.1007/978-3-030-31434-7_3.

Weirich, C.S., Erzberger, J.P., Flick, J.S., Berger, J.M., Thorner, J., and Weis, K. (2006). Activation of the $\mathrm{DExD} / \mathrm{H}$-box protein Dbp5 by the nuclear-pore protein Gle1 and its coactivator InsP6 is required for mRNA export. Nat. Cell Biol. 8, 668-676.

Yang, P., Mathieu, C., Kolaitis, R.-M., Zhang, P., Messing, J., Yurtsever, U., Yang, Z., Wu, J., Li, Y., Pan, Q., et al. (2020). G3BP1 Is a Tunable Switch that Triggers Phase Separation to Assemble Stress Granules. Cell 181, 325-345.e28. 


\section{Figure legends}

\section{1) Acute Dbp5 depletion causes nuclear mRNA accumulation and Nab2 condensation}

A) Schematic representation of the auxin-inducible protein depletion tool and the single RNA visualization in vivo. (upper) Upon addition of Auxin, degron-tagged Dbp5 gets recognized by TIR1 and targeted for proteasomal degradation (Nishimura et al., 2009). (lower) 24 PP7 stem loops (PP7sl) are integrated after the STOP codon of a low-copy number gene of interest. A second locus drives the expression of GFP-tagged PP7 coat protein (PP7CP-GFP) that can bind to PP7sl with high affinity, thereby allowing single RNA visualization (Larson et al., 2011).

B) Cells expressing GFA1-PP7sl, PP7CP-GFP, the nuclear rim marker Ndc1-mKate and the Dbp5degron with or without TIR1 are treated for $1 \mathrm{hr}$ with auxin (IAA) before imaging using a custom-built microscope (Smith et al., 2015). Scale bar $5 \mu \mathrm{m}$.

C) Quantification of mean squared displacement (MSD) of PP7-labeled GFA1 mRNA in cells from B). Images were taken every $15 \mathrm{~ms}$. Shown are means \pm SD of three biological replicates with $\geq 265$ RNA particles per condition.

D) FRAP of Nab2-GFP cells expressing the Dbp5-degron with or without TIR1 treated for $2 \mathrm{hr}$ with auxin (IAA). FRAP curves are normalized to prebleach and postbleach values. Mean curves \pm SEM of three biological replicates with $\geq 16$ cells per replicate are shown.

E) Half time of recovery retrieved from fitting individual FRAP curves from D) with a single component model. Shown are means \pm SEM of three biological replicates. ${ }^{*} \mathrm{p}=0.028$, unpaired t-test.

F) Representative FRAP images of a single nucleus from D)

G) FRAP of Nab2-GFP cells expressing either only the Dbp5-degron or both the Dbp5-degron and the Rpb2-degron with or without TIR1 treated for $2 \mathrm{hr}$ with auxin (IAA). FRAP curves are normalized to prebleach and postbleach values. Mean curves \pm SEM of three biological replicates with $\geq 15$ cells per replicate are shown.

$\mathrm{H})$ Half time of recovery retrieved from fitting individual FRAP curves from $G$ ) with a single component model. Shown are means \pm SEM of three biological replicates. ${ }^{*} \mathrm{p}=0.0271$ (TIR1(+Dbp5) vs. +TIR1(-Dbp5), * p=0.0232 +TIR1(-Dbp5) vs. +TIR1(-Dbp5, -Rbp2), ns $\mathrm{p}=0.6109((-\mathrm{TIR} 1(+\mathrm{Dbp} 5)$ vs. + TIR1 $(-\mathrm{Dbp} 5,-\mathrm{Rbp} 2))$, unpaired t-test.

\section{2) Nab2 phase-separates in vitro, which gets reverted by active Dbp5}

A) Recombinant Nab2-GFP droplets were formed in LSB150 buffer to a final $\mathrm{KCl}$ concentration of $94 \mathrm{mM}$ in the presence or absence of $0.04 \mathrm{mg} / \mathrm{mL}$ poly(A) RNA and imaged at $25^{\circ} \mathrm{C} 30 \mathrm{~min}$ after setup. Scale bar $10 \mu \mathrm{m}$.

B) Recombinant Nab2-GFP droplets were formed in LSB100 or LSB150 buffers to a final $\mathrm{KCl}$ concentration of 63 or $94 \mathrm{mM}$, respectively, at the indicated $\mathrm{pH}$ in the presence of $0.04 \mathrm{mg} / \mathrm{mL}$ poly(A) RNA and imaged at $25^{\circ} \mathrm{C} 30$ min after setup. Scale bar $10 \mu \mathrm{m}$.

C) Representative images and phase diagram of recombinant Nab2-GFP droplets, which were formed in LSB150 buffer (to a final $\mathrm{KCl}$ concentration of $94 \mathrm{mM}$ ) containing the indicated single-nucleoside polymers and imaged at $25^{\circ} \mathrm{C} 20$ min after setup. Scale bar $5 \mu \mathrm{m}$.

D) Recombinant Nab2-GFP droplets were formed without Dbp5 or in the presence of increasing amounts of Dbp $5 \Delta \mathrm{N} 90$ or the ATPase-locked Dbp5- $\Delta \mathrm{N} 90-\mathrm{DQAD}$ and imaged at $25{ }^{\circ} \mathrm{C} 30 \mathrm{~min}$ after setup. Nab2 $9 \mu \mathrm{M}$ in LSB100 (final $63 \mathrm{mM} \mathrm{KCl}$ ), $0.04 \mathrm{mg} / \mathrm{mL}$ poly(A) RNA, Dbp5 concentrations 14/27/39 $\mu \mathrm{M}$. Scale bar $10 \mu \mathrm{m}$. 
3) Glucose stress causes reduction of nuclear $\mathrm{Nab} 2$ dynamics and bulk nuclear RNA retention

A) Cells expressing Dbp5-GFP and dsRed-HDEL were grown in medium + DEX or acutely shifted for 30 min or 24 hrs into medium without DEX. Scale bar $5 \mu \mathrm{m}$.

B) Quantification of Dbp5-GFP intensity at the nuclear envelope by NuRIM in the conditions shown in A). Shown are means \pm SEM of three biological replicates. At least 350 cells were analyzed per condition and replicate. Dbp5: $* * \mathrm{p}=0.0082(+\mathrm{DEX}$ vs. $30 \mathrm{~min}-\mathrm{DEX}),{ }^{*} \mathrm{p}=0.022$ (+DEX vs. 24 hrs -DEX), unpaired t-test.

C) RNA FISH against poly(A) using an oligo(dT)30 probe was performed in fixed cells expressing Nab2-GFP. Samples were taken in +DEX or after acute starvation in medium without DEX for 30 min. Insets show single nucleus (2.16x magnification). White arrows indicate Nab2-GFP focus. Scale bar $5 \mu \mathrm{m}$.

D) RNA FISH against poly(A) RNA using an oligo(dT)30 probe was performed in fixed cells expressing Nab2-GFP. Samples were taken in +DEX or after acute starvation in medium without DEX for $24 \mathrm{hrs}$. Insets show single nucleus (2.16x magnification). White arrows indicate Nab2-GFP focus. Scale bar $5 \mu \mathrm{m}$.

E) FRAP of Nab2-GFP cells in +DEX or $30 \mathrm{~min}$-DEX. FRAP curves are normalized to prebleach and postbleach values. Mean curves \pm SEM of three biological replicates with $\geq 15$ cells per replicate are shown.

F) Half time of recovery retrieved from fitting individual FRAP curves from E) with a single component model. Shown are means \pm SEM of three biological replicates. ${ }^{*} \mathrm{p}=0.04$, unpaired t-test.

G) FRAP of Nab2-GFP cells in +DEX or $24 \mathrm{hrs}$-DEX. FRAP curves are normalized to prebleach and postbleach values. Mean curves \pm SEM of three biological replicates with $\geq 15$ cells per replicate are shown.

H) Half time of recovery retrieved from fitting individual FRAP curves from $G$ ) with a single component model. Shown are means \pm SEM of three biological replicates. ${ }^{*} \mathrm{p}=0.01$, unpaired t-test.

I) Representative images of Nab2-GFP cells in wild type (WT) or Dbp5- ${ }^{\Delta N}$ Nup159 ('Dbp5 tether') background in +DEX or 24 hrs -DEX. Scale bar $5 \mu \mathrm{m}$.

J) FRAP of cells in I). FRAP curves are normalized to prebleach and postbleach values. Mean curves \pm SEM of three biological replicates with $\geq 15$ cells per replicate are shown.

K) Half time of recovery retrieved from fitting individual FRAP curves from $J$ ) with a single component model. Shown are means \pm SEM of three biological replicates. ns $p=0.4425$, * $\mathrm{p}=0.0425,{ }^{* *} \mathrm{p}=0.0067$ (wild type $24 \mathrm{hrs}-\mathrm{DEX}$ vs. Dbp5 $-{ }^{\Delta \mathrm{N}} \mathrm{Nup} 159+\mathrm{DEX}$ ), ${ }^{* *} \mathrm{p}=0.0032$ (Dbp5 $-^{\Delta \mathrm{N}} \mathrm{Nup} 159+\mathrm{DEX}$ vs. 24 hrs $-\mathrm{DEX}$ ), unpaired t-test.

\section{4) Nab2 dimerization, but not RGG domain function, drives condensation in vitro}

A) GFP-tagged recombinant Nab2 wild type or Nab2 mutant droplets were formed in LSB150 buffer to a final $\mathrm{KCl}$ concentration of $94 \mathrm{mM}$ at the indicated $\mathrm{pH}$ in the presence of $0.04 \mathrm{mg} / \mathrm{mL}$ polyA RNA and imaged at $25{ }^{\circ} \mathrm{C} 30 \mathrm{~min}$ after setup. Right side: phase diagram of droplet formation at $\mathrm{pH} 6.8$ with the indicated protein and RNA concentrations. Scale bar $10 \mu \mathrm{m}$.

B) FRAP of $20 \mu \mathrm{M} \mathrm{Nab2-GFP}$ and Nab2 $2^{\Delta Q-\Delta R G G-S V 40 N L S}$-GFP droplets $30 \mathrm{~min}$ after setup with 0.04 $\mathrm{mg} / \mathrm{mL}$ polyA RNA. FRAP curves are normalized to prebleach and postbleach values. Mean curves \pm SEM of three biological replicates with $\geq 14$ droplets per replicate are shown.

C) Representative images of GFP-tagged Nab2 wild type and mutant cells in +DEX conditions and after acute shift and incubation for $24 \mathrm{hrs}$ in -DEX. Scale bar $5 \mu \mathrm{m}$. 
D-F) FRAP of cells shown in C). D) Nab2-GFP, E) Nab2 $\left.2^{\Delta Q-\Delta R G G-S V 40 N L S}-G F P, F\right)$ Nab2 ${ }^{\text {F450A }}$-GFP. FRAP curves are normalized to prebleach and postbleach values. Mean curves \pm SEM of three biological replicates with $\geq 15$ cells per replicate are shown.

G) Half time of recovery retrieved from fitting individual FRAP curves from D-F) with a single component model. Shown are means \pm SEM of three biological replicates. ${ }^{*} \mathrm{p}=0.0155, * *$ $\mathrm{p}=0.0082$, ns $\mathrm{p}=0.3694$, unpaired t-test.

\section{5) The degree of $\mathrm{Nab} 2$ condensation determines the level of nuclear mRNA retention}

A) RNA FISH against poly(A) RNA using an oligo(dT)30 probe was performed in fixed cells expressing Nab2-GFP, Nab2 ${ }^{\Delta \mathrm{Q}-\Delta \mathrm{RGG}-\mathrm{SV} 40 \mathrm{NLS}}$-GFP or Nab2 $2^{\mathrm{F} 450 \mathrm{~A}}$-GFP. Samples were taken in + DEX or after acute starvation in medium without DEX for 24 hrs. Insets show single nucleus (2.16x magnification). Scale bar $5 \mu \mathrm{m}$.

B) Quantification of nuclear poly(A) RNA signal intensity in $24 \mathrm{hrs}-\mathrm{DEX}$ condition in A). Data is normalized to Nab2-GFP. Shown are means \pm SEM of five biological replicates, $n>100$ cells per replicate. ${ }^{* *} \mathrm{p}=0.003\left(\mathrm{Nab} 2-\mathrm{GFP}\right.$ vs. Nab2 ${ }^{\Delta \mathrm{Q}-\Delta \mathrm{RGG}-\mathrm{SV} 40 \mathrm{NLS}}$-GFP), ${ }^{* *} \mathrm{p}=0.0023$ (Nab2-GFP vs. $\left.\mathrm{Nab2}{ }^{\mathrm{F} 450 \mathrm{~A}}-\mathrm{GFP}\right),{ }^{* *} \mathrm{p}=0.0011\left(\mathrm{Nab2}{ }^{\mathrm{\Delta Q}-\Delta \mathrm{RGG}-\mathrm{SV} 40 \mathrm{NLS}}-\mathrm{GFP}\right.$ vs. Nab2 $\left.{ }^{\mathrm{F} 450 \mathrm{~A}}-\mathrm{GFP}\right)$, unpaired t-test.

C) Plot of ratios of nuclear RNA sequencing reads (CPM, counts per million). Single dots represent individual genes. Inset shows most abundant reads (blue dots, >500 CPM in Nab2-GFP). Boxes

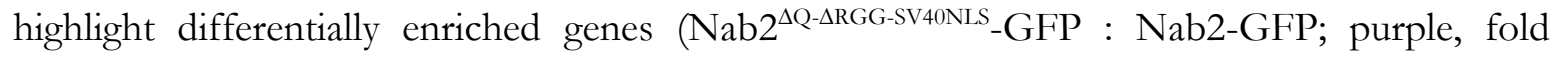
change ratio $>1.5)$ and not differentially enriched genes (Nab2 ${ }^{\Delta Q-\Delta R G G-S V 40 N L S}$-GFP : Nab2-GFP; grey, fold change ratio $<1.2)$.

D) Gene ontology (GO) term analysis of most abundant reads (blue dots) from C) using DAVID Functional Annotation Clustering tool (Huang et al., 2007).

6) Nab2 condensation confers selective mRNA retention in vivo during stress

A) RNA FISH against BTN2 was performed in fixed cells expressing Nab2-GFP, Nab2 ${ }^{\Delta Q-\Delta R G G-}$ SV40NLS_GFP or Nab2 ${ }^{\mathrm{F} 450 \mathrm{~A}}$-GFP. Samples were harvested in +DEX or after acute starvation in medium without DEX for 24 hrs. Scale bar $5 \mu \mathrm{m}$.

B) Quantification of $24 \mathrm{hrs}-\mathrm{DEX}$ condition in A). Shown are means \pm SEM of five biological replicates, $\mathrm{n}>100$ cells per replicate. ${ }^{* *} \mathrm{p}=0.0018$ (Nab2-GFP vs. Nab2 ${ }^{\Delta \mathrm{Q}-\Delta \mathrm{RGG}-S V 40 N L S}$-GFP), ns $\mathrm{p}=0.2943\left(\mathrm{Nab} 2-\mathrm{GFP}\right.$ vs. Nab2 $\left.{ }^{\mathrm{F} 450 \mathrm{~A}}-\mathrm{GFP}\right),{ }^{* *} \mathrm{p}=0.0064\left(\mathrm{Nab}^{\triangle \mathrm{Q}-\Delta \mathrm{RGG}-\mathrm{SV} 40 \mathrm{NL}{ }_{-} \text {GFP }}\right.$ vs. Nab2 ${ }^{\mathrm{F} 450 \mathrm{~A}_{-}}$ GFP), unpaired t-test.

C) RNA FISH against HSP42 was performed in fixed cells expressing Nab2-GFP, Nab2 ${ }^{\Delta \mathrm{Q}-\Delta \mathrm{RGG}-}$ SV40NLS_GFP or Nab2 ${ }^{\mathrm{F} 450 \mathrm{~A}}$-GFP. Samples were harvested in +DEX or after acute starvation in medium without DEX for 24 hrs. Scale bar $5 \mu \mathrm{m}$.

D) Quantification of $24 \mathrm{hrs}$-DEX condition in C). Data is normalized to Nab2-GFP. Shown are means \pm SEM of three biological replicates, $\mathrm{n}>100$ cells per replicate. ${ }^{*} \mathrm{p}=0.0249(\mathrm{Nab} 2-\mathrm{GFP}$ vs. Nab2 $2^{\Delta \mathrm{Q}-\Delta \mathrm{RGG}-\mathrm{SV} 40 \mathrm{NLS}}$-GFP), ns $\mathrm{p}=0.4480$ (Nab2-GFP vs. Nab2 $\left.{ }^{\mathrm{F} 450 \mathrm{~A}}-\mathrm{GFP}\right),{ }^{*} \mathrm{p}=0.0342$ (Nab2 ${ }^{\Delta \mathrm{Q}-\Delta R G G-S V 40 N L S}$-GFP vs. Nab2 ${ }^{\text {F450A }}$-GFP), unpaired t-test.

E) RNA FISH against HXT6 was performed in fixed cells expressing Nab2-GFP, Nab2 ${ }^{\Delta \mathrm{Q}-\Delta \mathrm{RGG}-}$ SV40NLS_GFP or Nab2 ${ }^{\mathrm{F} 450 \mathrm{~A}}$-GFP. Samples were harvested in + DEX or after acute starvation in medium without DEX for 24 hrs. Scale bar $5 \mu \mathrm{m}$.

F) Quantification of $24 \mathrm{hrs}$-DEX condition in E). Data is normalized to Nab2-GFP. Shown are means \pm SEM of five biological replicates, $n>100$ cells per replicate. ${ }^{* *} \mathrm{p}=0.0081$ (Nab2-GFP vs. Nab2 $2^{\Delta \mathrm{Q}-\Delta \mathrm{RGG}-S V 40 \mathrm{NLS}}$-GFP), ns $\mathrm{p}=0.2777$ (Nab2-GFP vs. Nab2 $\left.{ }^{\mathrm{F} 450 \mathrm{~A}}-\mathrm{GFP}\right),{ }^{*} \mathrm{p}=0.0135$ (Nab2 ${ }^{\triangle \mathrm{Q}-\triangle \mathrm{RGG}-\mathrm{SV} 40 \mathrm{NLS}}$-GFP vs. Nab2 $\left.{ }^{\mathrm{F} 450 \mathrm{~A}}-\mathrm{GFP}\right)$, unpaired t-test. 
G) RNA FISH against DED1 was performed in fixed cells expressing Nab2-GFP, Nab2 ${ }^{\triangle Q-\Delta R G G-}$ SV40NLS_GFP or Nab2 ${ }^{\mathrm{F} 450 \mathrm{~A}}$-GFP. Samples were harvested in +DEX or after acute starvation in medium without DEX for 24 hrs. Scale bar $5 \mu \mathrm{m}$.

H) Quantification of $24 \mathrm{hrs}$-DEX condition in G). Data is normalized to Nab2-GFP. Shown are means \pm SEM of three biological replicates, $n>100$ cells per replicate. $n s p=0.8324$ (Nab2-GFP vs. Nab2 $2^{\triangle \mathrm{Q}-\Delta \mathrm{RGG}-\mathrm{SV} 40 \mathrm{NLS}}-\mathrm{GFP}$ ), ns $\mathrm{p}=0.5458$ (Nab2-GFP vs. Nab2 ${ }^{\mathrm{F} 450 \mathrm{~A}}-\mathrm{GFP}$ ), ns $\mathrm{p}=0.9009$ (Nab2 ${ }^{\Delta \mathrm{Q}-\Delta \mathrm{RGG}-\mathrm{SV} 40 \mathrm{NLS}}$-GFP vs. Nab2 ${ }^{\mathrm{F} 450 \mathrm{~A}}$-GFP), unpaired t-test.

\section{7) Proper Nab2 condensation is essential for survival after prolonged stress}

A) Growth recovery assay of cells expressing Nab2-GFP, Nab2 ${ }^{\Delta \mathrm{Q}-\Delta \mathrm{RGG}-\mathrm{SV} 40 \mathrm{NLS}}$-GFP or Nab2 $2^{\mathrm{F} 450 \mathrm{~A}}$ GFP. Mid-log cultures grown in +DEX or acutely starved in medium without DEX for $24 \mathrm{hrs}$ or $120 \mathrm{hrs}$ were recovered as 1:5 serial dilutions (starting $\mathrm{OD}_{600} 0.2$ ) on rich medium plates containing glucose at either $25^{\circ} \mathrm{C}$ for 2 days or $37^{\circ} \mathrm{C}$ for 1 day.

B) Model depicting how nuclear Nab2 condensation blocks export of bulk mRNA and allows selective transport of stress-induced mRNAs.

\section{Supplemental Figures}

1) Acute depletion of Dbp5 does not affect NPC composition or NPC transport function; related to Figure 1

A) Left: Time lapse imaging of Dbp5-IAA7-GFP strain expressing TIR1 protein after addition of either $500 \mu \mathrm{M}$ IAA or solvent control (EtOH). Scale bar $2 \mu \mathrm{m}$. Right: GFP intensity quantification of $>200$ cells per condition, green: one-phase decay fit, half-life $=12.3 \mathrm{~min}$.

B) Growth assay on rich medium plates containing $500 \mu \mathrm{M}$ IAA or solvent control (EtOH). Cells of a Dbp5-IAA7 strain with or without expressing TIR1 protein were spotted as 1:5 serial dilutions (starting $\mathrm{OD}_{600} 0.2$ ) and incubated at $25^{\circ} \mathrm{C}$ for 2 days.

C) Quantification of GFP-tagged nucleoporin (NUP) intensity at the nuclear rim in wild type DBP5 background (wt), and in the presence (-TIR1) or absence (+TIR1) of the Dbp5 degron (Dbp5AID) after incubation with $500 \mu \mathrm{M}$ IAA for $0 \mathrm{~min}$ or $120 \mathrm{~min}$. Shown are means \pm SEM of three biological replicates, $\mathrm{n}>400$ cells.

D) Mid-log cultures of Dbp5-IAA7 xpo1-1 cells expressing an NLS-NES-2xGFP reporter and the nuclear rim marker dsRed-HDEL with or without TIR1 were treated for $1 \mathrm{hr}$ with either $500 \mu \mathrm{M}$ IAA, $200 \mu \mathrm{M}$ leptomycin B (LMB) or 1 hr $500 \mu \mathrm{M}$ IAA followed by $1 \mathrm{hr} 200 \mu \mathrm{M}$ LMB before imaging. Scale bar $5 \mu \mathrm{m}$.

E) Quantification of cells in B). Plot shows nuclear to cytoplasmic (N:C) GFP intensity ratio of NLS-NES-2xGFP reporter. Shown are means of three biological replicates, $n>100$ cells per replicate.

F) Time lapse imaging of cells in D). Scale bar $5 \mu \mathrm{m}$.

G) Quantification of time lapse imaging in F) shows nuclear to cytoplasmic (N:C) GFP intensity ratio of NLS-NES-2xGFP reporter. Means \pm SEM (dotted lines) of three biological replicates, $\mathrm{n}>100$ cells per replicate.

H) RNA FISH against the indicated RNAs was performed in cells expressing Dbp5-IAA7 + Ndc1GFP as a nuclear rim marker with or without TIR1. Samples were harvested after 2 hrs incubation with $500 \mu \mathrm{M}$ IAA. Scale bar $5 \mu \mathrm{m}$. 
2) Acute depletion of Dbp5 does not alter mobility of Yra1, Np13 or a nuclear GFP reporter; in vitro Nab2-GFP condensates are impaired in the presence of Dbp5, Gle1 and IP6; related to Figure 1 and 2

A) FRAP of GFP-Yra1 cells expressing the Dbp5-degron with or without TIR1. FRAP curves are normalized to prebleach and postbleach values. Mean curves \pm SEM of three biological replicates with $\geq 13$ cells per replicate are shown.

B) Half time of recovery retrieved from fitting individual FRAP curves from A) with a single component model. Shown are means \pm SEM of three biological replicates. ns $p=0.4818$, unpaired t-test.

C) FRAP of Npl3-GFP cells expressing the Dbp5-degron with or without TIR1. FRAP curves are normalized to prebleach and postbleach values. Mean curves \pm SEM of three biological replicates with $\geq 12$ cells per replicate are shown.

D) Half time of recovery retrieved from fitting individual FRAP curves from C) with a single component model. Shown are means \pm SEM of three biological replicates. ns $p=0.7217$, unpaired t-test.

E) FRAP of NLS-GFP(3x) cells expressing the Dbp5-degron with or without TIR1. FRAP curves are normalized to prebleach and postbleach values. Mean curves \pm SEM of three biological replicates with $\geq 12$ cells per replicate are shown.

F) Half time of recovery retrieved from fitting individual FRAP curves from E) with a single component model. Shown are means \pm SEM of three biological replicates. ns $p=0.2642$, unpaired t-test.

G) RNA FISH against poly(A) RNA using an oligo(dT)30 probe was performed in cells expressing Dbp5-IAA7, or Dbp5-IAA7 and Rpb2-IAA7, with or without TIR1 protein. Samples were harvested after 2 hrs incubation with $500 \mu \mathrm{M}$ IAA. Scale bar $5 \mu \mathrm{m}$.

H) Domain architecture of Nab2 (top), together with PONDR prediction of naturally disordered regions (bottom) (VL-XT predictor, trained on V ariously characterized Long disordered regions and two trained on $X$-ray characterized Terminal disordered regions). Black bars indicate predicted disordered regions.

I) Concentration determination of nuclear and cytoplasmic Nab2-GFP relative to Dhh1-GFP (approx. cellular concentration of $2 \mu \mathrm{M}$ ) as reference for in vitro condensate setup. Shown are means \pm SEM of three biological replicates.

J) Representative images depicting the nuclear and cytoplasmic compartment that was measured, respectively, and the calculated intensity ratios of Nab2-GFP vs. Dhh1-GFP, suggesting that Nab2-GFP has a nuclear concentration of approx. $24 \mu \mathrm{M}$. Scale bar $5 \mu \mathrm{m}$.

K) Recombinant Nab2-GFP droplets were formed in LSB100 buffer to a final $\mathrm{KCl}$ concentration of $63 \mathrm{mM}$ in the presence or absence of $0.04 \mathrm{mg} / \mathrm{mL}$ polyA RNA. Time lapse imaging at $25^{\circ} \mathrm{C}$ was started $60 \mathrm{~min}$ after setup upon addition of water or 5\% 1,6-hexanediol. Scale bar $5 \mu \mathrm{m}$.

L) Quantification of K). Shown are means \pm SD of GFP droplet intensity of two biological replicates.

M) Recombinant Nab2-GFP droplets were formed without or in the presence of the indicated proteins and imaged at $25^{\circ} \mathrm{C} 20 \mathrm{~min}$ after setup. Nab2 $8 \mu \mathrm{M}$ in LSB100 pH 6.2, $0.04 \mathrm{mg} / \mathrm{mL}$ polyA RNA, $12 \mu \mathrm{M}$ Gle1, $40 \mu \mathrm{M} \mathrm{IP}_{6}$, Dbp5-mCherry concentrations: 24/48 $\mu \mathrm{M}$. Scale bar 10 $\mu \mathrm{m}$.

3) Glucose stress does not affect Gle1 and Nup159 localization, or FRAP recovery kinetics of Yra1 and Np13; related to Figure 3 
A) Cells expressing Dbp5-GFP, Gle1-GFP or Nup159-GFP, and dsRed-HDEL were grown in medium + DEX or acutely shifted for $30 \mathrm{~min}$ or $24 \mathrm{hrs}$ into medium without DEX. Scale bar 5 $\mu \mathrm{m}$. Dbp5-GFP data also shown in Fig. 3A.

B) Quantification of Dbp5-GFP, Gle1-GFP or Nup159-GFP intensity at the nuclear envelope by NuRIM in the conditions shown in A). Shown are means \pm SEM of three biological replicates. At least 350 cells were analyzed per condition and replicate. Dbp5-GFP data also shown in Fig. 3A. Dbp5: ** $\mathrm{p}=0.0082$ (+DEX vs. $30 \mathrm{~min}-\mathrm{DEX}),{ }^{*} \mathrm{p}=0.022$ (+DEX vs. 24 hrs $\left.-\mathrm{DEX}\right)$; Gle1: n.s. $\mathrm{p}=0.4342$ ( $+\mathrm{DEX}$ vs. $30 \mathrm{~min}-\mathrm{DEX}),{ }^{*} \mathrm{p}=0.0368$ (+DEX vs. 24 hrs $\left.-\mathrm{DEX}\right)$; Nup159: n.s. $\mathrm{p}=0.2453$ (+DEX vs. $30 \mathrm{~min}-\mathrm{DEX}),{ }^{*} \mathrm{p}=0.0499$ (+DEX vs. $\left.24 \mathrm{hrs}-\mathrm{DEX}\right)$; unpaired t-test.

C) Representative images of GFP-Yra1 cells in +DEX or 24 hrs -DEX. Scale bar $5 \mu \mathrm{m}$.

D) Representative images of Npl3-GFP cells in +DEX or 24 hrs -DEX. Scale bar $5 \mu \mathrm{m}$.

E) FRAP of GFP-Yra1 cells in +DEX or $24 \mathrm{hrs}$-DEX. FRAP curves are normalized to prebleach and postbleach values. Mean curves \pm SEM of three biological replicates with $\geq 15$ cells per replicate are shown.

F) Half time of recovery retrieved from fitting individual FRAP curves from E) with a single component model. Shown are means \pm SEM of three biological replicates. ns $p=0.154$, unpaired t-test.

G) FRAP of Npl3-GFP cells in +DEX or $24 \mathrm{hrs}$-DEX. FRAP curves are normalized to prebleach and postbleach values. Mean curves \pm SEM of three biological replicates with $\geq 14$ cells per replicate are shown.

$\mathrm{H})$ Half time of recovery retrieved from fitting individual FRAP curves from $G$ ) with a single component model. Shown are means \pm SEM of three biological replicates. $n s p=0.679$, unpaired t-test.

I) Representative images of wild type (Dbp5-GFP) or GFP-Dbp5 $-{ }^{\Delta \mathrm{N}} \mathrm{Nup} 159$ ('GFP-Dbp5 tether') cells in + DEX or 24 hrs - DEX. Scale bar $5 \mu \mathrm{m}$.

4) Nab2-GFP focus formation in glucose stress is RNA-dependent, reversible, and mildly affected upon addition of 1,6-hexanediol in vivo; related to Figure 3

A-C) Time lapse imaging of Nab2-GFP cells that were treated with water or 5\% 1,6-hexanediol in A) +DEX, B) 30 min -DEX or C) 24 hrs -DEX. Scale bar $5 \mu \mathrm{m}$.

D) Time lapse imaging of Nab2-GFP cells after release from 24 hrs Dextrose starvation into + DEX medium. Scale bar $5 \mu \mathrm{m}$.

E) FRAP of Nab2-GFP cells in +DEX, 30 min -DEX or pre-treated for 15 min with $3 \mu \mathrm{g} / \mathrm{mL}$ thiolutin before starving cells for $30 \mathrm{~min}$ in -DEX. FRAP curves are normalized to prebleach and postbleach values. Mean curves \pm SEM of three biological replicates with $\geq 14$ cells per replicate are shown.

F) Half time of recovery retrieved from fitting individual FRAP curves from E) with a single component model. Shown are means \pm SEM of three biological replicates. ${ }^{*} \mathrm{p}=0.0454$, ns $\mathrm{p}=0.1437$, unpaired $\mathrm{t}$-test.

G) RNA FISH against poly(A) RNA using an oligo(dT)30 probe was performed in fixed cells expressing Cbc1-GFP or Cbc2-GFP. Samples were harvested in +DEX or after acute starvation in medium without DEX for $24 \mathrm{hrs}$. Scale bar $5 \mu \mathrm{m}$.

5) Characterization of Nab2 mutants in vivo and in vitro, and nucleus isolation efficiency; related to Figure 4 and 5 
A) GFP-tagged recombinant Nab2 $2^{\Delta \mathrm{RGG}-\mathrm{SV} 40 \mathrm{NLS}}$ or $\mathrm{Nab2} 2^{\Delta \mathrm{Q}}$ mutant droplets were formed in LSB150 buffer at the indicated $\mathrm{pH}$ in the presence of $0.04 \mathrm{mg} / \mathrm{mL}$ polyA RNA and imaged at $25{ }^{\circ} \mathrm{C} 30$ min after setup. Scale bar $10 \mu \mathrm{m}$.

B) Growth assay on rich medium plates containing $500 \mu \mathrm{M}$ IAA or solvent control (EtOH). The indicated strains were spotted as 1:5 serial dilutions (starting $\mathrm{OD}_{600} 0.2$ ) and incubated at $25^{\circ} \mathrm{C}$ for 2 days.

C-D) Growth assay on rich medium plates. The indicated strains were spotted as 1:5 serial dilutions (starting $\mathrm{OD}_{600} 0.2$ ) and incubated at $25^{\circ} \mathrm{C}$ for 2 days.

E) Representative images of Nab2 ${ }^{\Delta Q_{-}}$GFP cells in + DEX or 24 hrs -DEX. Scale bar $5 \mu \mathrm{m}$.

F) FRAP of Nab2 ${ }^{\Delta Q_{-}}$GFP cells in +DEX or 24 hrs -DEX. FRAP curves are normalized to prebleach and postbleach values. Mean curves + SEM of three biological replicates with $\geq 14$ cells per replicate are shown.

G) Half time of recovery retrieved from fitting individual FRAP curves from F) with a single component model. Shown are means \pm SEM of three biological replicates. ${ }^{*} \mathrm{p}=0.0132$, unpaired t-test.

H) Quantification of the ratio of mean nuclear poly(A) RNA signal intensity versus mean cellular poly(A) RNA signal intensity in +DEX and 24 hrs -DEX from RNA FISH experiment shown in Figure 5A. Shown are means \pm SEM of five biological replicates, $n>100$ cells per replicate. +DEX: ${ }^{*} \mathrm{p}=0.0168$ (Nab2-GFP vs. Nab2 ${ }^{\Delta \mathrm{Q}-\Delta R G G-S V 40 N L S}$-GFP), n.s. $\mathrm{p}=0.3346$ (Nab2-GFP vs.

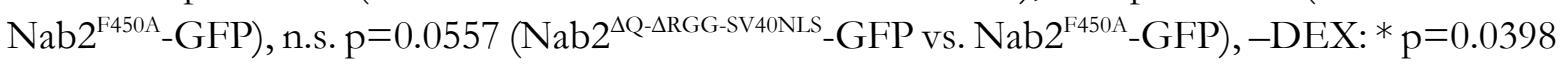
(Nab2-GFP vs. Nab2 $2^{\Delta \mathrm{Q}-\Delta R G G-S V 40 N L S}$-GFP), n.s. $\mathrm{p}=0.2159$ (Nab2-GFP vs. Nab2 $\left.{ }^{\mathrm{F} 450 \mathrm{~A}}-\mathrm{GFP}\right)$, * $\mathrm{p}=0.0161\left(\mathrm{Nab} 2^{\Delta \mathrm{Q}-\Delta \mathrm{RGG}-\mathrm{SV} 40 \mathrm{NLS}}-\mathrm{GFP}\right.$ vs. Nab2 $\left.{ }^{\mathrm{F} 450 \mathrm{~A}}-\mathrm{GFP}\right)$, unpaired t-test.

I) Quantification of the ratio of cellular (left) and nuclear (right) poly(A) RNA signal intensity comparing +DEX and 24 hrs -DEX from RNA FISH experiment shown in Figure 5A. Shown are means \pm SEM of five biological replicates, $n>100$ cells per replicate. Cellular ratios: $n . s$. $\mathrm{p}=0.3076$ (Nab2-GFP vs. Nab2 ${ }^{\Delta \mathrm{Q}-\Delta R G G-S v 40 N L S}$-GFP), n.s. $\mathrm{p}=0.3645$ (Nab2-GFP vs. Nab2 $2^{\mathrm{F} 450 \mathrm{~A}}$ GFP), n.s. $\mathrm{p}=0.0733$ (Nab2 ${ }^{\Delta \mathrm{Q}-\Delta \mathrm{RGG}-\mathrm{SV} 40 \mathrm{NLS}}$-GFP vs. Nab2 ${ }^{\mathrm{F} 450 \mathrm{~A}}$-GFP), Nuclear ratios: ${ }^{* *} \mathrm{p}=0.008$ (Nab2-GFP vs. Nab2 $\left.2^{\Delta Q-\Delta R G G-S v 40 N L S}-G F P\right)$, n.s. $p=0.1616$ (Nab2-GFP vs. Nab2 ${ }^{\mathrm{F} 450 \mathrm{~A}}$-GFP), ** $\mathrm{p}=0.0023\left(\mathrm{Nab} 2^{\Delta \mathrm{Q}-\Delta \mathrm{RGG}-\mathrm{Sv} 40 \mathrm{NLS}}-\mathrm{GFP}\right.$ vs. Nab2 $\left.{ }^{\mathrm{F} 450 \mathrm{~A}}-\mathrm{GFP}\right)$, unpaired t-test.

J) RNA FISH against poly(A) RNA using an oligo(dT)30 probe was performed on spheroplasts or extracted nuclei from indicated strains harvested after 24 hrs starvation in -DEX. BF, bright field. Scale bar $5 \mu \mathrm{m}$.

K) Quantification of extracted nuclei fraction in J). Shown are means \pm SEM of 3 biological replicates.

6) RNA sequencing analysis of whole cell extracts and nuclear extracts; related to Figure 5

A) Similarity matrix of individual replicates of whole cell RNA sequencing reads, and hierarchical clustering (one minus Pearson correlation) using Morpheus software (Broad Institute, https://software.broadinstitute.org/morpheus).

B) GO term analysis of 204 genes upregulated in $24 \mathrm{hrs}-\mathrm{DEX}$ compared to + DEX (pval $<0.05$ and $\log 2$ Fold Change $>3$ ) in the indicated strains.

C) Similarity matrix of individual replicates of nuclear RNA sequencing reads, and hierarchical clustering (one minus Pearson correlation) using Morpheus software (Broad Institute).

D) Comparison of nuclear RNAseq reads (CPM, counts per million), left: Nab2-GFP vs. Nab2 ${ }^{\Delta Q-}$ $\triangle$ RGG-SV40NLS_GFP, right: Nab2-GFP vs. Nab2 ${ }^{\mathrm{F} 450 \mathrm{~A}}$-GFP. Each dot represents one gene. Grey line represents a 1:1 ratio. Shown are average CPMs of three biological replicates. 
E) Distribution of average reads of most abundant genes ( $>500$ CPM in Nab2-GFP, 318 genes) from D). Box-and-whiskers plot, min to $\max . * * * * \mathrm{p}<0.001$, ns $\mathrm{p}=0.3439$, unpaired t-test.

F) Comparison of whole cell RNAseq reads (CPM, counts per million) of differentially enriched vs. not differentially enriched genes of most abundant genes (>500 CPM in Nab2-GFP, 318 genes). Box-and-whiskers plot, $10^{\text {th }}$ to $90^{\text {th }}$ percentile.

G) Comparison of transcript length (log10) of differentially enriched (149 genes) vs. not differentially enriched (100 genes) vs. all transcripts (5506). Box-and-whiskers plot, $10^{\text {th }}$ to $90^{\text {th }}$ percentile. $* * * *$ $\mathrm{p}<0.001$, ns $\mathrm{p}=0.2563$, Mann Whitney test.

H) Comparison of intron-containing transcripts of differentially enriched ( 3 out of 149 genes) vs. not differentially enriched (14 out of 100 genes) vs. all transcripts (263 out of 5506).

7) Proper Nab2 condensation is essential for survival after glucose stress, both acutely and in stationary phase; related to Figure 7

A) Growth recovery assay of cells expressing Nab2-GFP, Nab2 $2^{\triangle \mathrm{Q}-\Delta \mathrm{RGG}-\mathrm{SV} 40 \mathrm{NLS}}$-GFP or Nab2 ${ }^{\mathrm{F} 450 \mathrm{~A}_{-}}$ GFP. Mid-log cultures grown at $25^{\circ} \mathrm{C}$ in + DEX or acutely starved in medium without DEX $120 \mathrm{hrs}$ (5 days) were recovered as 1:5 serial dilutions (starting $\mathrm{OD}_{600} 0.2$ ) on rich medium plates containing glucose at either $18{ }^{\circ} \mathrm{C}$ for 4 days, $25^{\circ} \mathrm{C}$ for 2 days, $30^{\circ} \mathrm{C}$ for 1 day or $37^{\circ} \mathrm{C}$ for 1 day.

B) Growth recovery assay of cells expressing Nab2-GFP, Nab2 $2^{\triangle \mathrm{Q}-\Delta R G G-S V 40 N L S}$-GFP or Nab2 ${ }^{\text {F450A }}$ GFP. Cultures in +DEX were grown from mid-log into stationary phase for 1 day at $25{ }^{\circ} \mathrm{C}$ and subsequently recovered as $1: 5$ serial dilutions (starting $\mathrm{OD}_{600} 0.2$ ) on rich medium plates containing glucose at either $18{ }^{\circ} \mathrm{C}$ for 4 days, $25^{\circ} \mathrm{C}$ for 2 days, $30^{\circ} \mathrm{C}$ for 1 day or $37^{\circ} \mathrm{C}$ for 1 day.

Video S1 Cells expressing GFA1-PP7sl, PP7CP-GFP, the nuclear rim marker Ndc1-mKate and the Dbp5-degron without TIR1 are treated for $1 \mathrm{hr}$ with Auxin (IAA) before imaging using a custom-built microscope (Smith et al., 2015). Scale bar $5 \mu \mathrm{m}$. related to Figure 1.

Video S2 Cells expressing GFA1-PP7sl, PP7CP-GFP, the nuclear rim marker Ndc1-mKate and the Dbp5-degron with TIR1 are treated for $1 \mathrm{hr}$ with Auxin (IAA) before imaging using a custom-built microscope (Smith et al., 2015). Scale bar $5 \mu \mathrm{m}$. related to Figure 1.

Video S3 Recombinant Nab2-GFP droplets were formed in LSB100 buffer to a final KCl concentration of $63 \mathrm{mM}$ in the presence or absence of $0.04 \mathrm{mg} / \mathrm{mL}$ poly(A) RNA and imaged every 2 min for 2 hrs at $25{ }^{\circ} \mathrm{C}$ directly after setup. Scale bar $10 \mu \mathrm{m}$. 
Figure 1 preprint (which was not certified by peer review) is the author/funder. All rights reserved. No reuse allowed without permission.

A

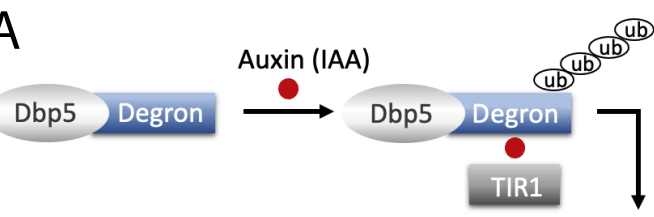

combined with

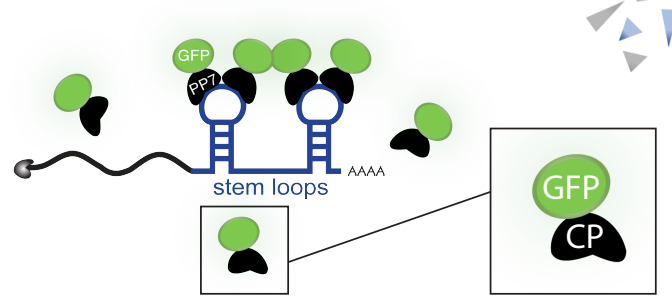

D
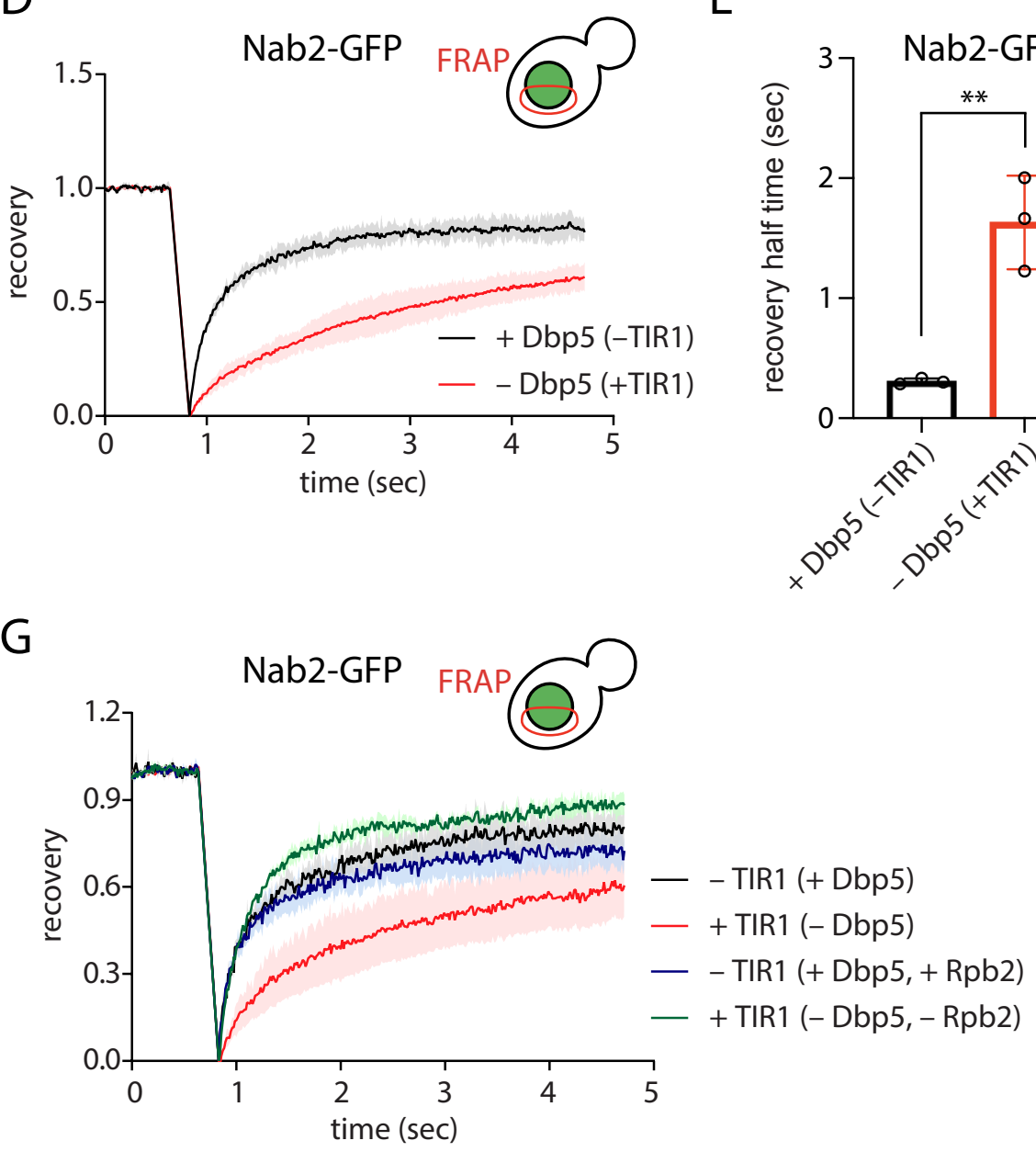

E
C nuclear RNA movement
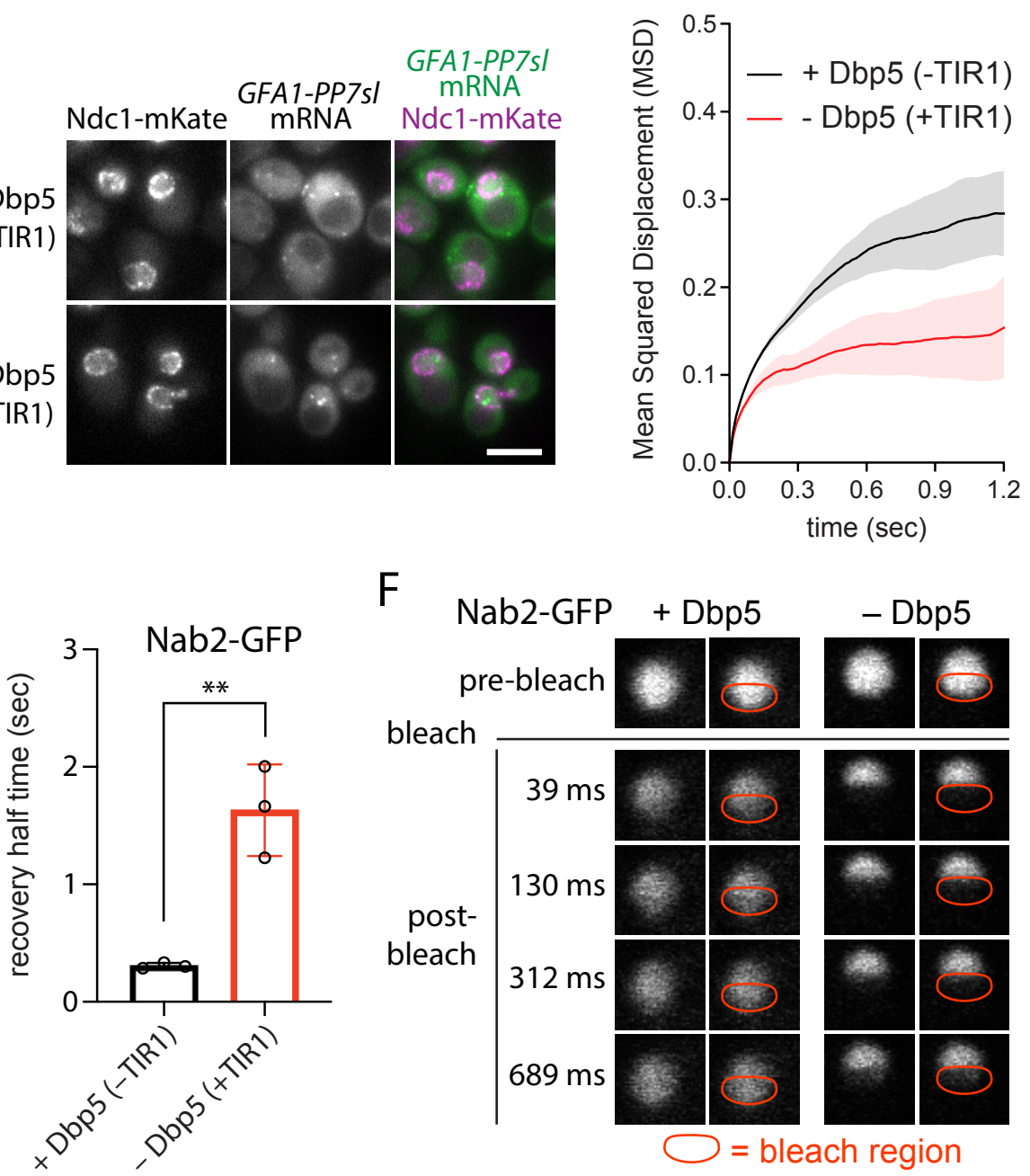

F

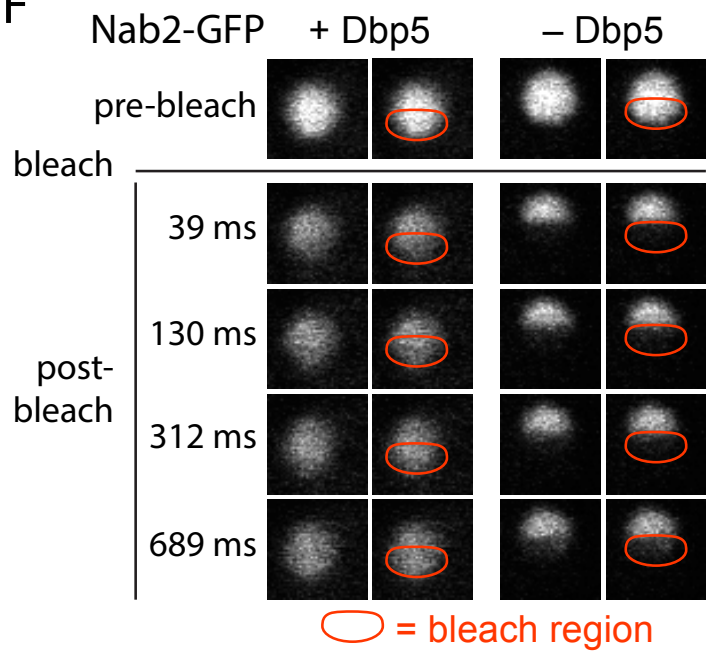

H Nab2-GFP
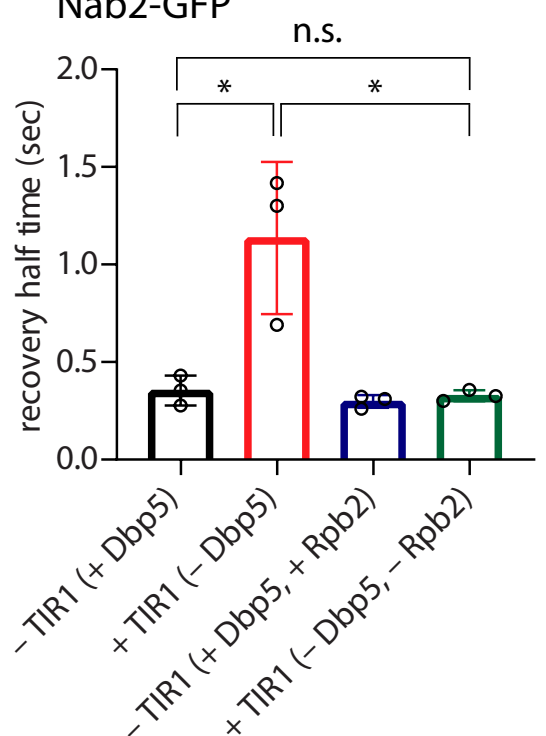
Figure 2 preprint (which was not certified by peer review) is the author/funder. All rights reserved. No reuse allowed without permission.

A

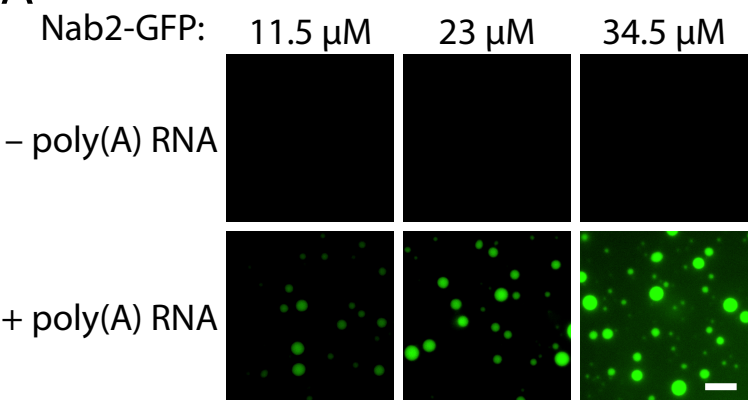

C
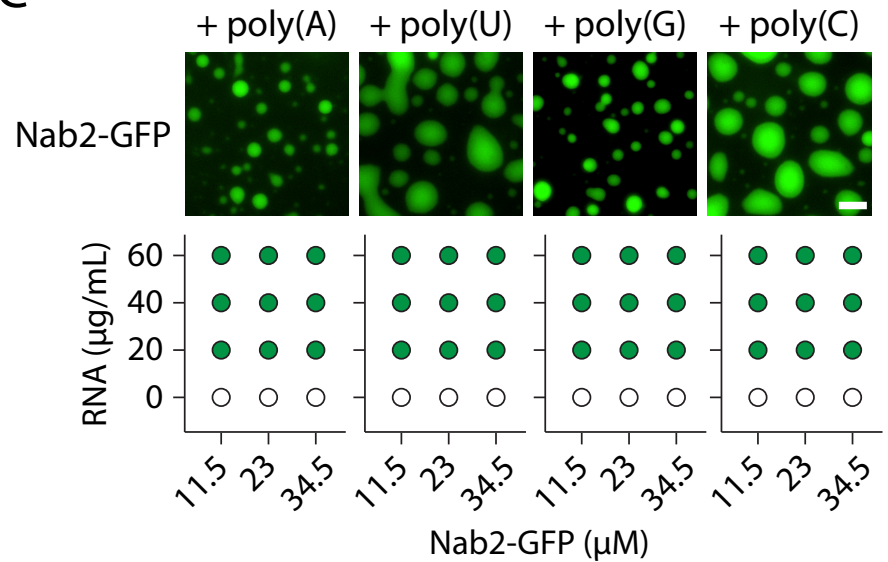

B

Nab2-GFP: $\begin{array}{llll}\mathrm{pH} 6.6 & \mathrm{pH} 6.8 & \mathrm{pH} 7.0 & \mathrm{pH} 7.2\end{array}$ $\mathrm{pH} 7.4$ $+\operatorname{poly}(A)$ RNA $63 \mathrm{mM} \mathrm{KCl}$

$+\operatorname{poly}(\mathrm{A}) \mathrm{RNA}$ $94 \mathrm{mM} \mathrm{KCl}$
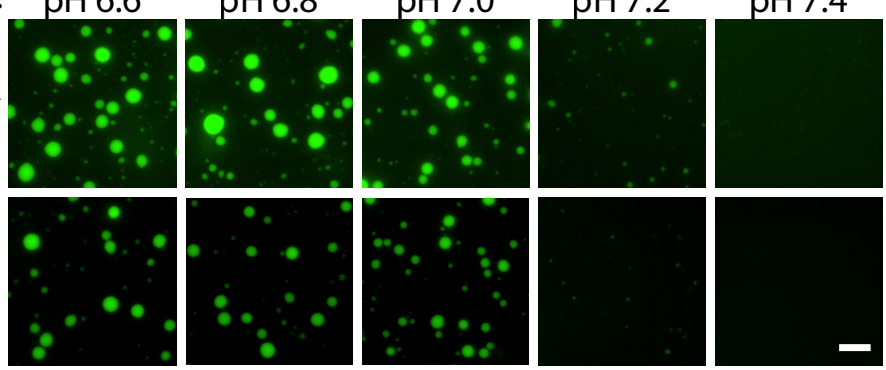

D

Nab2-GFP $+\operatorname{poly}(A)$ RNA
$+\mathrm{Dbp}^{\Delta \mathrm{N} 90}$

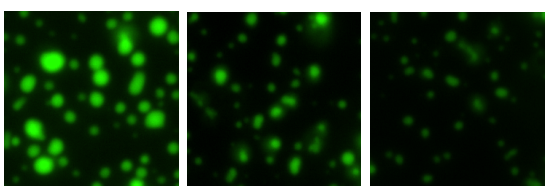

+ Dbp5 $5^{\triangle N 90-D Q A D}$

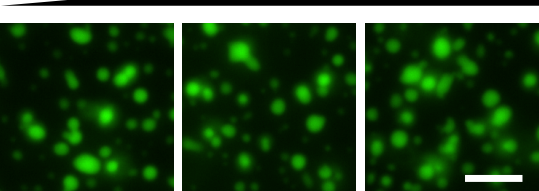


Figure 3 preprint (which was not certified by peer review) is the author/funder. All rights reserved. No reuse allowed without permission.

A
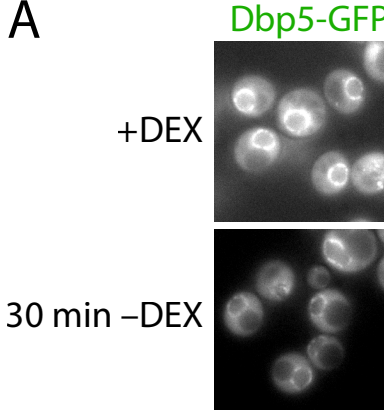

24 hrs -DEX

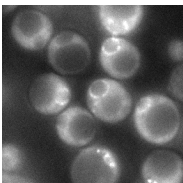

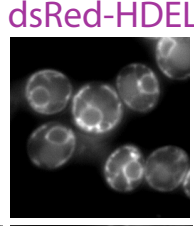

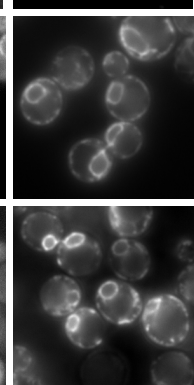

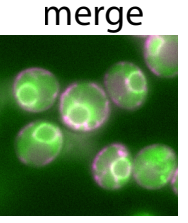

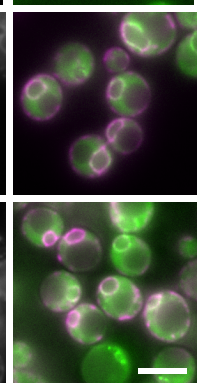

B Dbp5-GFP

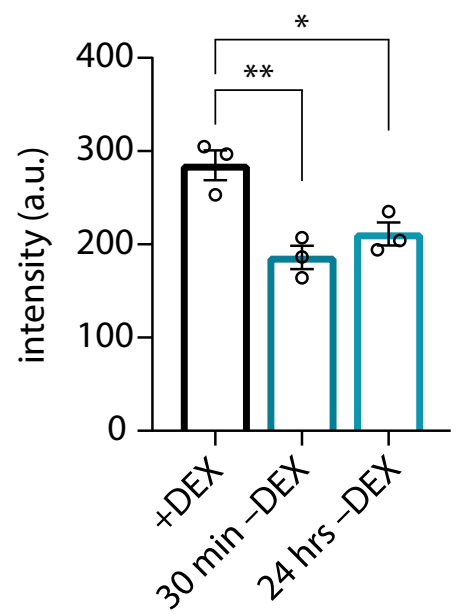

C

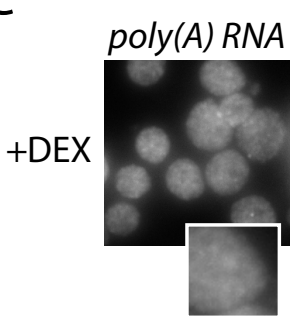

poly (A) RNA

E

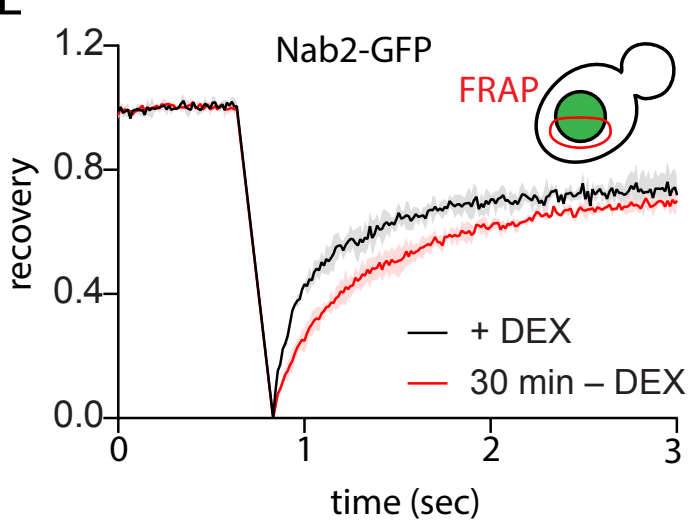

F

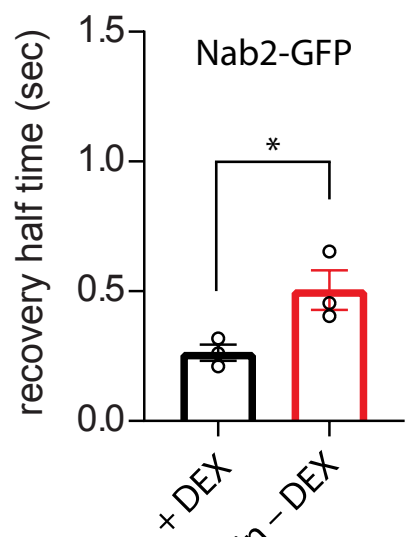

H

G

$\operatorname{poly}(A) R N A \quad G$

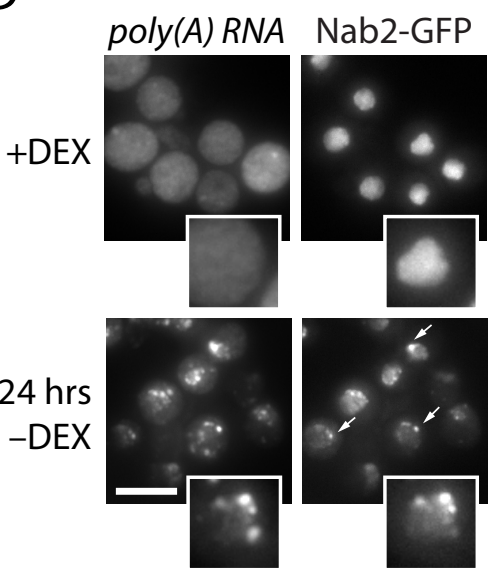
Nab2-GFP
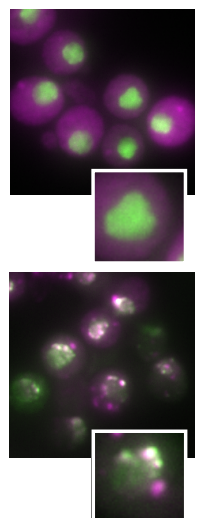

Nab2-GFP

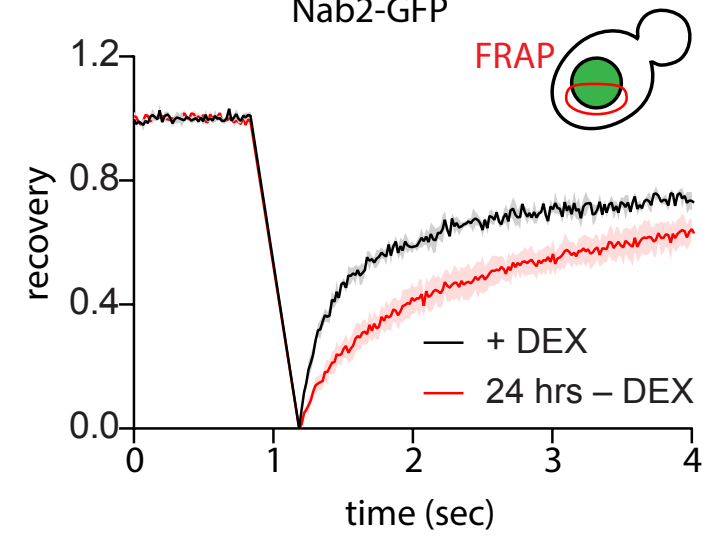

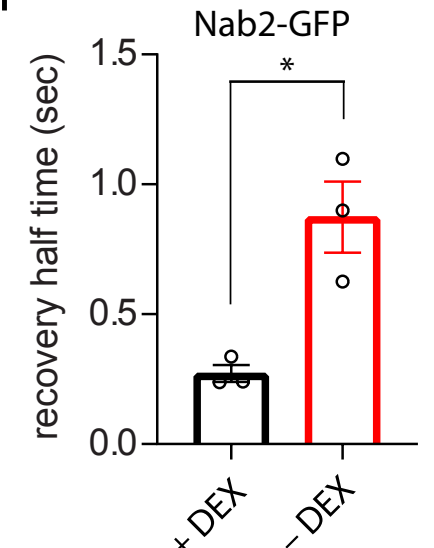

$n^{n}$

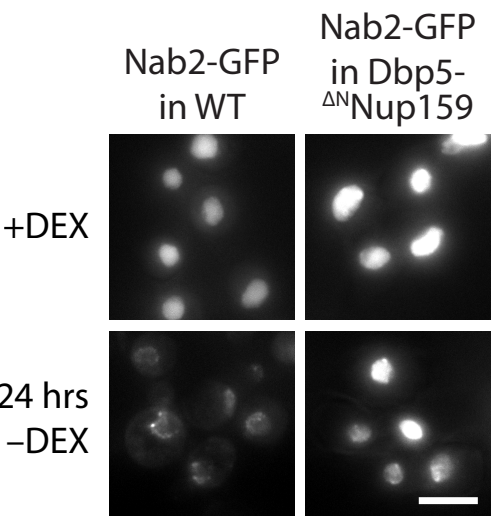

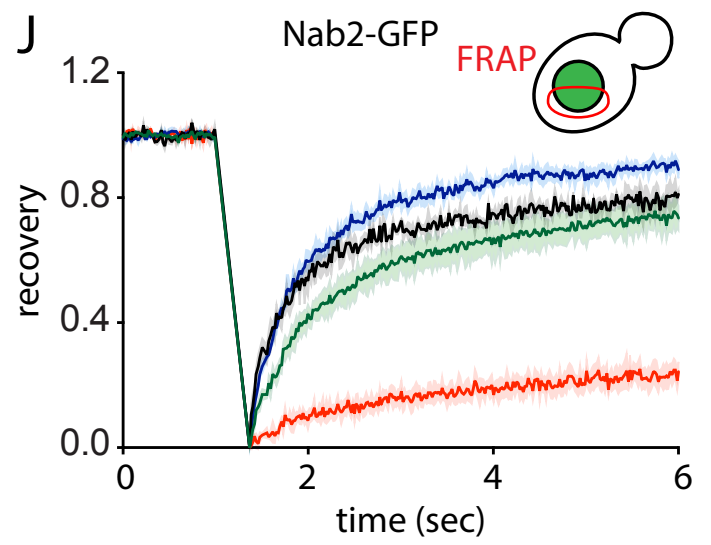

\begin{tabular}{l|l} 
- + DEX & wild type
\end{tabular}

- + DEX

- 24 hrs - DEX
K
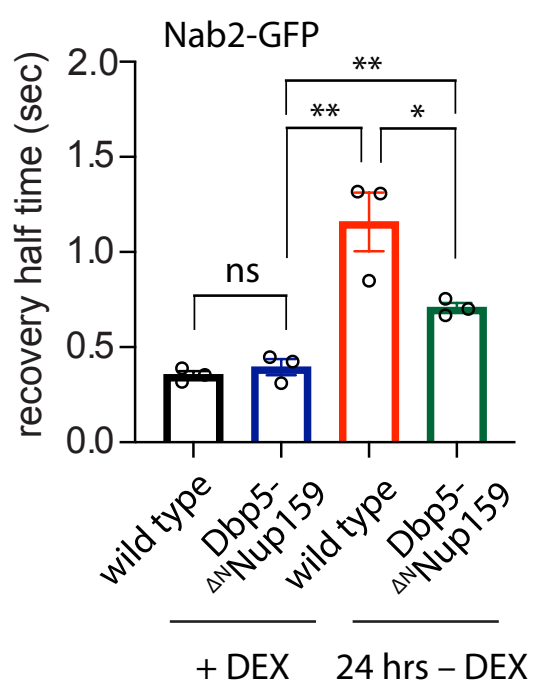
Figure 4 preprint (which was not certified by peer review) is the author/funder. All rights reserved. No reuse allowed without permission.

A
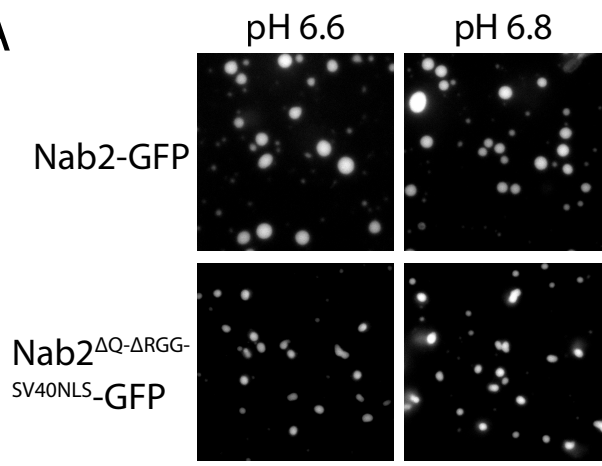

$\mathrm{Nab} 2^{\mathrm{F} 450 \mathrm{~A}}-\mathrm{GFP}$
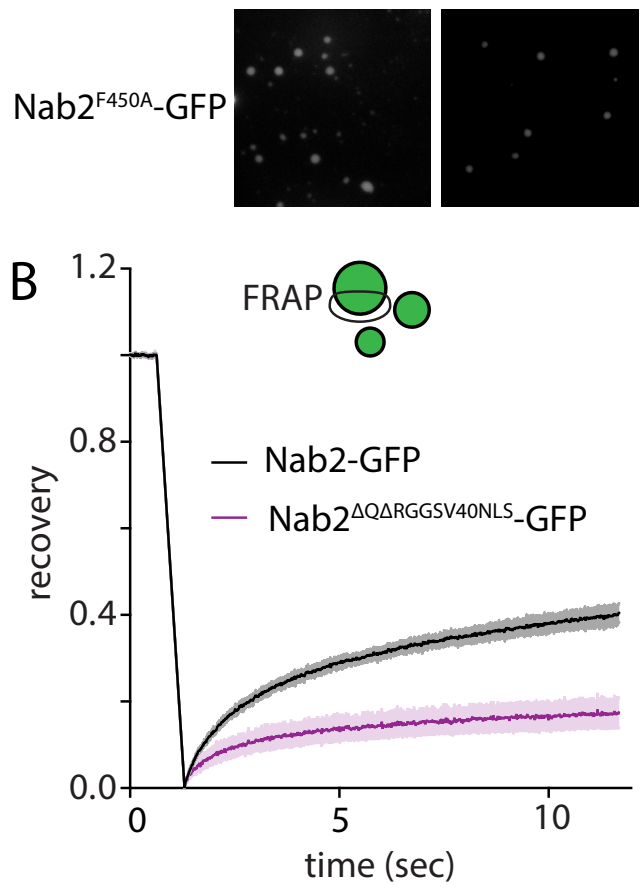

D
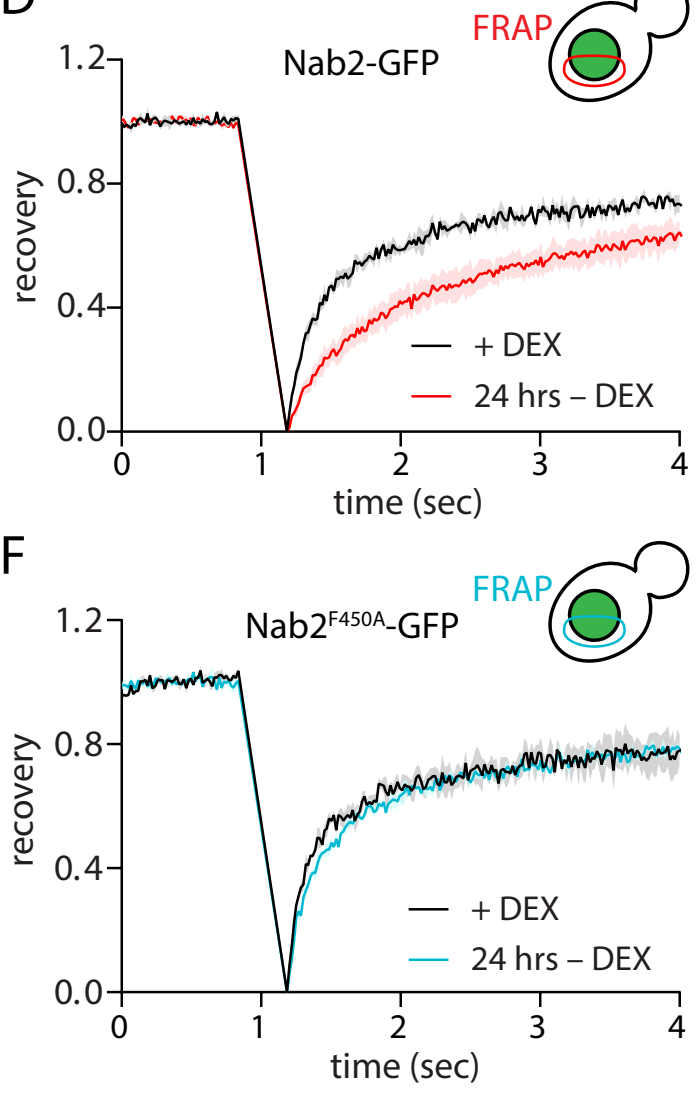

$\mathrm{pH} 7.0$
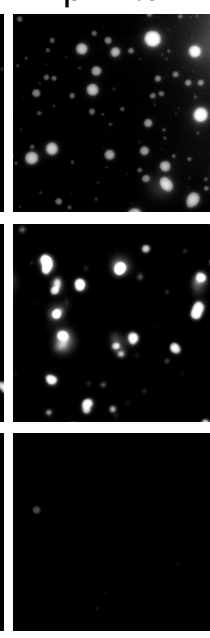

C

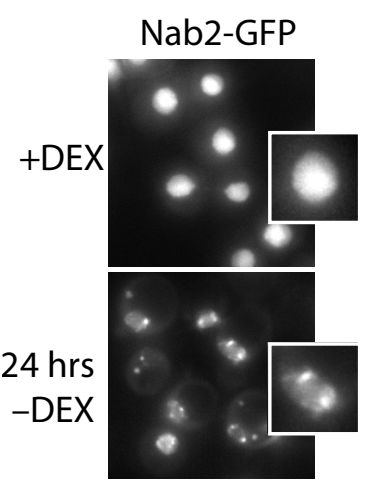

pH 7.4
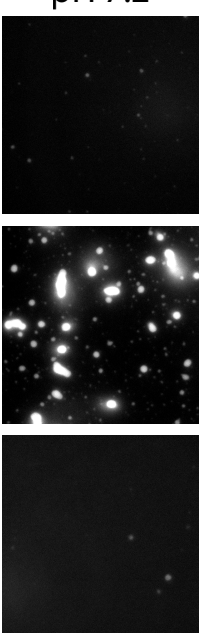
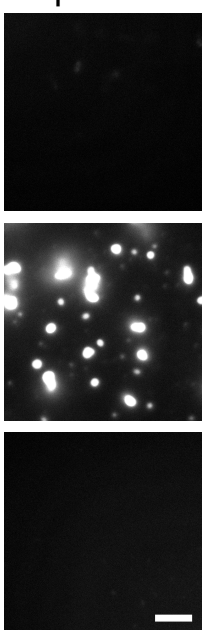

$\mathrm{Nab} 2^{\triangle \mathrm{Q}} \triangle \mathrm{RGG}$ SV40NLS_GFP

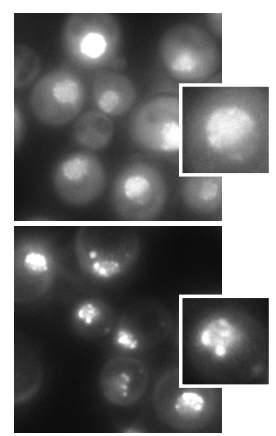

$\mathrm{Nab} 2^{\mathrm{F} 450 \mathrm{~A}}$-GFP

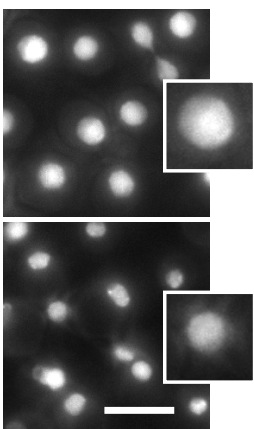
pH 6.8 poly $(\mathrm{A}) \mathrm{RNA}(\mu \mathrm{g} / \mathrm{mL})$
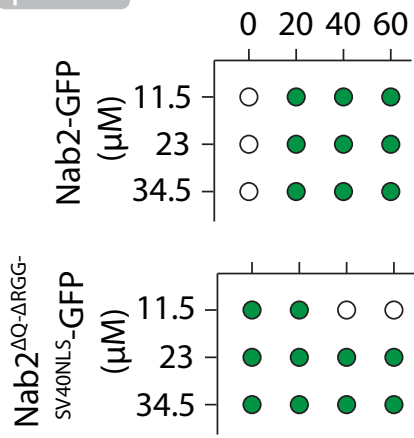

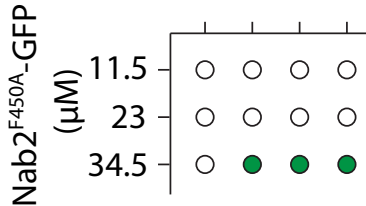

E

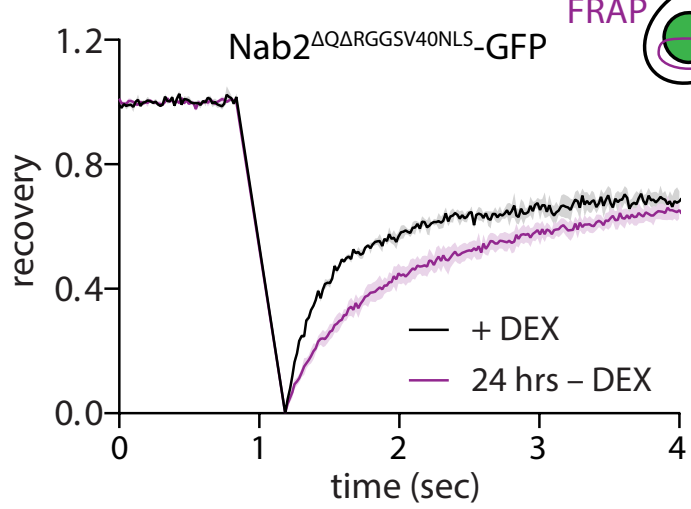

$G$

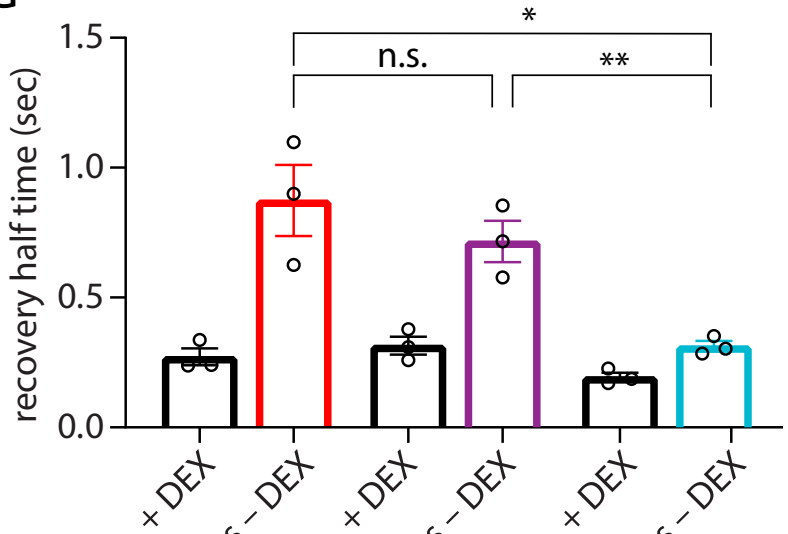


Figure 5 preprint (which was not certified by peer review) is the author/funder. All rights reserved. No reuse allowed without permission.

A

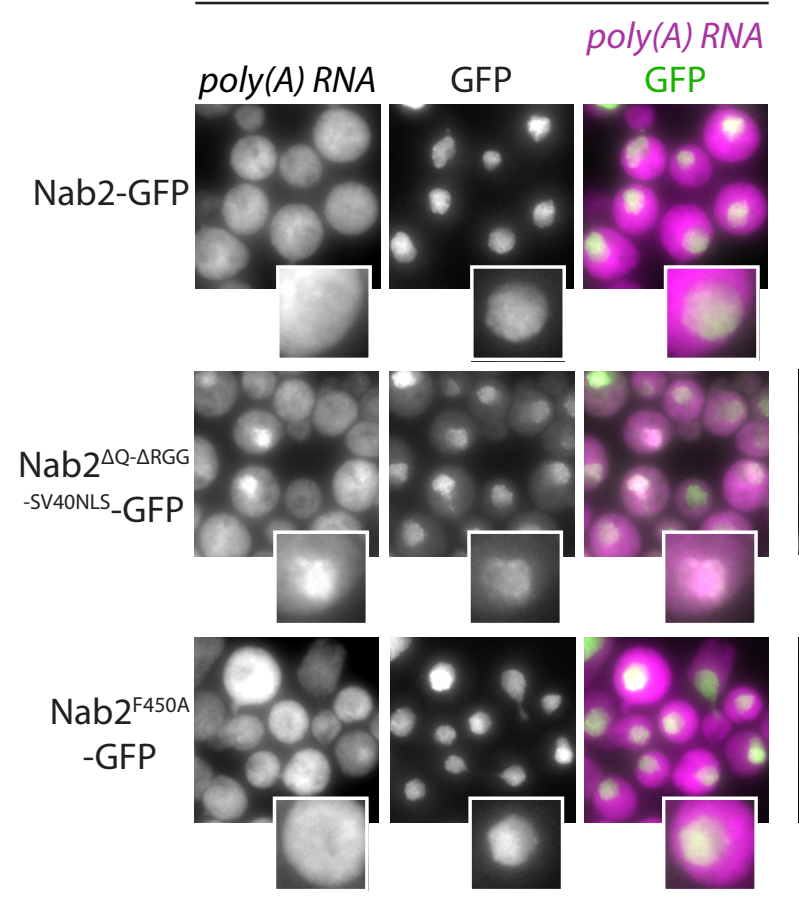

C

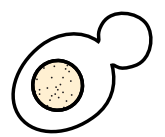

all transcripts

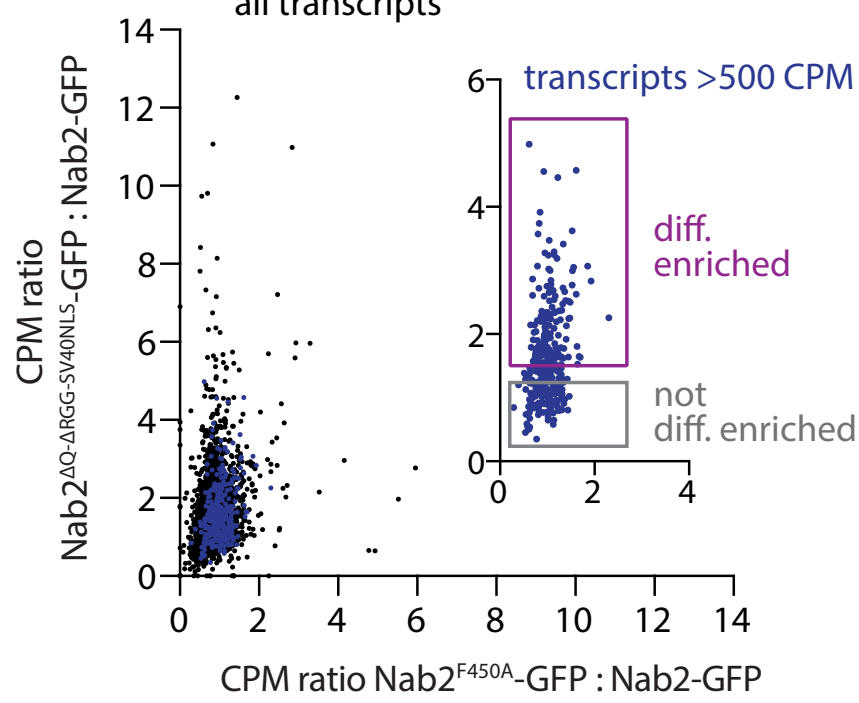

$24 \mathrm{hrs}-\mathrm{DEX}$

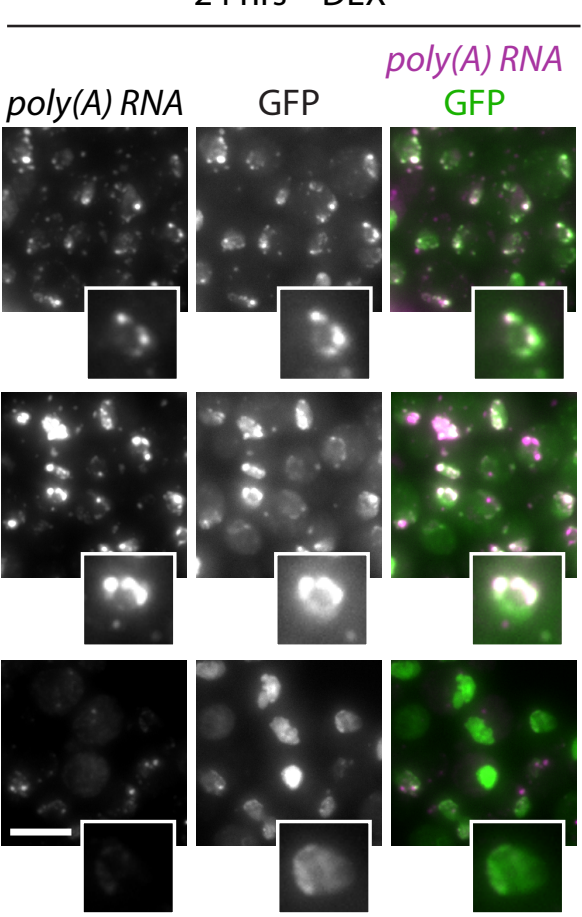

B

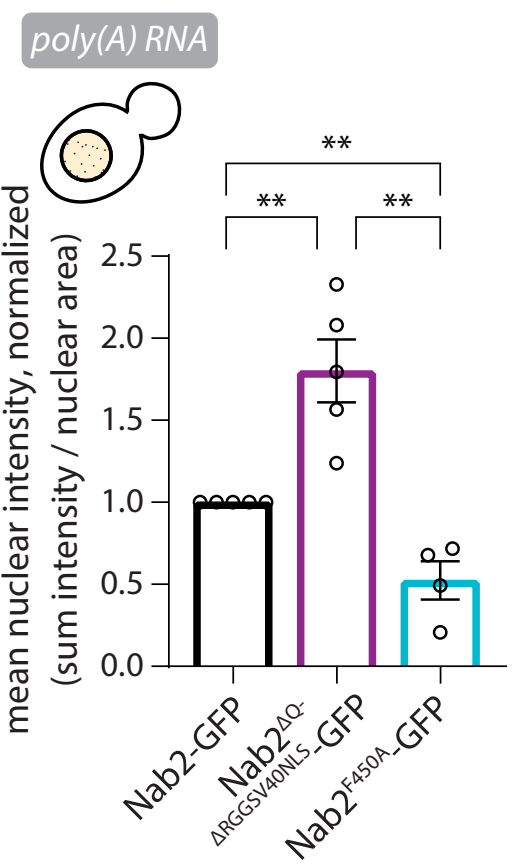

D

Nab2 ${ }^{\triangle Q-\Delta R G G-S V 40 N L S}$-GFP vs. Nab2-GFP

$\begin{array}{cc}\begin{array}{c}\text { \# of } \\ \text { prot. }\end{array} & \text { p value } \\ 34 & 3.88 \mathrm{E}-12 \\ 18 & 7.96 \mathrm{E}-11 \\ 10 & 7.63 \mathrm{E}-04 \\ 9 & 2.75 \mathrm{E}-07 \\ 7 & 6.76 \mathrm{E}-05 \\ & \\ 20 & 1.21 \mathrm{E}-06 \\ 18 & 8.24 \mathrm{E}-03 \\ 8 & 1.72 \mathrm{E}-07 \\ 6 & 1.26 \mathrm{E}-05 \\ 5 & 4.04 \mathrm{E}-02\end{array}$


bioRxiv preprint doi: https://doi.org/10.1101/2022.01.30.478372; this version posted January 30, 2022. The copyright holder for this

Figure 6 preprint (which was not certified by peer review) is the authorffunder. All rights reserved. No reuse allowed without permission.

A

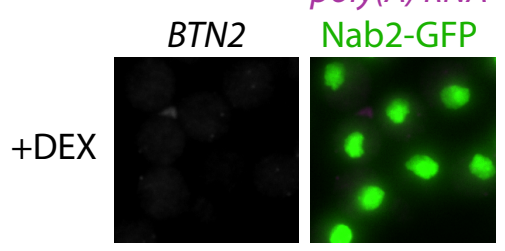

$24 \mathrm{hrs}$

-DEX
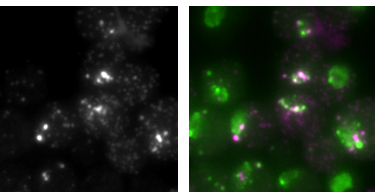

C

poly (A) RNA HSP42 Nab2-GFP

+DEX
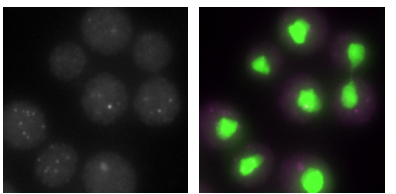

$24 \mathrm{hrs}$

-DEX
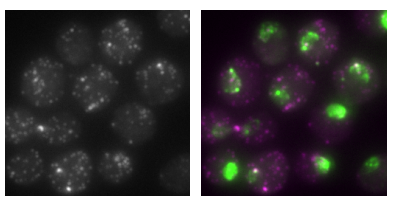

E

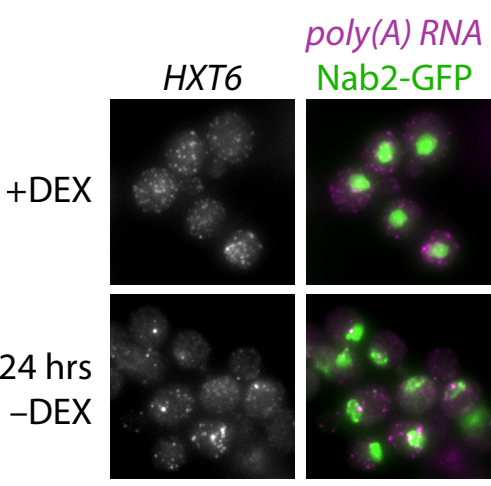

G

poly(A) RNA

DED1 Nab2-GFP

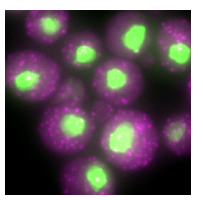

$24 \mathrm{hrs}$

-DEX
$\operatorname{poly}(A) R N A$

$\mathrm{Nab} 2^{\triangle \mathrm{Q}-\triangle \mathrm{RGG}}$
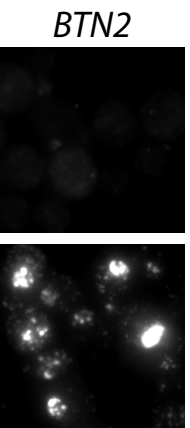

poly $(A) R N A$

$\mathrm{Nab} 2^{\triangle \mathrm{Q}-\Delta R G G}$

HSP42
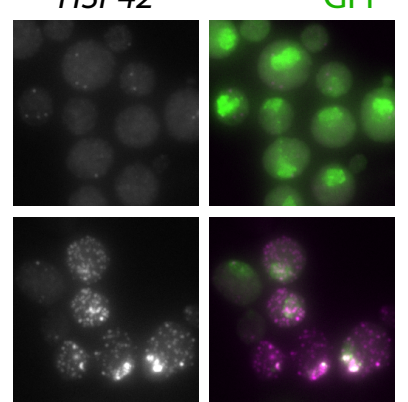

poly(A) RNA

$\mathrm{Nab} 2^{\triangle \mathrm{Q}-\triangle \mathrm{RGG}}$
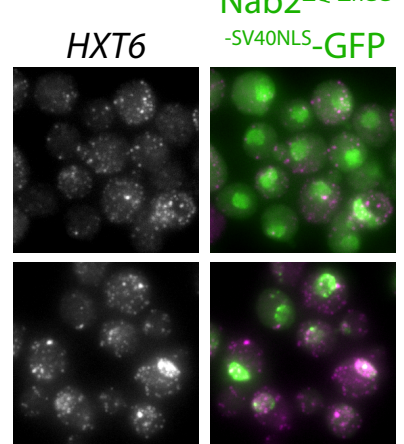

poly (A) RNA

$\mathrm{Nab} 2^{\triangle \mathrm{Q}-\triangle \mathrm{RGG}}$
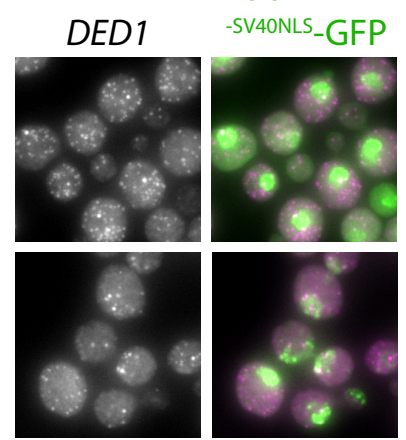

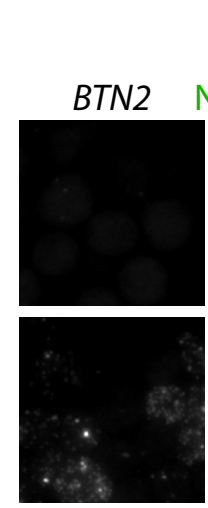

poly (A) RNA
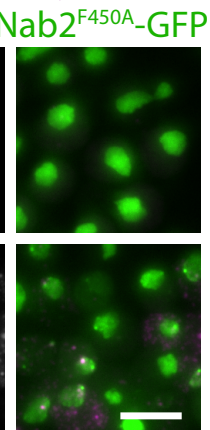

poly $(A) R N A$

HSP42 Nab2 ${ }^{\mathrm{F} 450 \mathrm{~A}}$-GFP
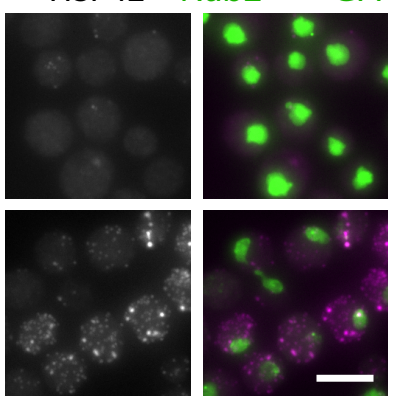

poly $(A) R N A$
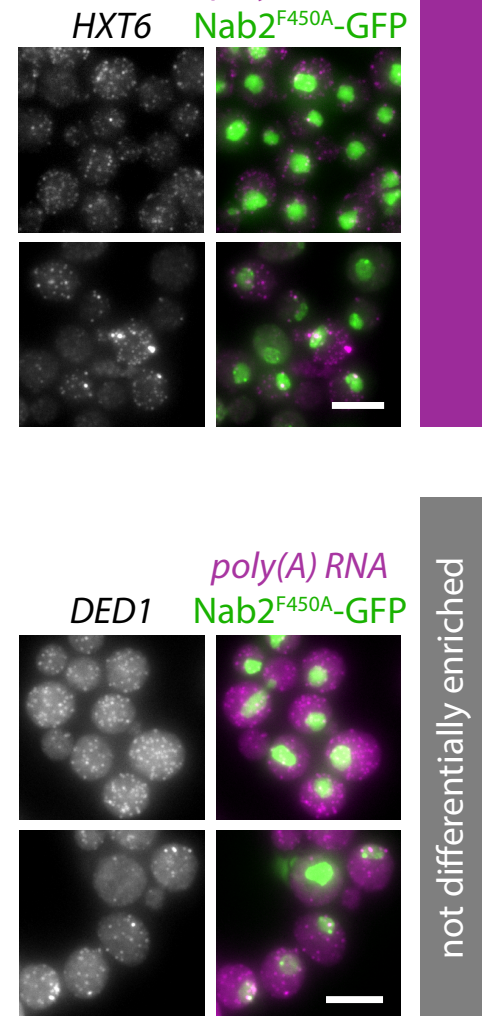

B

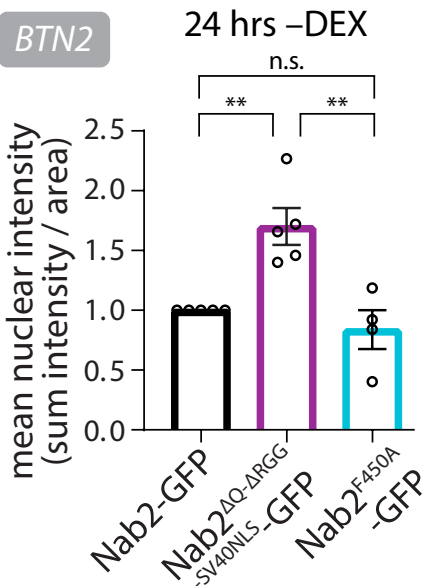

D

\section{HSP42 24 hrs-DEX}

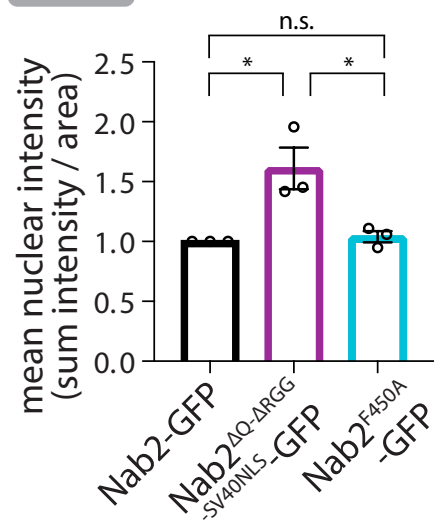

F HXT6 $24 \mathrm{hrs-DEX}$

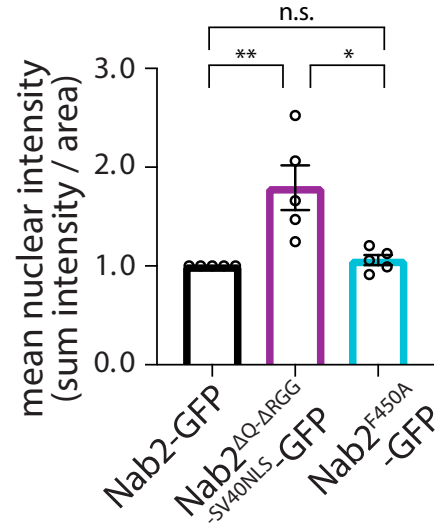

\section{H DED1 24 hrs-DEX}

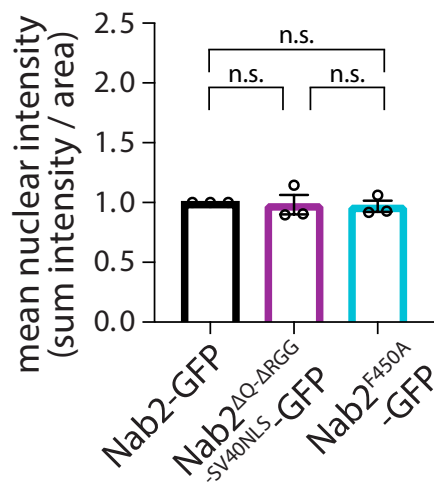


Figure 7 preprint (which was not certified by peer review) is the author/funder. All rights reserved. No reuse allowed without permission.

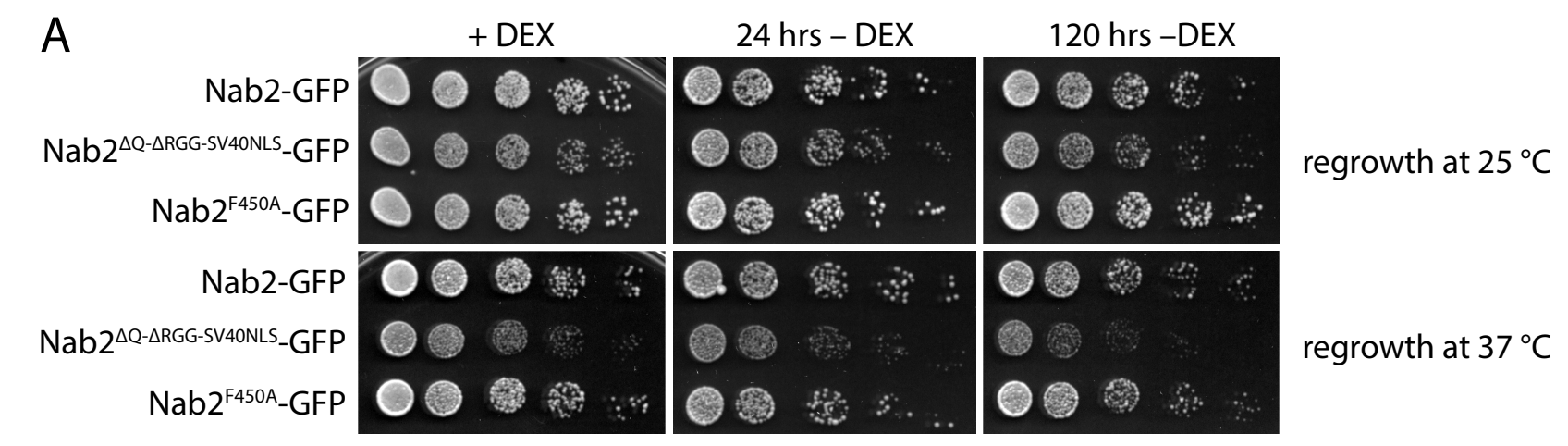

B
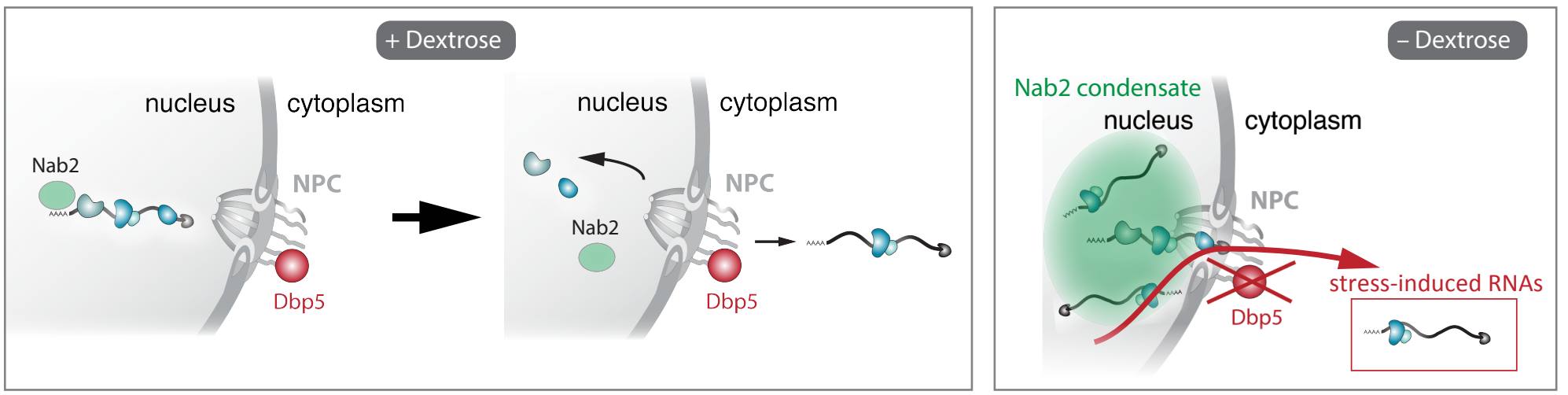